\title{
The determinants and effects of implementing a digital business strategy
}

Citation for published version (APA):

de Baat Doelman, M. S. (2021). The determinants and effects of implementing a digital business strategy. [Doctoral Thesis, Maastricht University]. Maastricht University. https://doi.org/10.26481/dis.20210302mb

Document status and date:

Published: 01/01/2021

DOI:

10.26481/dis.20210302mb

Document Version:

Publisher's PDF, also known as Version of record

\section{Please check the document version of this publication:}

- A submitted manuscript is the version of the article upon submission and before peer-review. There can be important differences between the submitted version and the official published version of record.

People interested in the research are advised to contact the author for the final version of the publication, or visit the DOI to the publisher's website.

- The final author version and the galley proof are versions of the publication after peer review.

- The final published version features the final layout of the paper including the volume, issue and page numbers.

Link to publication

\footnotetext{
General rights rights.

- You may freely distribute the URL identifying the publication in the public portal. please follow below link for the End User Agreement:

www.umlib.nl/taverne-license

Take down policy

If you believe that this document breaches copyright please contact us at:

repository@maastrichtuniversity.nl

providing details and we will investigate your claim.
}

Copyright and moral rights for the publications made accessible in the public portal are retained by the authors and/or other copyright owners and it is a condition of accessing publications that users recognise and abide by the legal requirements associated with these

- Users may download and print one copy of any publication from the public portal for the purpose of private study or research.

- You may not further distribute the material or use it for any profit-making activity or commercial gain

If the publication is distributed under the terms of Article $25 \mathrm{fa}$ of the Dutch Copyright Act, indicated by the "Taverne" license above, 


\section{The Determinants and Effects of Implementing a Digital Business Strategy}

Marc de Baat Doelman 


\section{ISBN}

978-94-6423-136-6

\section{Design Cover}

Marc de Baat Doelman

\section{Printed by}

ProefschriftMaken.nl

(C) 2021 Marc de Baat Doelman 


\title{
The Determinants and Effects of Implementing a Digital Business Strategy
}

\author{
DISSERTATION \\ to obtain the degree of Doctor at Maastricht University, \\ on the authority of the Rector Magnificus Prof.dr. Rianne M. Letschert \\ in accordance with the decision of the Board of Deans, \\ to be defended in public on Wednesday $3^{\text {rd }}$ of February 2021 at 13.00 hours. \\ by
}

Marc Sebastian de Baat Doelman 
Supervisors:

Prof. Dr. Alexander Brüggen

Co-Supervisor:

Dr. Anant Joshi

Assessment Committee:

Prof. Dr. Ann Vanstraelen (Chairperson)

Prof. Dr. Dominik Mahr

Prof. Dr. Jose Benitez

Prof. Dr. Steven De Haes 


\section{ACKNOWLEDGEMENTS}

Moving to Maastricht in 2012 for my studies was the beginning of a wonderful journey which led me to this dissertation. I will always be deeply grateful for all the things that I have experienced and the people I have met during my time at Maastricht University. Who would have thought during my early years of education, that this journey will guide me to the completion of my dissertation at one point? My teachers at school definitely not. For the past 3.5 years this dissertation has always accompanied me either actively during writing phases or passively when my bad conscience got bigger since I had not put anything on paper for too long. In retrospect, it has definitely presented me with a great opportunity to develop virtues such as patience, discipline, and accuracy. Despite the many learnings I am nevertheless very glad to have finally completed my dissertation. This would have not been possible without the help of great people who supported me during the entire process. I would like to take the opportunity to express my gratitude in the following.

First and foremost, I am deeply thankful for the continuous support of my supervisory team Alexander Brüggen and Anant Joshi. My journey towards finishing this dissertation would have been impossible without your continuous guidance, suggestions, academic mindset, and critical views. It has always been a great pleasure to discuss the topic of my dissertation from your academic perspective. I have found it very refreshing to escape the business world and tackle the problems with your innovative thinking and approaches. I owe extra thanks to the freedom and trust you have granted me even though I was sitting more than 600 kilometers away most of the time. Given this fact, I appreciate even more that you always responded my messages within a few minutes whenever I had a question. As much as I learned and benefited from you during writing this dissertation, I enjoyed our dinners just as much, regardless whether it was in Munich or Maastricht. I hope that we will continue to have regular dinners together in the future.

I further want to thank all members of my assessment committee, Ann Vanstraelen (chair), Dominik Mahr, Jose Benitez, and Steven De Haes for their prompt evaluation of my dissertation and very helpful comments. Further, I want to 
thank Mieke Jans, Roger Meuwissen, and Frank Harmsen for being a member of my defense committee.

Next, I would like to thank all members of the Accounting and Information Management department of Maastricht University who always welcomed me warmly and gave me a feeling of belonging to the department despite my rare presence. Thank you to Florian, Simon, and Lena for the times you offered me a table in your $\mathrm{PhD}$ office. I would like to thank Britt for being my paranymph and supporting me with all kinds of organizational questions especially towards the end of my dissertation. I still suspect that you are doing this since you feel bad about not keeping me from Accounting as my tutor in the first year Accounting Bachelor course.

I moreover would like to thank my highly respected colleagues from BMW for their support and insights during the process of writing this dissertation. I want to thank you, Thomas, for our conversations and debates regarding future digital developments and how traditional organizations need to change. Your ideas and thoughts have been an invaluable source. With the knowledge of your online courses you have pointed out the concept of digital business strategy to me early in the process of this dissertation. I want to thank you, Jens, for your mentoring and the trust you put in me. Further, I want to thank all the other $\mathrm{PhD}$ candidates who have walked (or better hiked) this path together with me. It has always been comfortable to know that you dealt with the same problems. Among others, I would like to thank Nico F., Jens, Nico L., Johannes, Martin, Florian, Max, and Niko. I owe very special thanks to Dominik without whom this project would not have been possible in the first place. I am very thankful for all the infinite support, trust, loyalty, and especially freedom you gave me. I have always admired how you manage to reconcile your professional and private life. Sebastian, thank you for your endless support, guidance, and opportunities you provided me with. Thank you also for the positive presence you brought to the department every single day. There was almost no moment when you did not have the right joke at hand. I was very happy that you accepted the role as my paranymph. I am very grateful to call the two of you, Dominik and Sebastian, not just colleagues but friends. I will definitely miss our daily coffee breaks.

I would like to express my gratitude to my friends outside of the academic and business world, who have accompanied me on this journey. Thank you to my 
hometown friends Philipp, Cornelius, Marc, Timo, Christoph, Luis, Moritz, Nico, Simon, Thomas, Lukas, Tim, Sören and Sebastian (die "Sektion") for your support and friendship. I am very grateful that we have maintained this strong friendship despite the many different places we have spread over during the last years. A special thank you to Sebastian for all the countless hours of proofreading this dissertation and many other texts during the last years. I most probably speak for a lot of people here. Thank you to my Maastricht friends (among others Felix, Amadeus, and Florian) for all the fun times we had during our studies and the years after. Another thank you to all my friends in Maastricht whose couch I crashed during the University visits of my $\mathrm{PhD}$ time.

I am grateful to my family for their unconditional support and love. Mama and papa, I am very thankful and I owe you an immense debt for the freedom you gave me to go abroad after school, study in Maastricht, and complete my dissertation. It is a special feeling to know that your parents always believe in you. Papa, thank you for introducing me to the business world and providing me with a mindset that is open to the world. Thank you for always spreading positivity and calmness. Mama, thank you for always fighting for us children and being a role model for us in many ways. Thank you for putting your main focus on us children since nearly 30 years. To my siblings, Jens and Eva, thank you for not just supporting me all the time but being my best friends. Above all, I want to thank my girlfriend, Birte, who has been indispensable throughout the writing of this dissertation. I owe many thanks to you for your never-ending patience, understanding and love. Without your support this dissertation would probably be far from ready. Like everything in our life, we did it together, thank you.

I finally dedicate this dissertation to my grandfather, Robert Vogel, who has been a role model to me and always appreciated education and the knowledge it gives us over all material things. You were my source to start this $\mathrm{PhD}$ journey in the first place and my motivation to bring it to an end.

Marc de Baat Doelman Munich, January 2021 



\section{Table of Content}

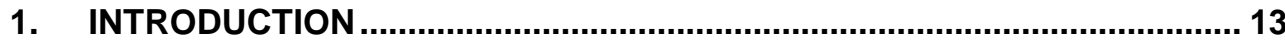

1.1. Introduction to Motivation and Objectives of this Dissertation .........13

1.2. The Effect of Digitalization ....................................................14

1.3. The Role and Relevance of a Digital Business Strategy ................16

1.4. The Effect of Dynamic Capabilities on Business Unit Performance and Digital Business Strategy ....................................................18

1.5. An Empirical Assessment of the Impact of Strategy Implementation Actions on Digital Business Strategy

1.6. The Effect of Disaggregated Performance Measures on Misreporting and the Influence of Performance Targets......................................22

1.7. Overall Contribution of Dissertation ................................................24

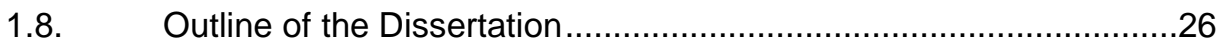

2. THE EFFECT OF DYNAMIC CAPABILITIES ON BUSINESS UNIT PERFORMANCE AND DIGITAL BUSINESS STRATEGY '.......................... 27

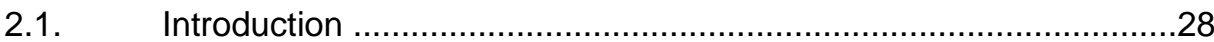

2.2. Theoretical Background and Hypotheses .....................................31

2.2.1. Dynamic Capabilities .......................................................... 31

2.2.2. Digital Business Strategy ................................................... 34

2.2.3. The effect of dynamic capabilities on digital business strategy implementation ................................................................ 36

2.2.4. Business Unit Performance ..................................................... 37

2.2.5. The mediating effect of a digital business strategy on the relation between dynamic capabilities and business unit performance .. 40

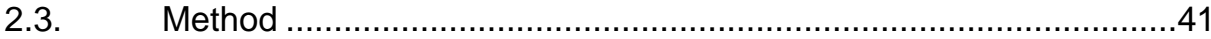

2.3.1. Sample and Data Collection .................................................. 41

2.3.2. Measurement and Validation .................................................. 43

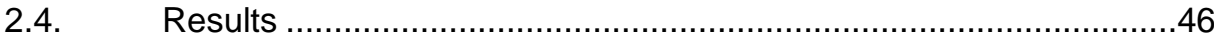

2.4.1. Measurement model ........................................................... 47

2.4.2. Structural Model................................................................. 49

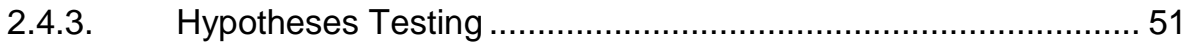

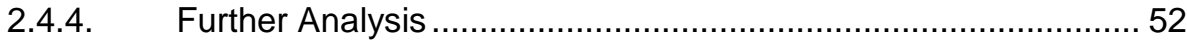

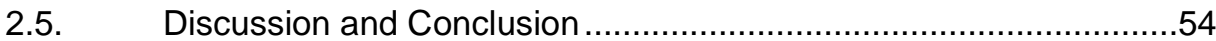

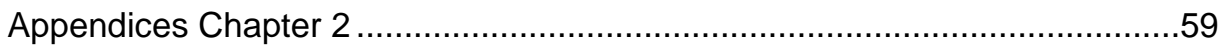


3. AN EMPIRICAL ASSESSMENT OF THE IMPACT OF STRATEGY IMPLEMENTATION ACTIONS ON DIGITAL BUSINESS STRATEGY, ....... 71

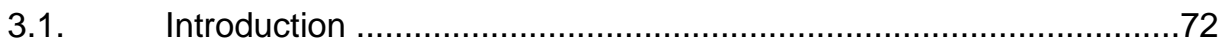

3.2. Theoretical Background and Hypotheses ..................................76

3.2.1. Digital Business Strategy ................................................... 76

3.2.2. Strategy Implementation Actions ………............................... 77

3.2.2.1. The effect of unfolding on strategy implementation actions ... 82

3.2.2.2. The effect of coordination on strategy implementation actions ..

3.2.2.3. The effect of communication on strategy implementation actions.

3.2.2.4. The effect of control and feedback on strategy implementation actions.

3.2.2.5. The effect of development of human resources policies and employee competences on strategy implementation actions. 87

3.2.3. The effect of strategy implementation actions on digital business strategy 88

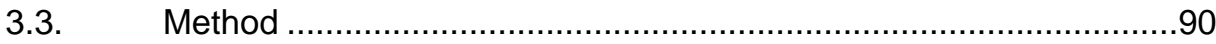

3.3.1. Sample and Data Collection ….............................................. 91

3.3.2. Measurement and Validation ................................................ 92

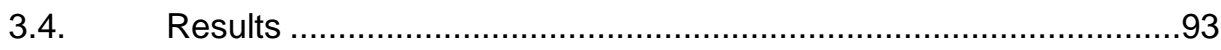

3.4.1. Measurement model ................................................................. 94

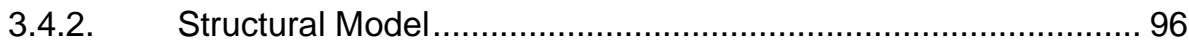

3.4.3. Hypothesis Testing ............................................................. 98

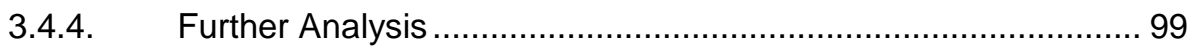

3.5. Discussion and Conclusion .......................................................101

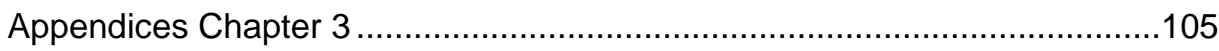

4. THE EFFECT OF DISAGGREGATED PERFORMANCE MEASURES ON MISREPORTING AND THE INFLUENCE OF PERFORMANCE TARGETS,

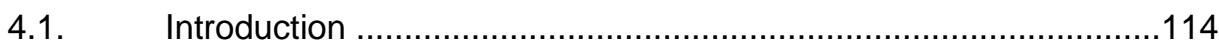

4.2. Theory and Hypotheses Development.....................................118

4.2.1. Misreporting ................................................................. 118

4.2.2. Information Aggregation .................................................... 119

4.2.3. Performance Target........................................................... 122 


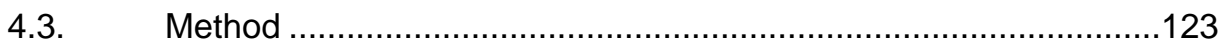

4.3.1. Experimental Design and Variable Measurement ................... 124

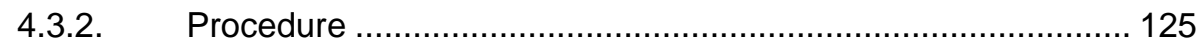

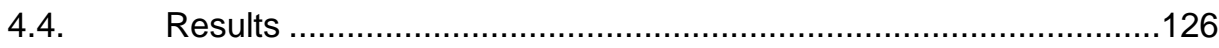

4.4.1. Descriptive Statistics ........................................................ 126

4.4.2. Hypotheses Testing ......................................................... 129

4.4.3. Further Analysis ............................................................. 131

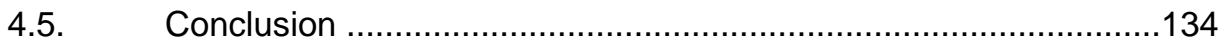

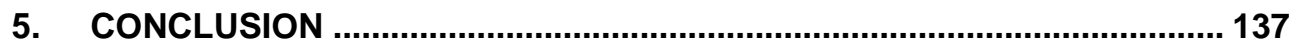

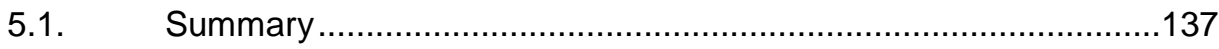

5.2. Contributions and Implications ...............................................141

5.2.1. Contributions and Implications for Academics.......................... 141

5.2.2. Contributions and Implications for Practice ............................ 143

5.3. Limitations and Future Research .............................................145

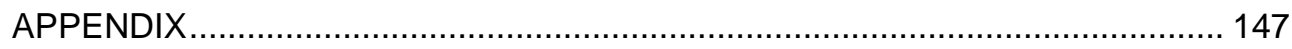

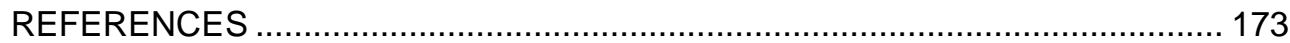

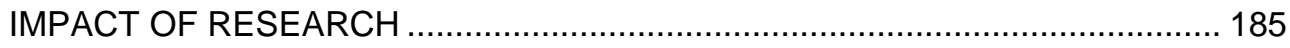

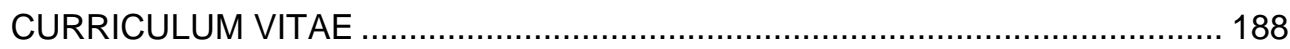





\section{INTRODUCTION}

\subsection{Introduction to Motivation and Objectives of this Dissertation}

Ever since the last decade, digital technologies have increasingly impacted organizations worldwide (Bharadwaj, El Sawy, Pavlou, and Venkatraman 2013). These developments have fundamentally changed aspects like customer interaction, collaboration models, knowledge acquisition, supply chains, production chains, and many more. Digitalization touches upon nearly all fields in the business as well as academic world. The interplay of determinants and effects associated with this change (e.g. in contexts like strategy, processes, competencies or performance outcomes) is however largely unknown (e.g. Leischnig, Wölfl, Ivens 2016; Matt, Hess, and Benlian 2015). As a result, many established organizations lose their market position since digitalization changes the boundaries of competition (Bughin, LaBerge and Mellbye 2017). One prominent example can be found in the automotive industry. Formerly, this industry was limited to automotive manufactures, whose expertise lay in the field of production and the development of car components like engines, car bodies or interior. Nowadays, players from other industries are pushing into the market as customer expectations have significantly changed regarding the car's software, information/entertainment content, required displays and sales channels (Xu and Lie 2018). As a result, technology companies like Google, Apple or Intel are entering into the market and developing systems like in-car entertainment or autonomous driving functions (Wessel 2015). This development however can be shown for many other industries as well (e.g., watch industry, music industry, retail industry). In order to address this change appropriately, it is important to have a suitable strategy in place. The motivation of this dissertation lies in providing organizations as well as academics with a deeper understanding regarding digitalization and its determinants and effects. This dissertation thereby aims in understanding digitalization as opportunity rather than threat.

As the research stream on technological developments and their effects on organizations is still in its infancy, I use literature from a diverse set of backgrounds like strategic management, management accounting and information systems management to investigate: (1) what effects does the implementation of a digital 
business strategy have for organizations (2) what factors will enhance the implementation of a digital business strategy, and (3) how do some of these factors need to be organized. In order to understand these effects and determinants associated with digitalization the next sections will cover the effects of digitalization on organizations.

\subsection{The Effect of Digitalization}

For many organizations, digital technologies fundamentally altered the sources of their competitive advantage and created new industry barriers. These technological advancements are often referred to using the umbrella term 'digitalization'. To avoid confusion, before addressing the alterations caused by these technological changes it is important to clarify the term digitalization, as it is often used interchangeably with the expression 'digitization'. According to Legner et al. (2017), digitization describes the technical process of transforming information from physical carriers like paper into binary digits. On the other hand, the authors describe digitalization as "the manifold sociotechnical phenomena and processes of adopting and using [...] technologies in broader individual, organizational, and societal contexts" (p.301). The remainder of this dissertation will therefore deal with the underlying phenomena and process of digitalization.

Technological advancements have transformed business and society in three waves according to Legner et al. (2017). The first wave was characterized by the replacement of paper by computers as the physical carriers of information. This heavily increased automation and efficiency in work routines. The second wave is characterized by the advent of the internet as global communication infrastructure. This wave changed organizations' value creation logic and generated completely new types of business, such as e-commerce or a plethora of platforms such as Airbnb or Facebook. The third and current wave is characterized by a combination of converging SMAC technologies (social, mobile, analytics, and cloud computing), continuing miniaturization, and an exponential growth in power, storage, and communication bandwidth. This last wave has a significant impact on organizations, as it enables the development of new products, services, and entire business models "by connecting machines, things, and individuals, as well as by enabling new work, collaboration, and automation models" (Legner et al. 2017, p. 306). At the same time however, this development heavily disrupts existing organizations. According to 
Bughin et al. (2017), digital technologies have just recently commenced to penetrate organizations. Their study finds that on average, industries are less than 40 percent digitalized. Organizations across a wide range of industries therefore redesign processes and their business models to address this penetration and incorporate the technological developments (Leischnig et al. 2016). This exploitation and integration of technologies affects large and varied parts of organizations and can even go beyond the firm by affecting aspects such as sales channels or supply chains (Matt et al. 2015).

Following this development, digitalization can require changing an organization's monetization strategy or business scope, as the addressable market or customer segment might shift (Legner et al. 2017). As this is the case, digital developments can turn out to be either an opportunity or a threat for organizations, or both. While they proved to be opportunities for organizations like eBay, Google, Amazon, or Netflix, they heavily threatened or outright invalidated the business models of Kodak, Borders, or Blockbuster (Mithas and Lucas 2010). As profiteer of these developments, companies like Alibaba and Amazon use platforms to outsource activities which were previously performed within firms. They outsource functions like selecting suppliers, negotiating prices, enforcing contracts and managing payments. Thereby, these companies are less capital-intensive (McGrath and McManus 2020) as digitalization heavily simplifies important key success factors such as customer interaction, processing speed and individualized offerings. On the contrary, there are several actors who suffer from these developments as mentioned earlier. These failures are however linked to several different factors. While Kodak failed to adapt to new technologies, companies like Blockbuster, Borders or Quelle failed to revise its business model and adapt to the threats associated with platforms like Netflix or Amazon (McGrath and McManus 2020; Mithas and Lucas 2010).

Overall, these developments reveal how digitalization will be one of the main factors influencing organizations in the future. In order to obtain the benefits associated with digitalization, it is important to have a suitable strategy in place. Organizations must develop a unique value proposition by incorporating digital technologies, which are hard for competitors to replicate (Ross, Sebastian, and Beath 2017). It is pivotal for organizations to find the right strategic answers to reap the advantages of digital technologies and to re-evaluate one's business model for 
the digital age (Legner et al. 2017). This can prevent missing important developments like a change in technical advancements available, customer needs, market dynamics or value creation. One promising answer to keep track of these developments is provided by digital business strategy.

\subsection{The Role and Relevance of a Digital Business Strategy}

The purpose of a digital business strategy is to generate a high-level plan that supports organizations in integrating technological developments into their long-term planning to ensure value creation and value capturing associated with digitalization. While the broader topic of digitalization has emerged as a research priority within a number of academic disciplines, such as business research and information science (Leischnig et al. 2016), the field of digital business strategy is largely based on a work by Mithas and Lucas (2010) and has been ever-expanding since the 2013 publication of the MIS Quarterly special issue on this topic. An article in this special issue defined digital business strategy as an "organizational strategy formulated and executed by leveraging digital resources to create differential value" (Bharadwaj et al. 2013, p. 472). This definition signifies that the field is a combination of management information systems and strategic management research.

Due to the increased digitalization of business processes, products, and services, it is critical to develop a better understanding of digital business strategy (Mithas, Tafti, and Mitchell 2013). It is however important to first clarify the term strategy itself. A strategy is generally defined as "the direction and scope of an organization over the long-term, which achieves advantage in a changing environment through its configuration of resources and competences with the aim of fulfilling stakeholder expectations" (Johnson, Scholes, and Whittington 2008, p. 3). According to Porter (1996), an organization's strategy thus consists of three underlying principles: the first principle states that strategy needs to generate a unique and valuable market position by defining a set of activities. An important aspect regarding the creation of a unique mix of values is to decide between performing activities differently or performing different activities compared to other market participants. This means that an organization has to decide whether it serves few needs of many customers, broad needs of few customers, or broad needs of many customers in a narrow market. The second principle states that strategy means making trade-offs by setting a clear direction. This incorporates aspects such as 
deciding between revenue growth or cost savings. The third principle states that strategy needs to ensure the coordination of an organization's activities, as they are mostly interdependent. These principles clearly indicate the importance organizations have to put on the strategy process if they want to ensure long-term success.

In comparison with organizational strategy, the focus of a digital business strategy is narrower. It mainly focusses on the proactive role of digital technologies in addressing the three strategy principles outlined above (e.g., Mithas, Tafti, Bardhan, and Goh 2012; Mithas et al. 2013). A digital business strategy therefore represents an element of the organizational strategy and combines the roles of business- and IT-strategy (Bharadwaj et al. 2013). By concentrating on the growing relevance of digital technologies, a digital business strategy has to address aspects like investments in general information technology, relationships to other firms or industries, IT outsourcing, and IT infrastructure (see Bharadwaj et al. 2013; Mithas et al. 2013). Digital business strategy thus helps organizations in shielding themselves from the erosion of competitive advantage and in defining how to position themselves within the industry in order to ensure unique and valuable positioning (Mithas et al. 2013). In short, a digital business strategy defines potential future business opportunities and sets the long-term plan for organizations that are partially, or fully based on digital technologies (Matt et al. 2015).

Despite the rising importance associated with the field of digital business strategy, the academic contributions are still at an early stage, resulting in a limited number of quantitative studies. Most of the studies investigating digital business strategy focus on its effect on performance. While Leischnig et al. (2016) find that the effect of digital business strategy on performance is largely based on firm-internal and external factors, Wunderlich and Beck (2018) find evidence that a digital business strategy triggers organizational innovativeness which subsequently increases market-based performance. Leischnig, Wölfl, Ivens, and Hein (2017) find similar indirect effects by analyzing how an organization's digital business strategy translates into market performance, in light of the intervening roles of market intelligence capability and subsequent value creation and value capture. Their results show an indirect, positive effect of digital business strategy on market 
performance (i.e. achievement of market-based goals). All studies emphasize the importance of digital business strategy, yet more research in the field is needed.

In this dissertation, I therefore investigate the effects and determinants of implementing a digital business strategy. I will investigate both its effect on organizations, as well as the factors facilitating the implementation process. The first study delves into aspects, determinants and effects of a digital business strategy. It examines the role of dynamic capabilities by answering how they facilitate the implementation of a digital business strategy and how they increase the performance of business units. In addition, the study investigates how the implementation level of a digital business strategy mediates the relation between the two variables dynamic capabilities and business unit performance. The second study concentrates on determinants to successfully implement a digital business strategy by addressing the research question of how specific strategy implementation actions influence the level of implementation of a digital business strategy. The third study investigates a narrow aspect of one of the strategy implementation actions, namely 'control and feedback'. It examines how misreporting is influenced by the disaggregation of performance reporting and the introduction of performance targets. The next section will present each study in more detail.

\subsection{The Effect of Dynamic Capabilities on Business Unit Performance and Digital Business Strategy}

The previous sections pointed out that digitalization will heavily impact organizations in the near future. It is therefore important for organizations to address the challenges adequately. One potential approach towards the rapidly changing environment is the implementation of a digital business strategy as outlined above. In order to benefit from this implementation, it is however crucial to understand its determinants as well as its effects. The first study, which is described in detail in chapter two, uses the dynamic capabilities construct to test for two aspects. First, it investigates whether dynamic capabilities serve as appropriate preconditions to implementing a digital business strategy. Second, the study tests the effect of dynamic capabilities on business unit performance and whether this relation is mediated by a digital business strategy. The concept of dynamic capabilities is mostly defined as the "firm's ability to integrate, build, and reconfigure internal and external competences to address rapidly changing environments" (Teece, Pisano, and Shuen 1997, p.516). As this 
definition describes a rather broad scope, many researchers divide the construct into subcategories, namely sensing, seizing and reconfiguring (e.g., Teece 2007; Wilden, Gudergan, Nielsen, and Lings 2013). In addition, the definition indicates the concept's applicability to the phenomenon of digitalization, as it applies in times of rapid change. Dynamic capabilities are further perceived as key factors for setting the strategic outline of organizations (Vivas López 2005) and translating strategy into action (Harreld, O'Reilly, and Tushman 2007). Based on these findings, the first study predicts the beneficial effects of dynamic capabilities when implementing digital business strategy. With regards to the second anticipated effect of dynamic capabilities, namely increasing business unit performance, prior literature remains limited (Drnevich and Kriauciunas 2011; Wilden et al. 2013). So far, the academic findings range from having identified direct (e.g., Drnevich and Kriauciunas 2011; Pezeshkan, Fainshmidt, Nair, Frazier, and Markowski 2016) to indirect (e.g., Leischnig et al. 2017) or context-dependent effect (e.g., Wilden et al. 2013). Grafton, Lillis and Widener (2010) however view the ability of a business unit to use its dynamic capabilities as the main driver of performance. The second study therefore argues in favor of a direct effect on business unit performance.

The previous section concerning the role and relevance of a digital business strategy demonstrates that more research is needed. As indicated, some scholars already found an indirect positive effect of digital business strategy on performance (e.g., Leischnig et al. 2016; Leischnig et al. 2017; Wunderlich and Beck 2018). In line with their argumentation, the first study additionally tests whether the implementation level of a digital business strategy has a positive mediation effect on the aforementioned relation between dynamic capabilities and business unit performance. In order to test these predictions, I cooperated with a large German manufacturing firm and applied two means of data collection methods. First, I conducted expert interviews with each member of the strategy digitalization team, including the vice president of strategy digitalization $(n=14)$. The main aim was to understand the completeness of my measure. Second, an online survey with all senior vice presidents and vice presidents of the targeted organization $(n=502)$ was carried out. In the end, a response rate for the final survey of $38.1 \%$ was achieved, which translates into 191 fully completed and usable responses. The study finds that dynamic capabilities are indeed an important determinant for the implementation of 
a digital business strategy. The findings indicate that business units scoring higher on dynamic capabilities in turn also achieve a higher implementation level of digital business strategy. Further, the findings support the prediction that dynamic capabilities indeed have a positive, significant effect on business unit performance. The findings do however not support the prediction that this relation between dynamic capabilities and business unit performance is mediated by the implementation level of a digital business strategy. These findings hold under various conditions, which underlines the generalizability of my findings. In an additional analysis, I find that the results are applicable to all kinds of business units regardless of the implementation level of a digital business strategy (i.e. high implementation level or low implementation level) or the daily tasks (i.e. central functions or operational functions).

This study provides several contributions for academics and practitioners alike. The fact that I find a direct, positive effect of dynamic capabilities on business unit performance adds quantitative evidence to the debate on the general effect of dynamic capabilities. I further show that it is important to analyze constructs and effects beyond the firm-level. Lastly, the findings show that it is important to consider the appropriate determinants before implementing a digital business strategy. Managers thus have to focus more closely on the given capabilities within their firm before starting implementation initiatives.

\subsection{An Empirical Assessment of the Impact of Strategy Implementation Actions on Digital Business Strategy}

Since the first study focuses on the relevant preconditions for implementing a digital business strategy, the second study, which can be found in chapter three of this dissertation, investigates the implementation process. The successful implementation of a digital business strategy is crucial in order to address the aforementioned radical transformation caused by digital technologies. Many executives put a lot of time into the formulation of a strategy yet neglect the implementation process at the same time (de Oliveira, Carneiro, and Esteves 2019). The implementation of a strategy is however an essential stage to achieve the objectives set out in the strategy itself and to gain a competitive advantage ( $\mathrm{Ho}, \mathrm{Wu}$, and Wu 2014; Hrebiniak 2006; Neilson, Martin, and Powers 2008; Noble 1999). The academic knowledge regarding either implementation guidelines or a theoretical 
model however remains limited (Atkinson 2006; de Oliveira et al. 2019; Pryor, Anderson, Toombs, and Humphreys 2007). This results in reported failure rates of implementation efforts that range from 7 to 90 percent (Cândido and Santos 2015) and an implementation duration that ranges from 3 to 16 years in academic studies (Miller, Wilson, and Hickson 2004). The combination of a lack of strategy implementation knowledge and the need to successfully implement a digital business strategy to address the challenges caused by digitalization emphasize the importance of investigating the research question of which specific strategy implementation actions influence the level of implementation of a digital business strategy.

In order to address this research question adequately, I used the action component of an operational model for the strategy implementation process proposed by de Oliveira et al. (2019) as the basis for my study. The action component consists of five underlying dimensions: unfolding, coordination, communication, control and feedback, and development of human resources policies and employee competences. The first dimension, unfolding, describes the translation of the strategy into specific actions and aspects, such as goals and responsibilities to achieve alignment within the organization. The second dimension, coordination, represents the efforts of management to mobilize all stakeholders and to encourage aspects like understanding, commitment and cooperation. The third dimension, communication, aims at distributing information on the strategy and its implementation to enhance understanding within the organization. The fourth dimension, control and feedback, ensures the monitoring of two aspects, namely results achieved via set targets and potential changes in the internal and external environment, which might lead to a potential adjustment of actions. The last dimension, development of human resources policies and employee competences, expresses the joint actions of the human resource department and the stakeholders of the implementation process to establish the right policies and ensure the required competences. Overall, in the second study I predict that these five action dimensions are important aspects for strategy implementation actions and that they positively affect the implementation of a digital business strategy.

Analogous to study one, I cooperated with a large German manufacturing firm to test the stated predictions. I thus utilized the same sample of all senior vice 
presidents and vice presidents of the targeted organization $(n=502)$. Again, I conducted an online survey and attained 191 fully completed and usable responses leading to the same response rate of $38.1 \%$. The study finds that the five action dimensions have a significant positive impact on strategy implementation actions. The study's main finding however is that strategy implementation actions are an important precursor to increased implementation levels of an organization's digital business strategy. The findings show a positive and significant effect here. Lastly, the study shows that these findings hold irrespective of the type of business unit or the level of implementation within the business unit.

This study contributes to the literature by adding important findings to the fields of management information systems and strategic management by increasing the knowledge on the currently developing field of digital business strategy. In addition, the study provides important insights to the under-researched area of strategy implementation. Lastly, the results provide implementation guidelines to managers. This could work to increase the success rates of future digital business strategy implementations.

\subsection{The Effect of Disaggregated Performance Measures on Misreporting and the Influence of Performance Targets}

Amongst others, the second study highlights the importance of control and feedback activities during the strategy implementation process. Considering these findings, the third study, which can be found in chapter four of this dissertation, investigates the performance reporting process. This process plays a pivotal role in assessing performance in organizations, as well as for managing and controlling a diverse set of activities. Organizations thereby rely on the honesty of their employees. While research into misreporting has a long history (e.g., Chow, Cooper, and Waller 1988; Merchant 1985), most studies have focused on the creation of budgetary slack (e.g., Chow et al. 1988; Merchant 1985; Young 1985). In doing so, researchers neglect to investigate how the number of misreporting opportunities influences misreporting and how this relation is influenced by the presence of performance targets. Due to technological developments, managers have significantly larger and more detailed amounts of performance data at their disposal. While this can lead to more disaggregated information and subsequently to more detailed insights, it can also lead to an information overload. It is therefore important for managers to find the right 
level of aggregation in order to benefit from these technological developments, while preventing the drawbacks associated with them.

The desired level of information aggregation within the performance reporting process is an important consideration for designers of such measures. In fact, the level of aggregation determines the number of misreporting opportunities presented to the subordinate. Since performance reporting almost always involves an element of self-reporting, more disaggregated performance measures yield a greater number of opportunities to misreport, yet also a higher psychological cost associated with misreporting. The psychological theory of dishonesty states that individuals have a preference for honest behavior to maintain a positive self-image (Mazar, Amir, and Ariely 2008). Based on this theory, the study predicts that the psychological cost associated with misreporting increases in case of more disaggregated performance reporting, thus leading to less misreporting compared with aggregated performance reporting. Next to the level of information aggregation, designers of performance reporting systems have to carefully consider the implementation of performance targets, as these are one of the most effective managerial tools (Locke and Latham 1990). Research has shown that the usage of targets in general has no downsides and that loose targets even have a positive effect on honesty (Newman 2014). Additionally, targets provide a reference point to individuals when evaluating subsequent information (e.g., Heath, Larrick, and Wu 1999), thus indicating what is deemed reasonable. I therefore predict that the previously indicated increase of misreporting under aggregated performance reporting is diminished by the introduction of performance targets.

I tested these predictions by means of an experiment. Participants were assigned to different groups using a $2 \times 2$ between-subjects design including the manipulation for the reporting schemes (aggregated versus disaggregated) and absence or presence of a nonbinding performance target. In total, 119 students from a European university participated in this experiment. In line with the predictions, the findings show that an individuals' misreporting increased under an aggregated performance reporting scheme. In addition, the results indicate a beneficial effect of performance targets when using aggregated performance reporting. More precisely, performance targets reduce the level of misreporting under aggregated performance reporting schemes. 
This study provides several relevant contributions. The study provides evidence that the level of aggregation directly impacts the level of misreporting. This is an important aspect for future judgments through academics and managers. By setting performance targets for some participants, I show that performance targets represent an important mechanism to reduce misreporting under a more aggregated performance reporting scheme. The study thus has important implications for the design of performance measurement systems. Considering the second study of my dissertation, the findings provide guidelines for the 'control and feedback' dimension during the implementation process of a digital business strategy.

\subsection{Overall Contribution of Dissertation}

As the previous outline of each study shows, the aim of this dissertation is to identify the determinants and effects of digital business strategy. The conceptual framework of this dissertation including all three studies is shown in Figure 1.

Figure 1

Conceptualization of Dissertation

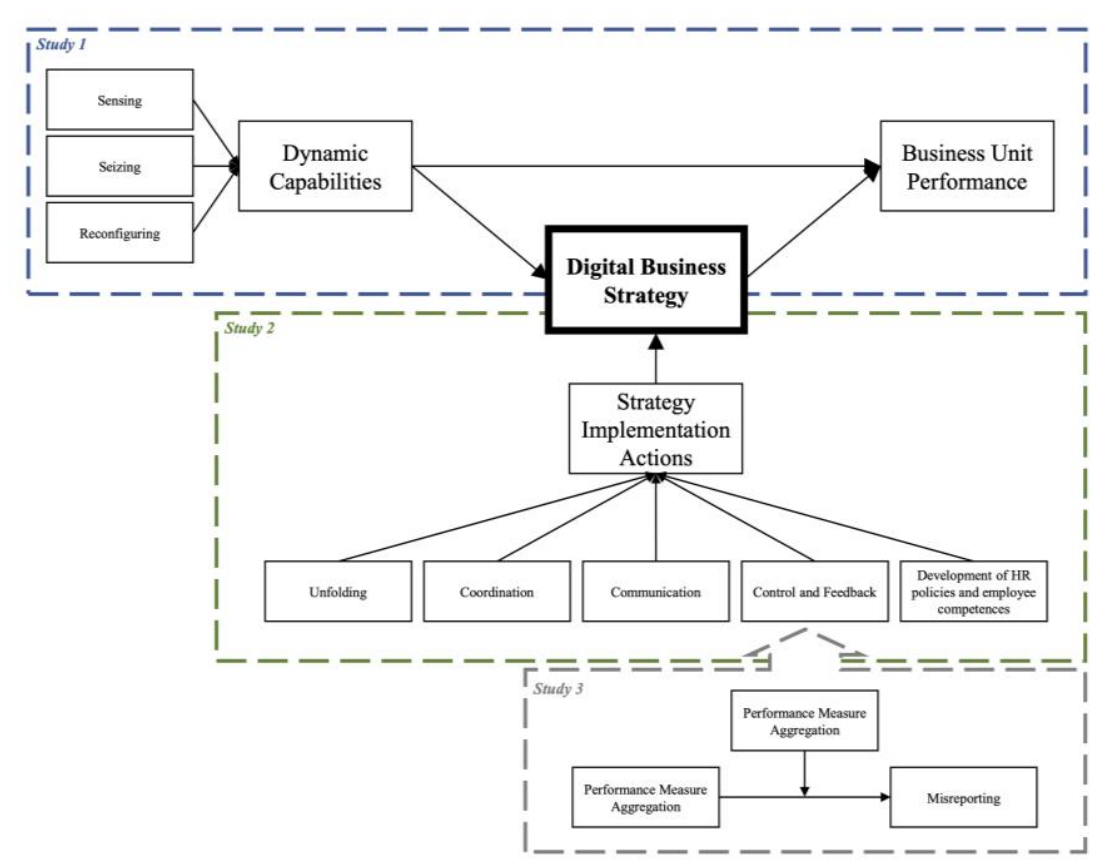


Overall, this dissertation points out that digitalization is a horizontal phenomenon that touches upon nearly all aspects in different business and academic activities. The understanding of the concept as well as the correct mechanisms to address this topic are therefore highly important to a wide audience.

The dissertation therefore provides several contributions to theory. The findings provide a well-founded picture of the digital business strategy concept. The interviews conducted enhance the concept's understanding and add important aspects towards the theory building process. More specifically, this dissertation adds the components data, IT, working methods, culture and customer centricity to the construct. It is however important to note that digital business strategy remains individual for each organization and is subject to the contingency approach. In addition, the dissertation shows that concepts from different academic fields, like strategy implementation actions or dynamic capabilities, can be applied to the digital business strategy context. This finding should encourage academics in the field of digital business strategy to investigate this concept beyond the initial level and incorporate aspects from a diverse set of research fields into future studies. In addition, this dissertation sheds light in the ethical behavior of individuals during the reporting process. With regards to the implementation of a digital business strategy these findings are especially helpful for controlling the implementation process.

Next to the theoretical contributions, the dissertation provides several highly interesting insights to practice. The different studies indicate that in order to implement a digital business strategy successfully, organizations and business units have to take a number of aspects into account before starting implementation initiatives. First, digital business strategy does not necessarily lead to increased performance. This is especially relevant with regards to the expectations of management during the digital business strategy implementation process. Second, digital business strategy implementation is strongly dependent on existing capabilities. Third, the dissertation highlights certain activities which are particularly beneficial for the implementation of a digital business strategy. This provides guidelines to practitioners on all managerial levels. Fourth, the successful implementation of a digital business strategy involves more than just the strategy department. The results demonstrate that the work of performance measurement 
and -reporting departments is equally important. While people have a preference for honesty, they still engage in unethical behavior like misreporting. It is therefore important to put emphasis on controlling the digital business strategy implementation process. Overall, this dissertation aims at providing more confidence to a diverse audience in both worlds, academia and business.

\subsection{Outline of the Dissertation}

The remainder of this dissertation focuses mainly on the three studies presented in this chapter. Chapter two presents the first study on the effect of dynamic capabilities on business unit performance and digital business strategy. Chapter three presents the study on understanding the role of strategy implementation actions on digital business strategy. Chapter four presents the study on the effect of disaggregated performance measures on misreporting and the influence of performance targets. Finally, Chapter five concludes this dissertation by summarizing the main findings of the three studies, discussing the implications and limitations, and offering avenues for future research. 


\title{
2. THE EFFECT OF DYNAMIC CAPABILITIES ON BUSINESS UNIT PERFORMANCE AND DIGITAL BUSINESS STRATEGY ${ }^{1}$
}

\begin{abstract}
In this paper we investigate the effect of dynamic capabilities on the implementation of a digital business strategy and business unit performance. In addition, we test the mediation effect of digital business strategy implementation on the relation between dynamic capabilities and business unit performance. The effects of digital technologies on the future of organizations is ever increasing and puts digital business strategies on the agenda of managers in most industries. The research on digital business strategy is however still in its early days. Although the dynamic capabilities field is a highly developed research area, their effect on performance remains unclear. We provide quantitative evidence by conducting an online survey with 191 responses from senior vice presidents and vice presidents of a large German manufacturing organization. Results from structural equation modeling (SEM) indicate the importance of dynamic capabilities for business unit performance and a better implementation of a digital business strategy. While we find a positive significant effect of dynamic capabilities on both business unit performance and digital business strategy, we fail to find a significant mediating effect of digital business strategy on the relation between dynamic capabilities and the performance of business units. We further find that these results hold regardless of the daily work of a business unit or the level of digital business strategy already implemented.
\end{abstract}

\footnotetext{
${ }^{1}$ This chapter is based on a working paper co-authored with Alexander Brüggen, and Anant Joshi.
} 


\subsection{Introduction}

Today, digital technologies are having a very significant impact on organizations. The emerging technologies are helping firms to revive existing digital services (e.g., automation) or even to create new business models (IT-enabled sharing platforms). This impact of digitalization is evident in some recent reports. A study by MIT Sloan Management Review and Deloitte found that nearly $90 \%$ of executives state that their industry will be disrupted by digitization to a great or moderate extent, while only $44 \%$ approve of their organization's preparation to this disruption (Kane et al. 2016). This is in line with a McKinsey study by Bughin et al. (2017) stating that digital technologies have just begun to penetrate organizations. The study reports that industries are less than 40 percent digitized on average. Trailing the average are industries like consumer packed goods (31\%) and automotive (32\%), while retail $(55 \%)$ and media/entertainment (62\%) are among the most digitized industries. In addition, the study identifies tremendous future discrepancies between the top quartile and bottom quartile of companies within the same industry. ${ }^{2}$ On average, the current level of digitization has already decreased annual revenue by six percent and resulted in a 4.5 percent drop in earnings before interest and taxes (EBIT). Based on the present digitization levels mentioned above, this pressure on organizations will increase in the future (Bughin et al. 2017). These findings are in line with a study conducted by Bughin and Catlin (2019), which reports that companies which neglect, fail, or refuse digitization will pay the price in terms of corporate underperformance. According to their data, the $20 \%$ of companies with no (or very low) digitization levels report largely negative revenue and earnings growth (EBITDA growth of minus $8 \%$ per year in some cases). As these numbers show, digitization will heavily impact the financial situation of organizations in the future. One of the key lessons from these findings is that firms can gain competitive advantage by tightly integrating its digital business strategy to overall corporate strategy since the study by Bughin et al. (2017) shows that firms ranked within the top quartile closely tie together their digital and corporate strategies. However, this holds true only for digitally maturing organizations as nearly $90 \%$ of them have already integrated their digital strategy within the overall strategy (Kane et al. 2016). A digital business strategy is generally

\footnotetext{
${ }^{2}$ Ranked by three measures: revenue growth, EBIT growth, and return on digital investment.
} 
defined as an "organizational strategy formulated and executed by leveraging digital resources to create differential value" (Bharadwaj et al. 2013, p. 472).

Next to the direct economic consequences, digitization has heavily lowered entry barriers, which introduces new competitors either from different industries (e.g., Apple's entry into the watch industry, Nestle's entry into the coffee industry) or initial start-ups that have successfully competed with large organizations (e.g., Spotify's entry into the music industry, Amazon's entry into the retail industry). In addition, the differentiating characteristics of many industries have shifted. While car manufacturers had previously differentiated themselves from their competitors by factors like engine quality or horsepower, aspects like connectivity or infotainment have become much more decisive today. Thus, organizations across a wide set of industries have started multiple initiatives to test new digital technologies and to quantify their effects (Matt et al. 2015).

In order to address these changes caused by digitalization, this paper investigates how specific capabilities (i.e. dynamic capabilities) can help organizations in addressing the shifting circumstance within their environment as well as the rising financial pressure. Thereby, we study the effect of those capabilities on the implementation of an organization's digital business strategy and on business unit performance. In such a way, the addressed research gap is twofold. First, we examine the relationship between the effect of dynamic capabilities and the implementation of a digital business strategy, which is largely unknown. The field of dynamic capabilities is ever increasing since the publication of Teece et al. (1997), who introduced them as the "firm's ability to integrate, build, and reconfigure internal and external competences to address rapidly changing environments" (p.516). This definition underlines the concept's importance in times of rapid change. Despite the concept's origin lying in the field of strategy (Eisenhardt and Martin 2000; Teece et al. 1997), it is nowadays studied among a wide range of management fields, such as management information systems (IS) (e.g., Pavlou and El Sawy 2010; Yeow, Soh, and Hansen 2018) and accounting (e.g., Grafton et al. 2010). Given the applicability of dynamic capabilities in turbulent environments, they serve as the ideal precondition for the implementation of a digital business strategy, as digitalization is the root cause of remarkable changes to society (Yoo, Henfridsson, and Lyytinen 2010). Due to remarkable developments in information technology (IT), digital 
business strategies have emerged as a priority among scholars and practitioners alike. Academic disciplines highlight the topic's importance as pertaining to its influence on business research and information science (Leischnig et al. 2016). Practitioners across multiple industries prioritize the formulation and implementation of a digital business strategy in order to keep up with technological developments, as well as to create and capture value through digital advancements (Leischnig et al. 2017).

Second, we investigate the effect of dynamic capabilities on performance. Regardless of the research interest in dynamic capabilities, the empirical evidence regarding the effect of dynamic capabilities on performance remains inconclusive (Drnevich and Kriauciunas 2011; Pezeshkan et al. 2016; Wilden et al. 2013). One reason is the fact that most of the studies follow a more theoretical research approach (e.g., Ambrosini and Bowman 2009; Easterby-Smith, Lyles, and Peteraf 2009; Eisenhardt and Martin 2000; Peteraf, Di Stefano, and Verona 2013; Teece 2007; Teece 2018; Teece et al. 1997). This paper aims to quantify the effect of dynamic capabilities on performance. In addition, most of the prior research has focused on firm level performance (e.g., Leischnig et al., 2017; Wilden et al. 2013). This study examines business unit performance. We argue that this is a novel contribution of our study, as the existing literature on dynamic capabilities and digital business strategy has largely focused on firm level performance. Overall performance is often influenced by a diverse set of non-task related factors (e.g., environment, business cycle). Business unit level research allows for a more detailed task related analysis with regards to aspects like type of daily work. This deepens the understanding of dynamic capabilities and digital business strategy in the larger context of one organization. Thereby, we can gain detailed insights into the underlying relationships. Considering the inconclusiveness regarding the understanding the effects of dynamic capabilities on a digital business strategy and performance especially on the business unit level, we investigate the research question of how dynamic capabilities influence both business unit performance and the implementation level of a digital business strategy and how the relation between dynamic capabilities and business unit performance is mediated by the implementation level of a digital business strategy. 
In order to achieve this goal, we cooperated with a large German manufacturing company. The company is more than 100 years old, is represented in more than 140 countries, produces more than half of its products outside of Germany, has more than 100,000 employees, and a revenue of nearly 100 billion Euros. We used a two-stage approach to answer the research question. In the first stage we conducted interviews with all 14 members of the strategy digitalization team to validate our measurements. In the second stage we carried out an online survey addressing all 502 senior vice presidents and vice presidents. Overall, the survey response rate is $38.1 \%$, which equivalents to 191 fully completed responses on business units.

The contribution of this study is threefold. First, we show the importance of dynamic capabilities for performance improvement and a better implementation of a digital business strategy. On the one hand, these findings add to the ongoing debate on the effects of dynamic capabilities. On the other hand, this helps managers to increase performance as well as to implement a digital business strategy. Thereby, we follow Ambrosini and Bowman's (2009) call for research to integrate the dynamic capabilities perspective into other complementary fields (i.e. digitalization). Second, this study provides guidance for academics and managers alike with regards to the expectations associated with a digital business strategy. This addresses Leischnig et al.'s (2016) call for research to analyze the effect of a digital business strategy on firm performance. Third, the findings shed light on the effects of dynamic capabilities and the implementation of a digital business strategy on the business unit level within a traditional organization. This follows Easterby-Smith et al.'s (2009) call for research to include more traditional industries when analyzing dynamic capabilities (i.e. automotive industry).

In the next section we develop our theory and hypotheses, followed by the explanation of our method. After that we provide the results, and we conclude with a discussion of our results, managerial implications and study limitations.

\subsection{Theoretical Background and Hypotheses}

\subsubsection{Dynamic Capabilities}

The field of dynamic capabilities has been rapidly growing since the publication of Teece et al. (1997) and still continues to raise attention among management 
scholars as well as practitioners (Easterby-Smith et al. 2009). The literature sees dynamic capabilities "as an emerging and potentially integrative approach to understanding the newer sources of competitive advantage" (Teece et al. 1997, p.510) and attribute to them the intention to change the firm's resource base (Ambrosini and Bowman 2009). They can be seen as the "new" behavioral theory of firms with a deeper focus on intangible assets, outsourcing, offshoring, and rapid change (Augier and Teece 2009). Scholars have identified the development and existence of dynamic capabilities as one of the main factors driving business performance (Drnevich and Kriauciunas 2011; Grafton et al. 2010; Leischnig et al. 2017; Peteraf et al. 2013; Teece 2007) and further state that they can be improved or decay over time (Easterby-Smith et al. 2009).

Dynamic capabilities are often associated with another well-established theory, namely the resource-based view. The resource-based view was introduced by Wernerfelt (1984), who was the first to highlight the importance of resource position barriers and was later described by Barney's (1991) framework on valuable, rare, difficult to imitate and non-substitutable (VRIN) resources to achieve sustainable competitive advantage. Dynamic capabilities extend this view by addressing how valuable resources can be created and refreshed in changing environments (Ambrosini and Bowman 2009). While the resource-based view is mainly focused on strategies that exploit the existing firm-specific assets, it has not adequately addressed the generation of competitive advantage within rapidly changing environments. Therefore, dynamic capabilities possess more equifinality, homogeneity, and substitutability across firms (Eisenhardt and Martin 2000).

Even though there is a large literature stream addressing dynamic capabilities, the construct is still lacking a clear definition (Easterby-Smith et al. 2009). Different definitions however are heading into comparable directions, implying that general consensus regarding the construct exists (Ambrosini and Bowman 2009). Teece et al. (1997) defines the term as the "firm's ability to integrate, build, and reconfigure internal and external competences to address rapidly changing environments" (p.516). Responding to criticism, Teece (2007) refines the definition and states that dynamic capabilities can be disaggregated into three different capacities, namely sensing, seizing and reconfiguring. Due to the lack of a clear definition adopted by all scholars, we proceed with a definition that is largely derived from Barreto's (2010) 
work, which itself is based on a literature review including 38 top-tier journal articles mentioning "dynamic capabilities" in their title and/or their abstract between 1997 and 2008, and Teece's (2007) refinement.

A dynamic capability is the firm's potential to systematically solve problems, formed by its propensity to sense opportunities and threats, to seize decisions timely and in a market-oriented approach, and to reconfigure its resource base.

The term 'capabilities' refers to the key role of strategic management to adopt, integrate, and reconfigure internal and external organizational skills, resources, and functional competences to meet the challenges of a changing environment. This is associated with the term 'dynamic', describing the capacity to renew competences to accomplish congruence with the changing business environment (Teece et al. 1997).

The definition clearly points out that dynamic capabilities are a multi-faceted construct (Teece 2018). When analyzing the construct, it is important to consider all dimensions holistically, as none can represent the overall construct alone (Barreto, 2010). Even though firms hardly master all types equally well (Teece 2018), it is important for organizations to take sensing, seizing and reconfiguring mechanisms into account in order to direct resources towards marketplace needs and imperatives (Teece 2007). Sensing describes activities which are associated with scanning, creation, learning and interpretation to identify new opportunities and threats. This capability requires the understanding of new events and developments as pertaining to customer needs, changing demands, technological requirements, suppliers and competitors. Therefore, this activity is enhanced by research investments and increased decentralization, as heightened local autonomy facilitates early detection of market and technological developments (Teece 2007). Management is especially important for identifying and capturing new strategic opportunities as the pursuit of new developments is in most cases heavily dependent on management support (Augier and Teece 2009). Seizing describes the activity of evaluating and addressing the sensed opportunities by making timely and market-oriented decisions, as aforementioned in the definition. This involves heavy investments and the orchestration of necessary complementarities as well as other organizational assets 
in the face of promising opportunities (Augier and Teece 2009; Teece 2007). Thus, good seizing capabilities require management to scrutinize established processes, resource allocations and decision rules, in order to eliminate dysfunctional features. This is especially crucial, as many established organizations sense opportunities, yet subsequently fail to incorporate them due to hierarchical decision-making processes and reluctance towards radical change. Therefore, a key element for good seizing capabilities will be the managements' competence with regards to devising and refining business models (Teece 2007). Reconfiguring describes the capability of recombining and reconfiguring the resource base, as well as the organizational structures to meet the sensed and seized opportunities. Moreover, it helps organizations in coping with growth and addressing changes in markets and technology, as is necessary to maintain evolutionary fitness by profitably building and renewing resources, assets, and ordinary capabilities (Teece 2018). In many cases this requires an escape from unfavorable path dependencies, even if routine is often necessary for operational efficiency and is induced by success. The successful departure from routines is heavily dependent on firm culture, as such alterations will automatically lead to heightened anxiety within organizations. These three actions clearly indicate why the nature, origin and evolution of dynamic capabilities lies in addressing change and new opportunities. They relate to the transformation of organizational processes, allocation of resources and operations (Easterby-Smith et al. 2009).

The effect of dynamic capabilities on a digital business strategy and performance will be discussed in the next sections.

\subsubsection{Digital Business Strategy}

The field of digital business strategy was first introduced by Mithas and Lucas (2010) and is ever expanding since the MIS Quarterly special issue on this topic in 2013. Digital business strategy represents a combination of management information systems and strategic management research. In general, "strategy is the direction and scope of an organization over the long-term, which achieves advantage in a changing environment through its configuration of resources and competences with the aim of fulfilling stakeholder expectations" (Johnson et al. 2008, p. 3). A firm's strategy can be divided into two major areas. First, corporate strategy, which determines the firm's scope regarding relevant industries and markets. It specifies 
the organization's diversification, vertical integration, acquisition, new venture, and resource allocation activities among different businesses. Second, business strategy, which lies one level below the corporate strategy and defines how the organization competes within a particular industry or market (Grant 2016). Thereby, it presents an intended course of action and has two important purposes, namely being prepared for actions in the future and being developed with caution and purpose (Mintzberg 1987).

This paper's focus lies on the newly developing field of a digital business strategy, which is currently considered a sub theme of business strategy in many organizations. According to Bharadwaj et al. (2013, p. 472) a digital business strategy is defined as an "organizational strategy formulated and executed by leveraging digital resources to create differential value". This implies that a digital business strategy is the combination of a business and an IT strategy, indicating that an IT strategy can no longer be treated as a functional-level strategy. Therefore, a digital business strategy should be equivalent in rank to a business strategy for the digital age rather than being treated as a sub-strategy (Bharadwaj et al. 2013). This growing importance is supported by IS literature which shows that aspects like IT investment or IT capabilities have a positive impact on performance (Bharadwaj, Bharadwaj, and Konsynski 1999; Santhanam and Hartono 2003).

The intention of a digital business strategy is to create a guiding frame that helps organizations in incorporating digital developments into their long-term planning, in order to create and capture value associated with digitalization. Even though these digital developments are mainly related to technological advancements, they alter the competitive landscapes within many industries and enable changes associated with aspects like products and services, internal processes, data management, customer interaction, working models or alliances/partnerships (Leischnig et al., 2016). With regards to internal processes, digital advancements heavily impact the speed of decision-making, as information are easier and faster to access due to real time information flow that had previously been slowed by information hierarchies such as management layers (Bharadwaj et al. 2013). A digital business strategy however does not exclusively focus on internal aspects, as it helps firms to incorporate external changes by raising awareness and heightening responsiveness to the competitive environment (Mithas et al. 2013). 


\subsubsection{The effect of dynamic capabilities on digital business strategy implementation}

Despite the rising interest in the field of digital business strategy, the literature findings are still in an early stage, resulting in a limited number of quantitative studies. The previous literature review points out that a digital business strategy is intended to address the changes within the business environment mainly associated with technological advancement and IT. In many cases, these changes are associated with a rapid change to the whole organization as cases like Kodak, Nokia or Blockbuster clearly exemplified in the past. The strategy process is about understanding these changes with regards to their effects on markets and technology and have the ability to execute them against the plans. Some companies however, as the example companies showed, find it difficult in the strategy process to anticipate the threats or are unable to adopt to the changes quickly enough (Harreld et al. 2007). In order to successfully implement a digital business strategy, it is therefore important for business units to have strong dynamic capabilities as they represent the firm's potential to systematically address economically significant changes (Helfat and Winter 2011). They are a concrete set of mechanisms that are intended on addressing the fundamental question of strategy namely, to develop sustainable competitive advantage (Harreld et al. 2007).

With regards to the effect of dynamic capabilities on digital business strategy, it is important to note that several studies suggest for a reverse relationship for the relation between dynamic capabilities and strategy in general (e.g. Pisano, 2017; Teece, 2018). While Pisano (2017) argues that strategy influences dynamic capabilities, it is important to note that the author argues for a specific type of strategy (i.e. capability search strategy). As this strategy purely intends to influence dynamic capabilities, the reverse causality in the author's study is a special case and cannot be transferred to the general field of strategy. Another study addressing the relation between dynamic capabilities and strategy has been conducted by Teece (2018). The author investigates how dynamic capabilities, strategy, and business models interact. In this context it is however important to indicate that the author considers the formulation process of a strategy and refers to its content which is influenced by the business model and dynamic capabilities. While the fact of reverse causality might be true for the respective settings of these studies, the focus of this study is on the implementation and not formulation of a digital business strategy. This is in 
line with Benitez, Llorens and Braojos (2018) who argue that "business strategies need organizational capabilities to be executed" (p. 510). In addition, a digital business strategy's focus does not lie on the transformation of an organization's dynamic capabilities but on the leveraging of digital resources to create differential value (Bharadwaj et al. 2013).

In line with our previous literature review on dynamic capabilities and a study by Vivas López (2005), dynamic capabilities are "key factors in optimizing the strategic course of the company's future" (p.668). They enable business units to sense the challenges associated with technological changes early, seize their opportunities and reconfigure according to their needs (e.g., adjust processes, change customer interaction). Harreld et al. (2007) find, that dynamic capabilities at IBM have been the key driver of bringing strategy into action on the corporate strategy level. In addition, a study by Braojos, Benitez and Llorens (2019) has investigated the effect of a sub-constructs of dynamic capabilities (i.e. social media capabilities and E-commerce capabilities) on online customer engagement, which can be considered a sub-element of a digital business strategy. The authors find a positive effect of social media capabilities and E-commerce capabilities on online customer engagement, which in turn improves firm performance. Lastly, a study by Yeow et al. (2018) analyzed the alignment process of an organization with a new digital business strategy by means of a case study. The authors conclude that dynamic capabilities are one of the main drivers in the alignment processes of a digital business strategy. Overall, these findings highlight the importance of dynamic capabilities in the context of digital business strategy. In line with the previous argumentation, we argue the following:

H1: Dynamic capabilities positively influence the implementation level of a digital business strategy.

\subsubsection{Business Unit Performance}

Performance is one of the most widely studied aspects across all types of disciplines (e.g., Bommer, Johnson, Rich, Podsakoff, and MacKenzie 1995). According to scholars, many papers investigating performance deal with the macro level (Felin and Foss 2005; Felin, Foss, and Ployhart 2015; Johnson, Melin, and Whittington 2003) and discuss organization-wide influence factors yet neglect the business unit 
level (Steers 1975). One important study highlighting the important role of business units has been done by Rumelt (1991). Using a variance components model, the author analyzes the impact of industry, corporate and business unit effects on the rate of return. The study reveals strong business unit effects and highlights the importance of business units on economic rents. Despite these findings, substantial research on the business unit level within organizations is still missing. Since we regard organizational performance to be the sum of the business units' performance, business unit performance can be linked to microfoundation research. It is not in and of itself considered a theory, but rather a more detailed analysis of outcomes (Felin et al. 2015). By measuring business unit performance, this paper goes beyond the firm as measurement level. This addresses practitioners' criticism as they call for more detailed findings with regards to their day-to-day operations (Johnson et al. 2003).

The microfoundation level has also found attention in the dynamic capabilities literature. Teece's (2007) paper investigates the role of dynamic capabilities and their microfoundations in achieving sustainable enterprise performance. The author establishes a framework which analyses the underlying microfoundations of dynamic capabilities with regards to skills, processes, procedures, organizational structures, and disciplines and concludes that these are the foundation of competitive advantage on the enterprise level. This is in line with a large stream of literature investigating the necessity and effectiveness of dynamic capabilities in different organizational environments and their effect on performance (Drnevich and Kriauciunas 2011; Eisenhardt and Martin 2000; Peteraf et al. 2013; Teece 2007; Teece et al. 1997). Based on the previous description of dynamic capabilities, the relation between performance and dynamic capabilities appears to be inherently intuitive. First, sensing and seizing activities enable an organization to detect and develop new processes, products and services, which leads to increased revenues (Augier and Teece 2009; Drnevich and Kriauciunas 2011; Teece 2007). Second, dynamic capabilities increase the speed of aligning the firm's resources in a dynamic environment (Teece 2018). Third, dynamic capabilities increase the quality of strategic decision making, which in turn creates value for organizations (Eisenhardt and Martin 2000). Fourth, dynamic capabilities support the creation, deployment, and protection of intangible assets, which support the achievement of superior longterm performance (Teece 2007). Even though the literature indicates a clear 
relationship, a quantitative understanding regarding this relationship however remains limited and elusive (Drnevich and Kriauciunas 2011; Wilden et al. 2013). Teece et al. (1997) state that dynamic capabilities describe fundamental characteristics of an organization since a shift in the environment is a far more crucial threat to the firm than a high employee turnover rate. Eisenhardt and Martin (2000) on the other hand state that competitive advantage is gained by resource configurations and not through dynamic capabilities. Further, the authors argue that dynamic capabilities are unstable in high-velocity markets. Peteraf et al. (2013) analyze the two positions and conclude that depending on the circumstances and actions required, dynamic capabilities can lead to sustainable competitive advantage regardless of the level of market dynamism. This view has later been acknowledged by Teece (2014), stating that dynamic capabilities are key to superior performance not only in fast-paced environments. Clearly, there has been significant debate with regards to the relation between dynamic capabilities and organizational performance (Easterby-Smith et al. 2009). According to Drnevich and Kriauciunas (2011) the question whether they affect performance has not been fully addressed so far. Based on a review of the capabilities literature, the authors found no scholars hypothesizing a direct negative effect of dynamic capabilities on firm performance. Most studies either find a direct link between dynamic capabilities and performance (e.g., Drnevich and Kriauciunas 2011; Pezeshkan et al. 2016) or an indirect link between dynamic capabilities and performance (e.g., Leischnig et al. 2017), or they find the effect to be context-dependent (e.g., Wilden et al. 2013). Pezeshkan et al. (2016) analyze 89 studies and find an overall positive and significant effect of dynamic capabilities on performance. Firms who lack dynamic capabilities will only be able to gain competitive advantage for a short period (Augier and Teece 2009). Wilden et al. (2013) find that firms which possess greater dynamic capabilities show better performance in the context of a more organic organizational structure and greater competitive intensity in the market. By investigating IT-based ordinary and dynamic capabilities in Chilean firms Drnevich and Kriauciunas (2011) find that ordinary and dynamic capabilities contribute positively to relative firm performance. They find that the effect of dynamic capabilities is stronger in more dynamic environments and less effective in more stable environments. In addition, Grafton et al. (2010) view business unit's ability to exploit their existing capabilities as the main driver of performance. Therefore, we argue the following: 
H2: Dynamic capabilities positively influence business unit performance.

\subsubsection{The mediating effect of a digital business strategy on the relation between dynamic capabilities and business unit performance}

The literature stream on the effects of a digital business strategy on performance is still in an early stage, with most studies focusing on market performance at the firm level. The effect of a digital business strategy on performance heavily depends on firm-internal and external factors (Leischnig et al. 2016). Wunderlich and Beck (2018) carried out an online survey with 228 senior IT decision makers, investigating how organizational innovativeness and subsequently market-based performance is influenced by digital business strategy. Their findings attribute high importance to a digital business strategy. The study by Leischnig et al. (2017) finds an indirect, positive effect of digital business strategy on market performance (i.e. achievement of market-based goals) through enhanced market intelligence capability, value creation and value capturing. Value creation is characterized by better customer knowledge, which leads to an improved offering development. Value capturing describes the process of competitor knowledge and subsequently pricing. The authors conducted a survey with 161 firms from different industries. In addition, literature finds that the condition under which an organization operates influences performance and further that a uniform prediction is likely misleading and rather varies depending on organizational and environmental factors. While for firms that have a business-to-business focus and act in a technologically turbulent environment a digital business strategy is not necessary to realize high market performance, firms that have to deal with frequent technological changes, a heterogeneous customer base and a business-to-customer focus, as well as firms that operate within a technologically stable environment, offer goods and focus on business-to-business operations benefit from a digital business strategy (Leischnig et al. 2016). Based on the previous argumentation regarding the effect of dynamic capabilities on the implementation of a digital business strategy and business unit performance in combination with the arguments stated in this section, we hypothesize the following: 
H3: The impact of dynamic capabilities on business unit performance is mediated by the implementation level of a digital business strategy.

The predicted hypotheses are shown in Figure 2.

Figure 2

Hypothesized Structural Model

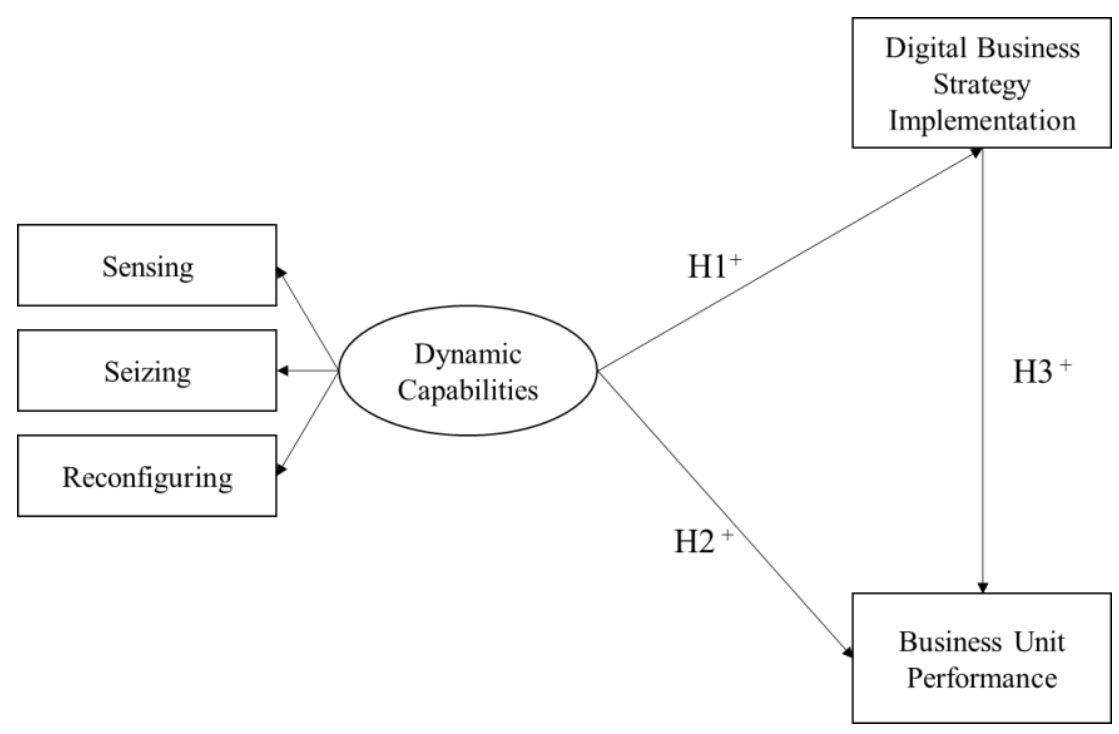

\subsection{Method}

The following section contains detailed information on the sample, data collection and measurement of the variables used in the model.

\subsubsection{Sample and Data Collection}

Our sample is based on all senior vice presidents and vice presidents of a large German manufacturing firm ( $n=502)$, which represents all company's business units. The company is one of the largest in the premium sector and is more than 100 years old. It is represented in more than 140 countries and produces more than half of its products outside of Germany. The yearly revenue has been nearly 100 billion Euros for the last years and the workforce remains constant at more than 100,000 
employees. The company's digital business strategy has been introduced two years prior to the data gathering process and was still in its infancy at the point of measurement. The organization's digital business strategy applies to all business units. As key topics, the company's digital business strategy has treated the following fields: connected products, digitalized processes, industry 4.0, digital customer ecosystem, data strategy, IT strategy, and cultural transformation.

The study specifically focuses on manufacturing firms for several reasons. First, the McKinsey study by Bughin et al. (2017) shows that the manufacturing industry is among the least digitized industries. Second, the whole industry is currently undergoing a transformation from a pure manufacturing focus to a manufacturer and service provider sector. This transformation is mainly driven by digitalization as it influences core functions like product development, IT, manufacturing, logistics, marketing, sales, and after-sale service. Thus, change is required with regards to topics like internal processes, products and customer interaction (Porter and Heppelmann 2015). Large corporations that miss out on adopting new technologies and fail to take the need for this change serious are likely to fall behind (Sebastian et al. 2017). Third, manufacturing companies operate in a very globally organized industry that is exposed to a diverse set of challenges such as changing regulations, customer expectations and competition. Therefore, it is important for manufacturing companies to anticipate changes early on and adopt adequately. Fourth, due to the large size of manufacturers, respondents found within our sample work in very diverse departments and countries with duties like production, development, human resources, finance, strategy or sales. In addition, the manufacturing industry represents a good fit according to Teece (2007), as it meets the following characteristics that indicate the importance of possessing dynamic capabilities: the industry is exposed to international commerce and opportunities; threats of technological change directly impact the business model; technological change is systematic in nature as multiple inventions have to be combined in order to be value adding for customers; the industry engages in globally developed markets to exchange goods and services; the business environment is characterized by poorly developed markets regarding technological and managerial know-how as it is geographically largely clustered within a few countries only. 
Top management represents an ideal sample since many scholars highlight the importance of managers' ability to adopt to new circumstances and development of dynamic capabilities (e.g., Ambrosini and Bowmann 2009; Augier and Teece 2009; Eisenhardt and Martin 2000; Teece 2007; Teece 2018), which indicates that our sample is a good fit for the research question at hand. They furthermore highlight the fact that dynamic capabilities are related to high-level activities to some extent as they are linked to managers ability to select and/or develop "routines, making investment choices, and in orchestrating non-tradable assets to achieve efficiencies and appropriate returns from innovation" (Augier and Teece 2009, p. 417).

In order to test our hypotheses, we created an online survey including 41 questions. All survey materials were presented in English to appropriately address all managers globally (see Appendix A). ${ }^{3}$ The online survey was tested in a pilot study with 15 department heads. Due to the seniority of our sample and the length of the survey, we achieved an overall response rate for the final survey of $38.1 \%$ leading to 191 fully completed and usable responses. The vice president of strategy digitalization was our primary contact and helped us to increase the response rate by addressing our sample personally.

\subsubsection{Measurement and Validation}

In order to measure our variables of interest correctly, we applied a two-stage approach to develop the final set of survey questions. First, we conducted expert interviews to understand the completeness of our measures with each member of the strategy digitalization team, including the vice president of strategy digitalization, who initiated the interviews $(n=14)$. The team was responsible for creating the organization's current digital business strategy and was subsequently responsible for its implementation. The method of choice was standardized, open-ended faceto-face interviews with six questions (see Appendix B). The interviews were conducted in German. Primary objective was to gain deeper insight into the construct of digital business strategy and its affected performance factors as we investigate

\footnotetext{
3 The questions including the different answering schemes are shown in Appendix 1 at the end of this dissertation.
} 
the business unit level instead of the common firm level. All interviews were transcribed and analyzed using NVivo. ${ }^{4}$

Second, we carried out an online survey. We conceptualized our online survey by using self-typing Likert-scale answering schemes for all questions to test our hypotheses. This is a well-accepted practice in this type of research. Merely the demographic questions deviated from this scheme. With regards to demographics we were only able to ask for the respondents' tenure at the company, the tenure within their current position and their current field of responsibility due to reasons of anonymity. Additional questions might have increased the likeliness that answers could be traced back to specific participants.

Dynamic capabilities: We measure this construct by an adapted version of Wilden et al.'s (2013) developed dynamic capabilities index. The measure is divided in the relevant mechanisms: sensing, seizing, and reconfiguring. The authors used an existing scale by Jantunen, Puumalainen, Saarenketo and Kyläheiko (2005) to measure 'reconfiguring'. For sensing and seizing the authors combined several existing scales (Danneels 2008; Jantunen 2005) with items derived from Teece's (2007) theoretical work. Initially the three mechanisms are each measured by fouritem scales. Sensing is estimated by processes like scanning the business environment, reviewing best practices and gathering information. Seizing is estimated by processes such as investing in appropriate solutions, adopting best practices and changing current practices. Reconfiguring is estimated by processes like implementing new methods, renewing business processes and changing ways to achieve targets and objectives. Analogous to the initial index, respondents were asked to rate the underlying processes on a seven-point interval scale ( $1=$ 'rarely' to $7=$ 'very often'). Compared to the initial index however, we had to adjust the questions in order to measure results at the business unit level instead of the organizational level. Each question consequently starts with the term "In my business unit..." instead of "In my organization...". In addition, we had to delete one question which was related to marketing activities, as not every business unit is engaged in such matters. As a result, reconfiguring is measured only by means of three-item scales. Lastly, we gave some additional explanation for the phrases 'professional

\footnotetext{
${ }^{4}$ Interview transcripts are available upon request from the author.
} 
association activities' and 'customer' within the relevant questions. The final ten questions are shown in Appendix A.

Digital Business Strategy: This variable intends to measure the level of implementation of the digital business strategy within the single business units. A clear definition of how to measure the variable has not been developed so far. Our measure is based on questions created by Leischnig et al. (2017) and enriched by the results of the interviews conducted. While the authors worked with six questions, only five questions were suitable to our setting. The initial questions were created to measure digital business strategy at the firm level, while in our setting, they need to address the business unit level. We did not make use of the statement "Our customers can interact with us in many ways via the Internet.", as not every business unit directly engages with customers external to the organization. In addition, we added the term "business unit" to every statement. Based on the findings of our interviews, we added five more questions covering the aforementioned topics, namely data, IT, working methods, culture and customer centricity. The added questions are in line with the previously mentioned fact that digital business strategy is the combination of an organizational and IT strategy (Bharadwaj et al. 2013). In line with the study by Leischnig et al. (2017) a seven-point interval scale (1='strongly disagree' to $7=$ 'strongly agree') has been used. The final ten questions are shown in Appendix A.

Business unit performance: We conceptualize business unit performance based on an effectiveness measure. This decision is based on the expert interviews, as effectiveness was mentioned by respondents as the key outcome of a digital business strategy. We decided not to use objective measures since they often tap a single lower-order construct and only cover narrow aspects of the performance dimension (Bommer et al. 1995). This is especially problematic in our setting due to two reasons. First, when measuring performance dimensions associated with the implementation of a strategy, they are not associated with objective measures in many cases (Govindarajan and Gupta 1985). Second, as our sample contains business units with a very diverse set of daily tasks like human resources, research and development or production, the narrow aspect of objective measures is not able to reflect this diversity. Hence, we used the effectiveness index created by Alper, Tjosvold and Law (2000) to measure our dependent variable. This variable is 
therefore based on managers' rating of team performance. The effectiveness index presents an excellent fit, as the authors also intended to measure performance on the team level within a company, in contrast to the majority of papers, which measure performance on the firm level. Moreover, their measure is also applicable to a diverse set of teams that engage in very diverse day-to-day tasks. In contrast to Alper et al. (2000), who aim to measure how conflicts among team members affect efficacy and overall team performance (measured by effectiveness), our focus was on measuring the performance of each senior vice president's and vice president's business unit. Here, we see the respondent as a crucial part. Therefore, each question in our setting starts with "My business unit ..." instead of the former "Team members ...". Thereby, the managers are not induced to only rate their employees but the overall business unit. In addition, we removed the original question "Team members do not abuse their sick leave policy.", as managers did not feel comfortable answering this question in our pilot study. This leaves a 17 -item effectiveness scale. Moreover, we adjusted the questions from a pure manufacturing focus to a more general setting, as the original study was addressing "a leading manufacturer of portable and stationary electric generators sets and related switchgear and controls, small gasoline engines, and alternating current generators" (Alper et al. 2000, p. 629). This implies changing terms like "tools and machinery" to "hardware and software" or "products" to "output". Respondents were asked to rate their effectiveness on a ninepoint interval scale ranging from 'very low effectiveness' to 'very high effectiveness'. The final questions for our business unit performance variable can be seen in Appendix A.

\subsection{Results}

The following section provides the results using structural equation modeling (SEM). This statistical analysis method is the preferred option as it provides a mechanism to analyze multiple relationships simultaneously while incorporating variables that have not been directly measured (i.e. latent variables). SEM is a prevalent estimation method to test theoretical derived models against empirical data (Chen, Curran, Bollen, Kirby, and Paxton 2008; Gefen, Straub, and Boudreau 2000). In order to test the underlying model, we used the AMOS 24.0 software program (Arbuckle and Wothke 1999). It is a covariance-based SEM (CB-SEM) approach (Byrne 2010), which is considered suitable to confirm theoretical assertions in a more conservative and rigorous way (Hair et al. 2011; Byrne 2010). Considering that our proposed 
relationships are fundamentally grounded with regards to the theoretical frameworks (Leischnig et al. 2017; Teece et al. 1997; Wilden et al. 2013; Yeow et al. 2018) this approach is suitable for our conceptual model. Descriptive statistics with regards to the directly measured variables can be seen in Table $1 .{ }^{5}$ Before undertaking the SEM method however, a confirmatory factor analysis has been carried out.

\section{Table 1}

\section{Descriptive Statistics}

\begin{tabular}{lllllll}
\hline Variable & Obs. & Min & Mean & Median & Max & Std. Dev. \\
\hline DBSI & 191 & 2.70 & 5.39 & 5.40 & 7 & 0.8579 \\
BUP & 191 & 3.63 & 7.77 & 8 & 9 & 0.8478 \\
Dynamic & Capabilities & & & & & \\
SEN & 191 & 2.25 & 3.76 & 3.75 & 5 & 0.5843 \\
SEI & 191 & 2.25 & 4.07 & 4 & 5 & 0.5539 \\
REC & 191 & 1 & 3.54 & 3.67 & 5 & 0.7451 \\
\hline
\end{tabular}

DBSI: Digital Business Strategy Implementation

BUP: $\quad$ Business Unit Performance

SEN: $\quad$ Sensing

SEl: $\quad$ Seizing

REC: Reconfiguring

\subsubsection{Measurement model}

In order to calculate the SEM results, it is necessary to assess the single components of the measurement model. Firstly, a principal component analysis was used to assess the variables directly measured by the different items. Secondly, the latent variable dynamic capability was tested using the first stage of the two-stage process recommended by Schumacker and Lomax (1996). Here, the single latent variable (i.e. dynamic capabilities) is modeled as a measurement model and tested using SEM. The second stage will be carried out later.

The principal component analysis has been executed for the variables sensing, seizing, reconfiguring, digital business strategy implementation and business unit performance. The results after an orthogonal rotation are reported in Appendix $\mathrm{C}$. The standardized factor loadings describe the variation an item explains in a latent variable. As a rule of thumb, this value should not be smaller than 0.5 and preferably above 0.7 (Hair, Anderson, Tatham, and Black 2006). Next, the

\footnotetext{
${ }^{5}$ The results of the factor analyses are already incorporated here.
} 
Eigenvalue must be above 1 to be considered as a factor. The Average Variance Extracted (AVE) is the average squared factor loadings and should exceed 0.5 to suggest adequate convergent validity (Hair et al. 2006). The Cronbach's alpha is a reliability coefficient indicating the consistency of the scale (Hair et al. 2006). An accepted lower limit is 0.7 (Robinson, Shaver, and Wrightsman 1991). An additional limitation we put in place is the number of items per construct needed. We apply Hair et al.'s (2006) rule of thumb to preferably have four items per factor. This guards against too much weight being assigned to any single question and the consequential interference in the SEM later, as all variables are being averaged by the items explaining it. The only exception is the variable reconfiguring, as this construct was measured by three items only since one question did not fit our setting, as previously mentioned. Altogether the variables sensing, seizing, reconfiguring and DBSI show acceptable fit. Nearly all factor loadings are above the preferred level of 0.7 and their eigenvalues exceed the threshold of 1 . The variable sensing has an AVE of 0.47 and a Cronbach's alpha of 0.62. Even though these fit indices are just below the minimum threshold, we decided to retain the variable in the model, as it represents an essential part in describing dynamic capabilities from a theoretical point of view, while the values only marginally violate our adopted rule of thumb. For the variables seizing and reconfiguring all fit indices are met. In case of the variable DBS, one factor loading is slightly below the 0.5 limit, as is the AVE. Since the Cronbach's alpha is well above the 0.7 threshold however, we opted to include all items regardless. All in all, for these variables the items loaded onto a single factor in all cases. More problematic is the principal component output for the variable BUP. Here, twelve items violate the factor loadings limit of 0.5 . In addition, the AVE value is 0.214 , which is well below the limit. Based on the principal component analysis, the items loaded on five different factors with eigenvalues greater than 1. We carried out an additional component factor analysis for BUP in order to find the five different factors. Results are shown in Appendix D. Ultimately, only one factor describing BUP meets all requirements, as the other four contained less than four items. Therefore, BUP is measured by eight different items in the final SEM. ${ }^{6}$ The correlation coefficients are shown in Table 2. The confirmatory factor analysis reveals a just-

\footnotetext{
${ }^{6}$ As shown in Appendix D BUP is measured by the items BUP1, BUP6, BUP10, BUP12, BUP13, BUP15, BUP16 and BUP17. Not included in the final model are the items BUP2, BUP3, BUP4, BUP5, BUP7, BUP8, BUP9, BUP11 and BUP14.
} 
identified model, which indicates a good fit. This case with 0 degrees of freedom is referred to as saturated model in the SEM terminology (Hair et al. 2006).

\section{Table 2}

Correlation Coefficients $(n=191)$

\begin{tabular}{|c|c|c|c|c|c|}
\hline & $\overline{S E N}$ & $\overline{\text { SEI }}$ & REC & $\overline{\text { DBSI }}$ & $\overline{B U P}$ \\
\hline SEN & 1.0000 & & & & \\
\hline SEI & $.6223^{\star \star \star}$ & 1.0000 & & & \\
\hline REC & $.4617^{\star \star * *}$ & $.4675^{\star \star *}$ & 1.0000 & & \\
\hline DBSI & $.3716^{\star \star \star}$ & $.3677^{\star * *}$ & $.4421^{\star \star \star}$ & 1.0000 & \\
\hline BUP & $.3509^{\star \star \star}$ & $.4128^{\star \star \star}$ & $.2733^{\star \star \star}$ & $.2633^{\star \star *}$ & 1.0000 \\
\hline $\begin{array}{l}\text { SEN: } \\
\text { SEI: } \\
\text { REC: } \\
\text { DBSI: } \\
\text { BUP: } \\
\text { *** }\end{array}$ & $\begin{array}{l}\text { Sensing } \\
\text { Seizing } \\
\text { Reconfiguring } \\
\text { Digital Business } \\
\text { Business Unit Pe } \\
\text { Significant at } p \text {-va }\end{array}$ & $\begin{array}{l}\text { gy Implemen } \\
\text { ance } \\
0.01\end{array}$ & & & \\
\hline
\end{tabular}

\subsubsection{Structural Model}

After completing the confirmatory factor check, the second stage of the analysis deals with the structural model. Again, the AMOS 24.0 software program (Arbuckle and Wothke 1999) has been used to estimate the base model shown in Figure 2. Significance tests were done by using the bootstrap method. This is especially desirable in studying indirect effects in mediation models with latent variables (Shrout and Bolger 2002). We used the bootstrap procedure with 2,000 samples and a bias-corrected confidence interval of 90 . Scores for each variable remaining after the confirmatory factor analysis were calculated by averaging the items. The exception here is the latent construct, which is calculated by AMOS. As previously mentioned, the sample includes 191 observations and the model estimates 19 parameters, which results in a subject-to-parameter ratio of 10.05 and thereby exceeds the rule of thumb of 5:1 (Hair et al. 2006). In general, there is not this single criterion to assess a model's validity, but fit indices give a good indication. Therefore, it is important to always report a series of fit indicators. Table 3 presents the results of the structural equation model and reports the model fit. In sum, the indices show good fit values. The chi-square value of 10.524 is significant at the 5 percent level $(d f=4, p=0.032)$. Since the chi-square statistic is influenced by large sample sizes, we used the CMIN/DF ( $\mathrm{x} 2$ / df) in addition. Even though different cutoff levels have 
been suggested by researchers (e.g., Carmines and Mclver 1981; Marsh and Hocevar 1985), in general the range from 2 to 5 has been accepted by literature. Hence the value of 2.631 indicates good fit. Another measure that corrects for sample size and model complexity is the Root Mean Square Error of Approximation (RMSEA) (Browne and Cudeck 1993). This index is better suited to confirmatory contexts (Rigdon 1996). The index value varies from zero to positive infinity with 0 indicating excellent model fit. The range that indicates good fit is debated amongst scholars, but most deem values below 0.1 acceptable (e.g., Browne and Cudeck 1993; Chen et al. 2008; Hair et al. 2006). Even though Kenny, Kaniskan and McCoach (2015) recommend being careful with the RMSEA value in case of small df models with small sample sizes as it might lead to rejecting too many models, the RMSEA for the SEM at hand indicates good fit with 0.08. Like the RMSEA, the Goodness-of-Fit Index (GFI) is an absolute fit measure, which are both direct measures that indicate the fit between the model specified and the observed data. In general, a value above 0.9 is considered a good model fit (Hair et al. 2006). This strengthens explanatory power of the SEM results with a GFI value of 0.978 . Lastly, we used the Comparative Fit index (CFI), which is an incremental fit index that describes how well the model fits relative to some alternative baseline model (Hair et al. 2006). In order to indicate reasonable fit, the CFI should be at least 0.9 and preferably above 0.95 to indicate good fit (Hu and Bentler 1999). Once again, our obtained value of 0.973 underlines the good fit of the model at hand. Overall, all indices are within the acceptable levels or close to them with regards to the $p$-value. The conclusions drawn from the model are based on a fundamental model and can thus be generalized. The final structural model is shown in Figure 3. 


\section{Table 3}

Structural Equation Model $(n=191)$

\begin{tabular}{lllll}
\hline Direct Effects & & & & \\
\hline $\begin{array}{l}\text { Independent } \\
\text { variable }\end{array}$ & Dependent variable & Direction & Coefficient & Hypothesis \\
\hline DC & DBSI & + & $0.53^{* * *}$ & Supported \\
DC & BUP & + & $0.47^{* * *}$ & Supported \\
\hline
\end{tabular}

\begin{tabular}{ll}
\hline Indirect Effects & \\
\hline $\begin{array}{l}\text { Independent Moderator } \\
\text { variable }\end{array}$ & $\begin{array}{l}\text { Dependent } \\
\text { variable }\end{array}$ \\
\hline
\end{tabular}

\begin{tabular}{ll}
\hline Model fit & \\
\hline $\mathrm{X}^{2}$ & 10.524 \\
$p$-value & 0.032 \\
DF & 4 \\
CMIN/DF & 2.631 \\
RMSEA & 0.093 \\
GFI & 0.978 \\
CFI & 0.973
\end{tabular}

The standardized coefficients are presented.

DC Dynamic Capabilities

DBSI Digital Business Strategy Implementation

BUP Business Unit Performance

*** Significant at $p$-value $<0.01$

\subsubsection{Hypotheses Testing}

The coefficients to the proposed hypotheses can be seen in Table 3. Hypothesis 1 examined the effect of dynamic capabilities on the implementation of a digital business strategy. The result indicates a positive and significant relationship $(\beta=.47$, $\mathrm{p}$-value $<0.01)$. Thus, hypothesis 1 is supported. With respect to hypothesis 2 , we aimed at contributing to the ongoing debate in literature regarding the effect of dynamic capabilities on performance. In order to add revealing insights to the debate, we analyzed performance on the business unit level. The results show a direct and significant relationship ( $\beta=.53$, $p$-value $<0.01$ ) specifying that performance improves in cases of higher results on the sensing, seizing and reconfiguring scores. Hypothesis 2 is supported. Lastly, hypothesis 3 tested the mediating effect of the implementation level of a digital business strategy on the relationship between a dynamic capabilities and business unit performance. We find no significant mediation effect, indicating that a higher level of implementation might not 
necessarily improve the effect of dynamic capabilities on business unit performance. Therefore, hypothesis 3 is rejected. This will be discussed in more detail later.

\section{Figure 3}

Final Model

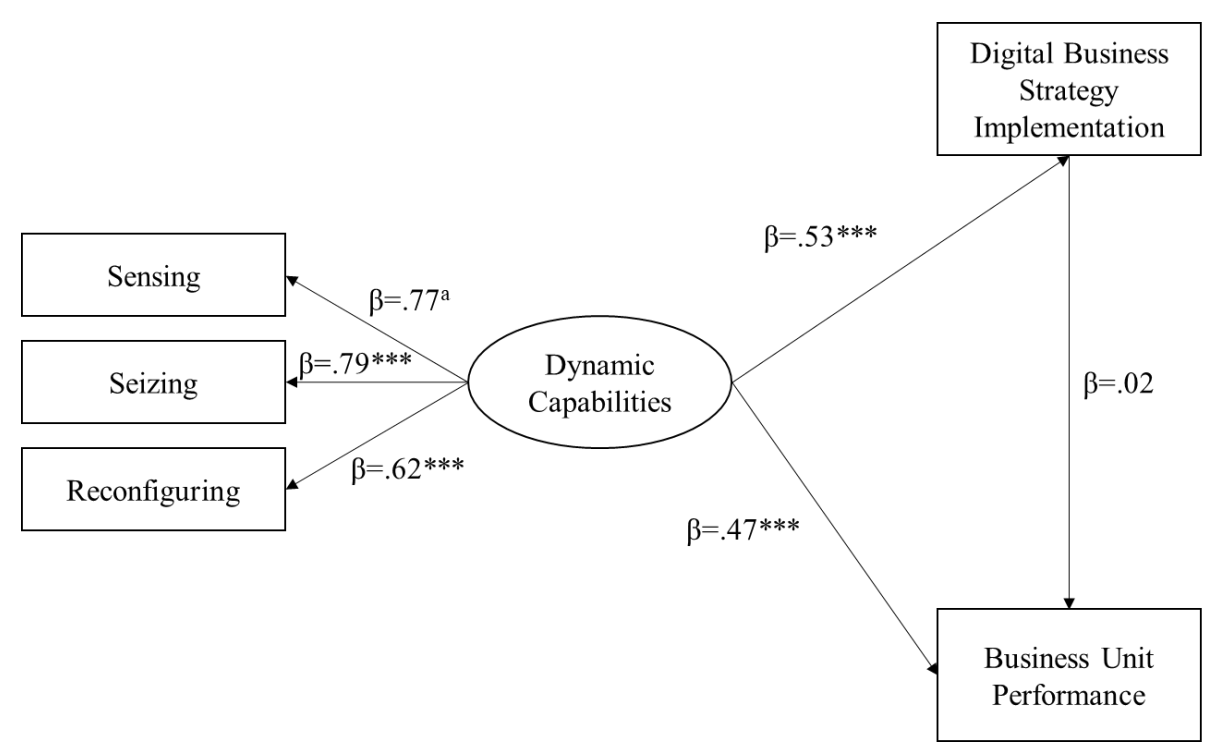

The standardized coefficients are presented.

a Loadings are fixed to 1 for identification purposes

*** $\quad$ Significant at $p$-value $<0.01$

\subsubsection{Further Analysis}

In order to test the robustness of our results, we carried out a number of additional analyses. We included all business units of our sample regardless of their function or implementation level in the base model. The following section presents the results of the SEM with only parts of the sample included. The method used remains identical.

First, we analyzed the sample based on the digital business strategy implementation level. In doing so, we split the sample in half, using the median of digital business strategy implementation (median $=5.4$ ) as the cutoff value, with every observation above the median indicating a high implementation level. The results are presented in Appendix E and F. We find the model fit indices for both models to 
be acceptable (SEM DBSI high: $\chi 2=5.983, \mathrm{df}=4, \mathrm{p}=0.200, \mathrm{CMIN} / \mathrm{DF}=1.496$, RMSEA=0.073, GFI=0.975, CFI=0.977; SEM DBSI low: $\chi 2=6.326, \mathrm{df}=4, \mathrm{p}=0.176$, $\mathrm{CMIN} / \mathrm{DF}=1.581, \mathrm{RMSEA}=0.078, \mathrm{GFI}=0.976, \mathrm{CFI}=0.972$ ). The results do not differ significantly from the base model. In the high implementation case of the DBS sample $(n=95)$, the coefficient for the relation between DBSI and BUP performance turned slightly negative but is still highly insignificant. The relations between $D C$ and DBSI ( $\beta=0.398, p$-value $<0.01$ ), and BUP $(\beta=0.54, p$-value $<0.01)$ respectively, remain positive and significant. The mediation effect stated in hypothesis 3 remains insignificant. In the low implementation case of the DBS sample $(n=96)$ the picture is analogous. The relationship between DBSI and BUP is negative, yet highly insignificant and the relations between DC and DBSI $(\beta=0.332, p$-value $=0.01)$, and BUP $(\beta=0.446, p$-value $<0.01)$ respectively, are significant and positive. Even though the coefficients are a bit smaller, they do not differ significantly between the two samples. Again, the mediation effect stated in hypothesis 3 remains insignificant. These results indicate that the level of implementation with regards to the DBS has no real impact on the proposed relations in the model at hand. The results found in this paper can be universally applied to business units regardless of their DBSI.

Second, we divided the sample according to the business units' function. The first group ( $n=70$ ) includes business units that deal with topics like human resources, controlling, finance, quality management, strategy or legal. This group includes all business units that are labeled as central functions. The second group $(n=121)$ contains business units in charge of - amongst others - research and development, purchasing, production, logistics or sales. These business units are labeled operating functions. The results are presented in Appendix $G$ and $H$. Similar to the previous analysis, the results do not differ from the base model and the model fit indices for both models are acceptable (SEM central functions: $\chi 2=7.432, \mathrm{df}=4$, $\mathrm{p}=0.115, \mathrm{CMIN} / \mathrm{DF}=1.858, \mathrm{RMSEA}=0.112, \mathrm{GFI}=0.958, \mathrm{CFI}=0.961 ;$ SEM operating functions: $\chi 2=5.908, \mathrm{df}=4, \mathrm{p}=0.206, \mathrm{CMIN} / \mathrm{DF}=1.477, \mathrm{RMSEA}=0.063, \mathrm{GFI}=0.981$, $\mathrm{CFI}=0.987$ ). The relation between $\mathrm{DC}$ and DBSI is positive and significant and does not significantly differ between samples (SEM central functions: $\beta=0.504, p$-value < 0.01; SEM operating functions: $\beta=0.536, p$-value $<0.01$ ). The relation between DC and BUP is positive and significant and likewise does not significantly differ between samples (SEM central functions: $\beta=0.509, p$-value $<0.01$; SEM operating functions: 
$\beta=0.515, p$-value $<0.01)$. The mediation effect is insignificant for both samples. This suggests that one cannot concentrate on single functions with regards to the deployment of dynamic capabilities. Hence, our results are generally applicable to a diverse set of functions.

\subsection{Discussion and Conclusion}

Digitalization has become an important topic in both research and practice. As organizations experience higher levels of industry penetration due to digital technologies, understanding the effects on organizations becomes increasingly important. The purpose of this study was to address the question of how dynamic capabilities influence both business unit performance and the implementation level of a digital business strategy and how the latter mediates the relation between dynamic capabilities and business unit performance. Despite the high interest in dynamic capabilities, the effect of dynamic capabilities on business unit performance remains unclear (Drnevich and Kriauciunas 2011; Wilden et al. 2013). The research field of digital business strategy in comparison is still in its infancy. In this study, we find that dynamic capabilities act as important trigger to increase the implementation level of a digital business strategy and business unit performance. This effect on business unit performance is however not influenced by the implementation level of the digital business strategy since the results indicate that a digital business strategy has no effect on business unit performance. Further, we find that these results are applicable to all kinds of business units regardless of the implementation level of a digital business strategy or the daily tasks. Responding to calls for research, we combined the extensive academic literature of dynamic capability with the emerging view of a digital business strategy (Ambrosini and Bowman 2009), we adopted the dynamic capabilities view to a more traditional industry (Easterby-Smith et al. 2009), and we extended the understanding regarding the effect of a digital business strategy on the relation between dynamic capabilities and performance (Leischnig et al. 2016).

This study provides several contributions to literature. First, the findings add to the debate on the effect of dynamic capabilities on performance. Our study shows that there is a direct positive effect, which highlights the importance of the dynamic capabilities' literature. This adds quantitative evidence to the mostly theoretical and qualitative driven discussion thus far. Thereby, we empirically contradict the findings 
by Wilden et al. (2013), who indicate that the effect of dynamic capabilities is not directly related to firm performance and strengthen the findings by Drnevich and Kriauciunas (2011), as well as Pezeshkan et al. (2016), who both find significant direct effects. Second, we show that the dynamic capabilities construct is not a vague and fuzzy construct by measuring and exploring the underlying mechanisms. Thereby, we address the criticism concerning the construct (e.g., Easterby-Smith et al. 2009; Winter 2003) and strengthen the index developed by Wilden et al. (2013). This is an important step towards gaining deeper insight into the effects caused by dynamic capabilities and could foster more quantitative research in the future. Third, our findings indicate that it is important to highlight constructs beyond the firm level on the business unit level. This gives more detailed insights into processes and mechanisms within an organization. Fourth, the study adopts an interdisciplinary approach. The combination of IS research and strategic managements yields results for scholars from both fields. It shows the importance of dynamic capabilities in the digital age to strategic management scholars and highlights the interplay of the digital business strategy concept with the broader organizational conditions. Fifth, the significant effect of dynamic capabilities on the implementation level of a digital business strategy shows the importance of considering given capabilities in future digital business strategy studies. It demonstrates that the implementation of a digital business strategy does not work for every business unit or firm equally, which might have implications on the results of future studies. This holds regardless of the daily tasks of business units. Sixth, we extended the understanding of a digital business strategy by refining the initial measurement instrument by Leischnig et al. (2017) by including the factors data, IT, working methods, culture and customer centricity. These were indicated as crucial parts of a digital business strategy during the expert interviews. This represents an important step regarding the measurement of a digital business strategy in the future. Moreover, we clarified the fact that we measure the implementation level of a digital business strategy, whereas this has not always been clearly indicated by previous studies (e.g., Leischnig et al., 2017).

In addition to the contributions for academia, the findings provide several contributions to management. First, our findings show that dynamic capabilities of business units are an important factor to be considered by managers. They are a good mechanism to address the penetration caused by digital technologies. 
Managers should consider a person's dynamic capabilities as an important aspect in future hiring processes. On the one hand, employees with high dynamic capabilities improve transformation efforts in the digital age, while on the other hand they improve the overall performance of business units. In addition, the results show that it is beneficial for managers to invest in dynamic capabilities. Potential investments could be implementing new management tools, regularly inviting keynote speakers to inform the workforce on new trends, or establishing customer feedback as a core criterion in every decision. Second, the study on the business unit level gives important insights into the identification of business units supporting the implementation of a digital business strategy. Battilana and Casciaro (2013) conducted a study investigating the success of such initiatives. Their results indicate that it is important to consider the extent to which the effort deviates from the organizational status quo and that such initiatives should be addressed systematically. They focus on two types of organizational members, namely fencesitters and resistors. ${ }^{7}$ Fence-sitters should always be considered as a strong ally regardless of how encompassing the change is. Resistors should only be considered in cases of a low divergence from the status quo. Applying this to our findings, the study of dynamic capabilities gives a quantitative indication whether a business unit should be considered as fence-sitter or resistor. Managers should assess the divergence of the digital business strategy from status quo and adjust their implementation plan accordingly. Consequently, the implementation team can build up their network ties more systematically in order to overcome resistance, which is associated with the implementation of a digital business strategy according to our expert interviews. Third, our results have important implications on the expectations regarding the effect of a digital business strategy on business unit performance. Since we failed to find a significant effect of the implementation level of a digital business strategy on the relation between dynamic capabilities and business unit performance, managers cannot expect a timely effect after the implementation. This is mainly driven by the fact that the implementation level of the digital business strategy has no effect on business unit performance. As we measured the effect two years after the start of the implementation, there is reason to assume that a significant effect of the digital business strategy on business unit performance has

\footnotetext{
7 "Resistors" are employees with a negative attitude toward the change. "Fence-sitters" are employees with an ambivalent attitude toward the change. Both types of employees can potentially influence change adoption.
} 
some level of time lag. Here, a comparison to research on the implementation of technologies like ERP systems can be drawn, in which scholars were only able to find long-run effects on performance (e.g., Hunton, Lippincott, and Reck 2003; Nicolaou 2004; Poston and Grabski 2001). Another potential explanation might lie in the general effect of a digital business strategy. In line with the study conducted by McKinsey, a digital business strategy might help in maintaining the status quo, while other companies fall behind (Bughin et al. 2017). The results are also in line with some of the statements made during the expert interviews, indicating that a digital business strategy might in the beginning lead to confusion and frustration.

The findings should be considered in light of the following limitations, which offer avenues for future research. First, all variables are measured subjectively through the perception of management, as the sample organization does not provide the needed data publicly. Future research can further test the proposed model by using both subjective and objective measures and more importantly a range of performance measures. Digital business strategy might not influence effectiveness as stated by the expert interviews but might affect other performance indicators. Second, all the variables in the model are measured at a single point in time. Future research can measure the proposed effects by conducting a longitudinal study, in order to check for potential time lag effects. Third, we are only measuring effects on the business unit level within one organization in one industry (i.e. manufacturing). Future studies can extend this view by testing business units in various organizations across different industries. Fourth, all our data is based on an online survey and thus exhibits the usual limitations such as sampling issues and self-selection bias (Wright 2005). This limitation could also be eliminated in future research by using objective measures. Fifth, we are only investigating mechanisms and processes within business units and neglect the specific actions taken in order to implement the digital business strategy. Future research can go beyond the dynamic capabilities construct and investigate the effect of specific strategy implementation actions on the implementation level. One potential starting point can be the actions proposed by de Oliveira et al. (2019). 


\section{Appendices Chapter 2}

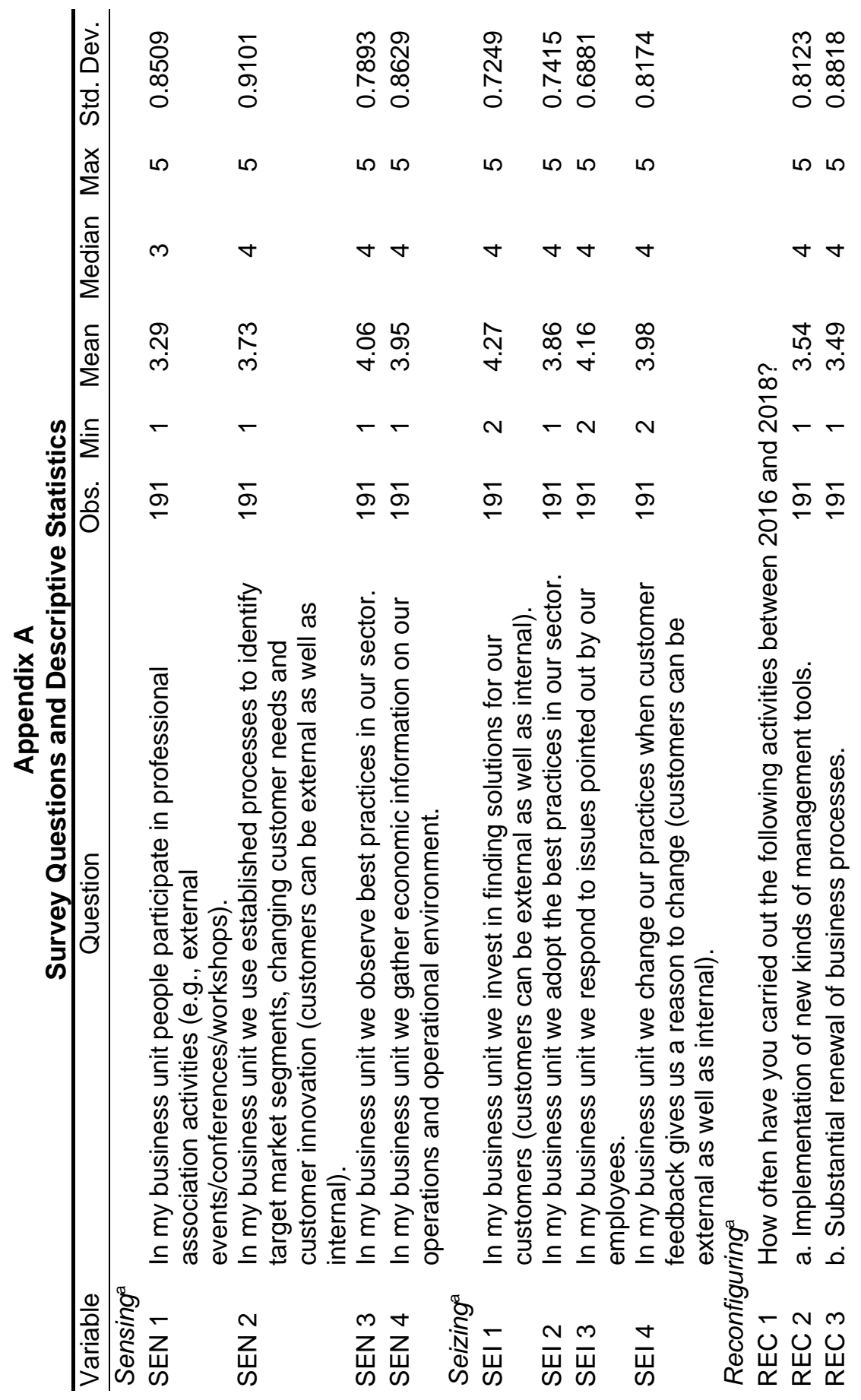




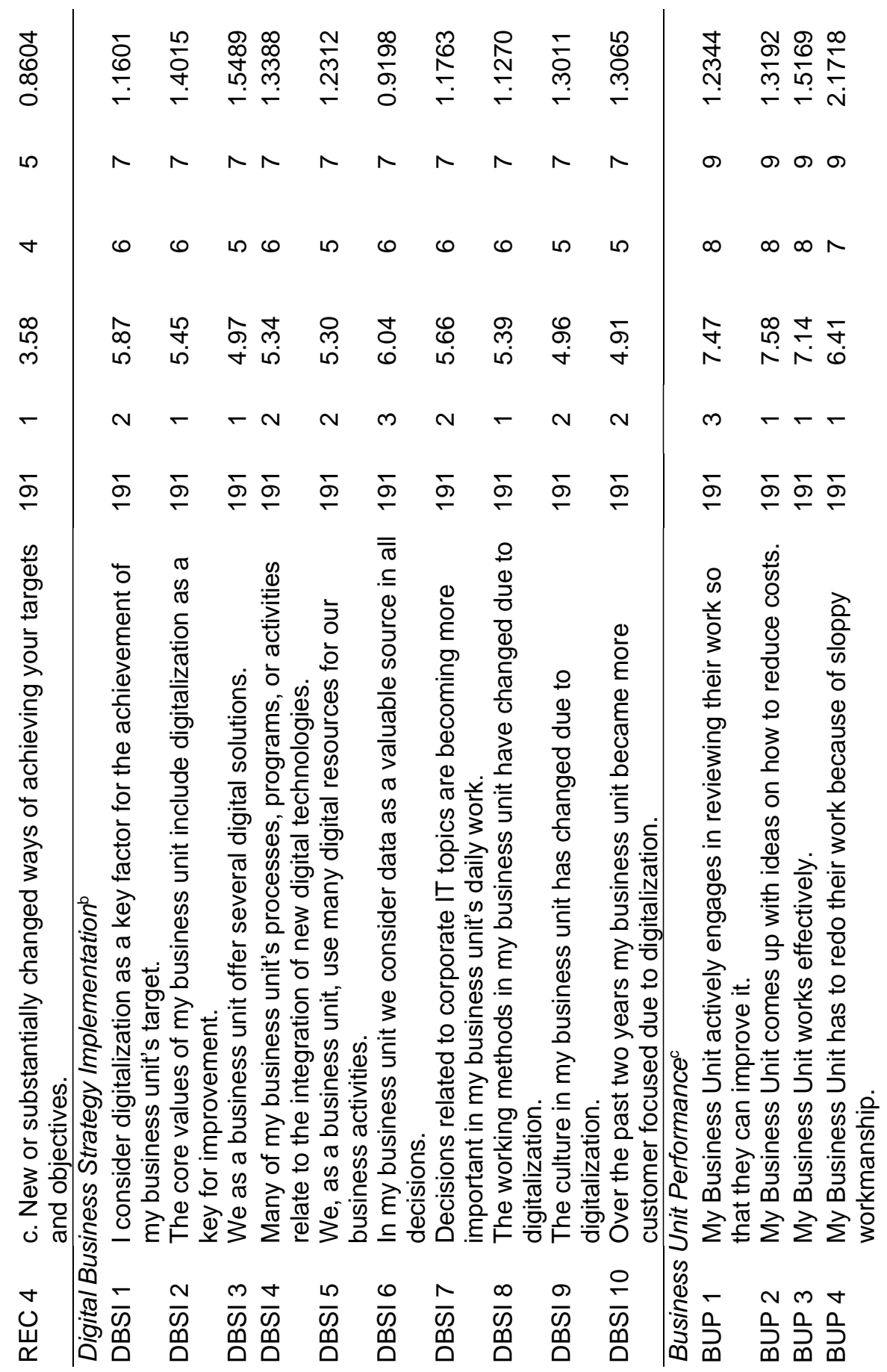




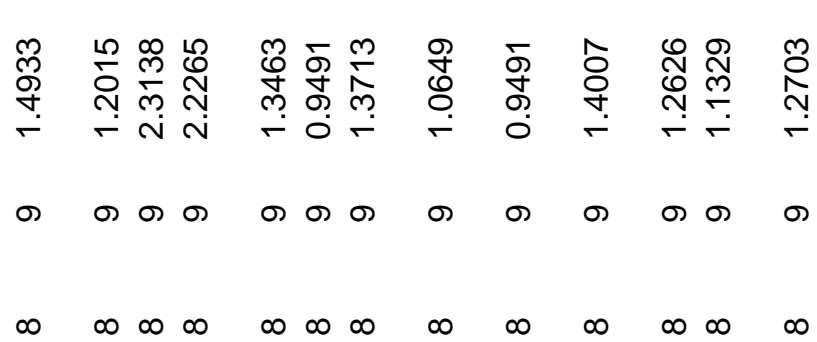

㐫

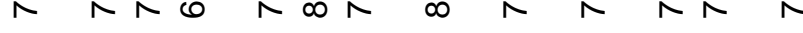

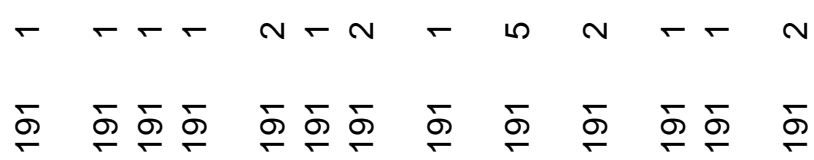

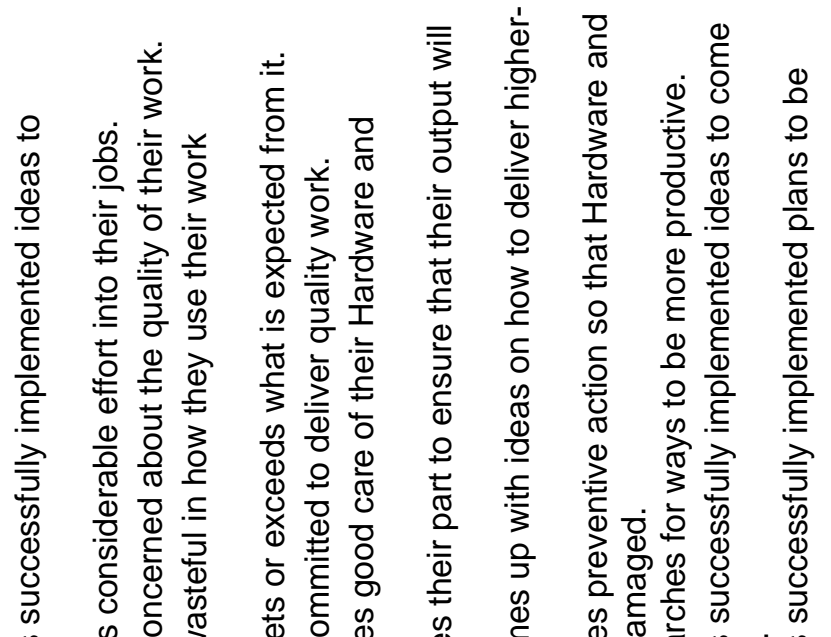

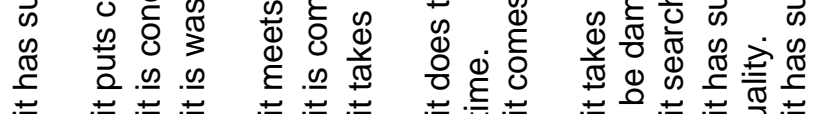

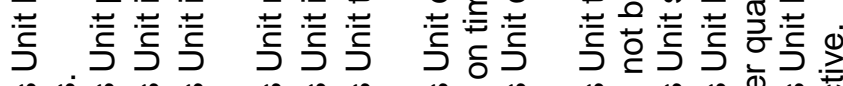
T.

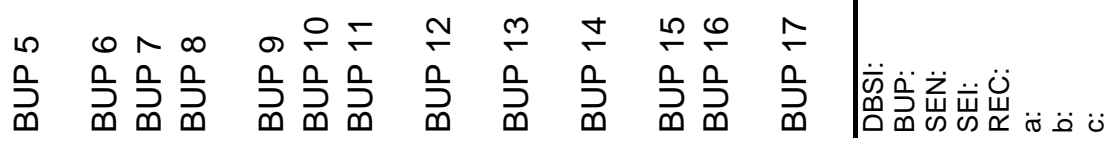


Appendix B

Expert interview questions

\begin{tabular}{|c|c|}
\hline Variable & Question \\
\hline \multirow{4}{*}{ DBS } & How would you describe \\
\hline & What does implementing the DBS mean for you? \\
\hline & $\begin{array}{l}\text { What are aspects of the DBS that are similar for all departments? } \\
\text { How would you measure the level of implementation of a DBS? }\end{array}$ \\
\hline & What performance factors are improved by a DBS? \\
\hline & of the DBS? \\
\hline
\end{tabular}




\section{Appendix C}

Standardized factor loadings ( $n=191)$

\begin{tabular}{|c|c|c|c|c|c|}
\hline & SEN & SEI & REC & DBS & BUP \\
\hline SEN 1 & 0.5729 & & & & \\
\hline SEN 2 & 0.7493 & & & & \\
\hline SEN 3 & 0.7471 & & & & \\
\hline SEN 4 & 0.6629 & & & & \\
\hline SEI 1 & & 0.7444 & & & \\
\hline SEI 2 & & 0.7224 & & & \\
\hline SEI 3 & & 0.7656 & & & \\
\hline SEI 4 & & 0.7489 & & & \\
\hline REC 2 & & & 0.8253 & & \\
\hline REC 3 & & & 0.8948 & & \\
\hline REC 4 & & & 0.9016 & & \\
\hline DBSI 1 & & & & 0.7159 & \\
\hline DBSI 2 & & & & 0.8057 & \\
\hline DBSI 3 & & & & 0.6401 & \\
\hline DBSI 4 & & & & 0.7497 & \\
\hline DBSI 5 & & & & 0.6706 & \\
\hline DBSI 6 & & & & 0.4596 & \\
\hline DBSI 7 & & & & 0.6050 & \\
\hline DBSI 8 & & & & 0.6942 & \\
\hline DBSI 9 & & & & 0.7194 & \\
\hline DBSI 10 & & & & 0.7180 & \\
\hline BUP 1 & & & & & 0.3976 \\
\hline BUP 2 & & & & & 0.1006 \\
\hline BUP 3 & & & & & 0.2644 \\
\hline BUP 4 & & & & & 0.0984 \\
\hline BUP 5 & & & & & 0.1022 \\
\hline BUP 6 & & & & & 0.7619 \\
\hline BUP 7 & & & & & 0.0654 \\
\hline BUP 8 & & & & & 0.0245 \\
\hline BUP 9 & & & & & 0.3101 \\
\hline BUP 10 & & & & & 0.8656 \\
\hline BUP 11 & & & & & 0.3782 \\
\hline BUP 12 & & & & & 0.7815 \\
\hline BUP 13 & & & & & 0.3773 \\
\hline BUP 14 & & & & & 0.0597 \\
\hline BUP 15 & & & & & 0.6744 \\
\hline BUP 16 & & & & & 0.6947 \\
\hline BUP 17 & & & & & 0.3350 \\
\hline Eigenvalue & 1.8871 & 2.2230 & 2.2949 & 4.6753 & 3.6384 \\
\hline AVE & 0.4718 & 0.5557 & 0.7645 & 0.4675 & 0.2140 \\
\hline CR & 0.1987 & 0.2299 & 0.1879 & 0.6271 & 0.5826 \\
\hline Cron. Alpha & 0.6205 & 0.7312 & 0.8462 & 0.8708 & 0.8403 \\
\hline
\end{tabular}




\begin{tabular}{ll}
\hline All values are based on an orthogonal rotation. \\
SEN: & Sensing \\
SEI: & Seizing \\
REC: & Reconfiguring \\
DBSI: & Digital Business Strategy Implementation \\
BUP: & Business Unit Performance \\
AVE & Average Value Extracted \\
CR & Composite Reliability
\end{tabular}




\section{Appendix D}

Standardized factor loadings after adjusting BUP ( $n=191)$

\begin{tabular}{|c|c|c|c|c|c|}
\hline & $\begin{array}{l}\text { BUP } \\
\text { Factor } 1\end{array}$ & $\begin{array}{l}\text { BUP } \\
\text { Factor } 2\end{array}$ & $\begin{array}{l}\text { BUP } \\
\text { Factor } 3\end{array}$ & $\begin{array}{l}\text { BUP } \\
\text { Factor } 4\end{array}$ & $\begin{array}{l}\text { BUP } \\
\text { Factor } 5\end{array}$ \\
\hline BUP 1 & 0.7237 & & & & \\
\hline BUP 6 & 0.7302 & & & & \\
\hline BUP 10 & 0.7825 & & & & \\
\hline BUP 12 & 0.7910 & & & & \\
\hline BUP 13 & 0.7092 & & & & \\
\hline BUP 15 & 0.7987 & & & & \\
\hline BUP 16 & 0.7676 & & & & \\
\hline BUP 17 & 0.6835 & & & & \\
\hline BUP 3 & & 0.8461 & & & \\
\hline BUP 5 & & 0.7596 & & & \\
\hline BUP 9 & & 0.7655 & & & \\
\hline BUP 11 & & & 0.8741 & & \\
\hline BUP 14 & & & 0.8741 & & \\
\hline BUP 4 & & & & 0.8192 & \\
\hline BUP 8 & & & & 0.8192 & \\
\hline BUP 2 & & & & & 0.7396 \\
\hline BUP 7 & & & & & 0.7396 \\
\hline Eigenvalue & 4.4921 & 1.8788 & 1.5281 & 1.3421 & 1.0939 \\
\hline AVE & 0.5615 & 0.6263 & 0.7641 & 0.6711 & 0.5470 \\
\hline CR & 0.5657 & 0.1573 & 0.0912 & 0.0805 & 0.0661 \\
\hline Cron. Alpha & 0.8846 & 0.7004 & 0.6911 & 0.5097 & 0.1495 \\
\hline
\end{tabular}

All values are based on an orthogonal rotation.

BUP: Business Unit Performance 
Appendix E

Structural Equation Model DBSI High $(n=95)$

\begin{tabular}{|c|c|c|c|}
\hline \multicolumn{4}{|l|}{ Direct Effects } \\
\hline Independent variable & $\begin{array}{l}\text { Dependent } \\
\text { variable }\end{array}$ & Direction & Coefficient \\
\hline DC & DBSI & + & $0.398^{\star * *}$ \\
\hline DC & BUP & + & $0.540^{* * *}$ \\
\hline \multicolumn{4}{|l|}{ Indirect Effects } \\
\hline $\begin{array}{l}\text { Independent } \\
\text { variable }\end{array}$ & $\begin{array}{l}\text { Dependent } \\
\text { variable }\end{array}$ & & \\
\hline DBS & BUP & - & 0.041 \\
\hline
\end{tabular}

\begin{tabular}{ll}
\hline Model fit & \\
\hline $\mathrm{X}^{2}$ & 5.983 \\
$p$-value & 0.200 \\
DF & 4 \\
CMIN/DF & 1.496 \\
RMSEA & 0.073 \\
GFI & 0.975 \\
CFI & 0.977 \\
\hline
\end{tabular}

\begin{tabular}{ll}
\hline The standardized coefficients are presented. \\
DC & Dynamic Capabilities \\
DBSI & Digital Business Strategy Implementation \\
BUP & Business Unit Performance \\
$\star \star \star *$ & Significant at $p$-value $<0.01$
\end{tabular}




\section{Appendix $F$}

Structural Equation Model DBSI Low $(n=96)$

\begin{tabular}{|c|c|c|c|c|}
\hline \multicolumn{5}{|c|}{ Direct Effects } \\
\hline \multicolumn{2}{|c|}{ Independent variable } & $\begin{array}{l}\text { Dependent } \\
\text { variable }\end{array}$ & Direction & Coefficient \\
\hline \multicolumn{2}{|l|}{$\mathrm{DC}$} & DBSI & + & $0.332^{* \star *}$ \\
\hline \multicolumn{2}{|l|}{ DC } & BUP & + & $0.446^{\star * *}$ \\
\hline \multicolumn{5}{|c|}{ Indirect Effects } \\
\hline \multicolumn{2}{|c|}{$\begin{array}{l}\text { Independent Moderator } \\
\text { variable }\end{array}$} & $\begin{array}{l}\text { Dependent } \\
\text { variable }\end{array}$ & & \\
\hline \multicolumn{2}{|r|}{ DBS } & BUP & - & 0.028 \\
\hline \multicolumn{5}{|l|}{ Model fit } \\
\hline $\mathrm{X}^{2}$ & 6.326 & & & \\
\hline \multirow{2}{*}{$\begin{array}{l}p \text {-value } \\
\text { DF }\end{array}$} & 0.176 & & & \\
\hline & & & & \\
\hline CMIN/DF & 1.581 & & & \\
\hline RMSEA & 0.078 & & & \\
\hline GFI & 0.976 & & & \\
\hline CFI & 0.972 & & & \\
\hline
\end{tabular}

The standardized coefficients are presented.

DC Dynamic Capabilities

DBSI Digital Business Strategy Implementation

BUP Business Unit Performance

*** $\quad$ Significant at $p$-value $\leq 0.01$ 


\section{Appendix G \\ Structural Equation Model Central Functions $(n=70)$}

\begin{tabular}{llll}
\hline Direct Effects & & & \\
\hline Independent variable & Dependent variable & Direction & Coefficient \\
\hline DC & DBSI & + & $0.504^{\star * *}$ \\
DC & BUP & + & $0.509^{\star * *}$ \\
& & & \\
\hline $\begin{array}{llll}\text { Indirect Effects } \\
\text { Independent } \\
\text { variable }\end{array}$ & Moderator & Dependent variable & \\
\hline DC DBS & BUP & + & 0.087
\end{tabular}

\begin{tabular}{ll}
\hline Model fit & \\
\hline $\mathrm{X}^{2}$ & 7.432 \\
$p$-value & 0.115 \\
DF & 4 \\
CMIN/DF & 1.858 \\
RMSEA & 0.112 \\
GFI & 0.958 \\
CFI & 0.961 \\
& \\
\hline The standardized coefficients are presented. \\
DC $\quad$ Dynamic Capabilities \\
DBSI & Digital Business Strategy Implementation \\
BuP & Business Unit Performance \\
$\star \star \star *$ & Significant at $p$-value $\leq 0.01$
\end{tabular}




\section{Appendix $\mathrm{H}$}

Structural Equation Model Operating Functions ( $n=121)$

\begin{tabular}{|c|c|c|c|}
\hline \multicolumn{4}{|l|}{ Direct Effects } \\
\hline Independent variable & Dependent variable & Direction & Coefficient \\
\hline$\overline{\mathrm{DC}}$ & DBSI & + & $0.536^{\star \star \star}$ \\
\hline DC & BUP & + & $0.515^{\star * *}$ \\
\hline \multicolumn{4}{|l|}{ Indirect Effects } \\
\hline $\begin{array}{l}\text { Independent Moderator } \\
\text { variable }\end{array}$ & $\begin{array}{l}\text { Dependent } \\
\text { Variable }\end{array}$ & & \\
\hline $\mathrm{DC}$ & BUP & + & 0.063 \\
\hline
\end{tabular}

\begin{tabular}{ll}
\hline Model fit & \\
\hline $\mathrm{X}^{2}$ & 5.908 \\
$p$-value & 0.206 \\
DF & 4 \\
CMIN/DF & 1.477 \\
RMSEA & 0.063 \\
GFI & 0.981 \\
CFI & 0.987 \\
\hline
\end{tabular}

\begin{tabular}{ll}
\hline The standardized coefficients are presented. \\
DC & Dynamic Capabilities \\
DBSI & Digital Business Strategy Implementation \\
BUP & Business Unit Performance \\
$* * *$ & Significant at $p$-value $<0.01$
\end{tabular}




\title{
3. AN EMPIRICAL ASSESSMENT OF THE IMPACT OF STRATEGY IMPLEMENTATION ACTIONS ON DIGITAL BUSINESS STRATEGY ${ }^{8,9}$
}

\begin{abstract}
In this paper we investigate the effect of strategy implementation actions on the implementation of a digital business strategy. Since digital technologies are increasingly disrupting industries, it is important for managers to ensure a successful implementation of strategic answers to the recent developments. One promising answer is provided by a digital business strategy. The field of digital business strategy as well as its implementation is however in its infancy. The results presented in this paper are based on an online survey with 191 responses from senior vice presidents and vice presidents of a large German manufacturing organization. Using structural equation modeling (SEM) we find a positive significant effect strategy implementation actions on the implementation of a digital business strategy. This is an important implication for academics and practitioners alike, as the actions can serve as implementation guidelines in the future.
\end{abstract}

\footnotetext{
${ }^{8}$ This chapter is based on a working paper co-authored with Alexander Brüggen, and Anant Joshi.

${ }^{9}$ Acknowledgements: I would like to thank two anonymous reviewers from the HICSS-54 conference 2021 for their helpful comments and suggestions.
} 


\subsection{Introduction}

The purpose of this study is to investigate how the strategy implementation process needs to be conducted to ensure a successful implementation of a digital business strategy. Ensuring a successful implementation of digital business strategy is crucial, as technological developments alter the competitive landscape of many industries (Bharadwaj et al. 2013). This is also confirmed by a recent study of senior executives, which suggests that $90 \%$ of executives expect great or moderate change within their industry through disruption by digital technologies (Kane et al. 2016). According to Davenport and Westerman (2018) many large organizations like GE, Lego, Nike or Procter \& Gamble therefore started digital initiatives (e.g., digitally transforming product and service offerings, embedding sensors into many products, building an extensive new software platform for the Internet of Things). The authors however find that most of these initiatives resulted in depressed stock prices, growth issues or cost and quality issues. This is in line with a study by Sutcliff, Narsalay and Sen (2019), which reports that while companies invested more than $\$ 100$ billion in digital reinvention between 2016 and 2018, most of the investments failed to produce the anticipated benefits. In this context, a study by Kane et al. (2016) shows that the three biggest threats associated with disruption by digital technologies are internal issues related to lack of agility or inflexible culture(19\%), market disruption related to product obsolescence or lower barriers to entry (17\%), and competitive pressure related to more intense competition and faster or new competitors $(16 \%)$. In order to address these threats, organizations need to act quickly and confidently. It is thus important for managers to formulate the right strategic answers to these developments.

One promising answer is offered by digital business strategy, which represents a component of organizational strategy (Bharadwaj et al. 2013). In general, an organization's business strategy consists of three underlying principles (Porter 1996). First, strategy generates a unique and valuable position by indicating a set of activities. Organizations must decide whether to perform activities differently or perform different activities compared to its competitors, in order to create a unique mix of values (i.e. serving few needs of many customers, serving broad needs of few customers, serving broad needs of many customers in a narrow market). Second, strategy means making trade-offs. Strategy thereby sets clear directions regarding decisions such as focusing on quality or cost. Third, strategy creates cohesion 
among a company's activities. The success of a strategy depends on conducting many activities in a simultaneous and integrated fashion, as activities in most cases are interdependent. Compared to the overall role of an organization's strategy, a digital business strategy focuses on the proactive role of digital resources to answer the three underlying principles (e.g. Mithas et al. 2012; Mithas et al. 2013). A digital business strategy is thus defined as an "organizational strategy formulated and executed by leveraging digital resources to create differential value" (Bharadwaj et al. 2013, p. 472).

While the literature stream on business strategy is well-researched, the academic knowledge on digital business strategy is still at an early stage. To this end, there are some studies explaining the concept of digital business strategy and its impact on firm performance (e.g. Leischnig et al. 2017; Wunderlich and Beck 2018). Nonetheless, what constitutes a successful implementation of digital business strategy remains largely unexplored. As a result, examining the determinants of digital business strategy implementation is essential for two reasons. First, the digital business strategy field is a combination of findings from the fields of management information systems and strategic management. It tries to exploit technological advancements by incorporating them into the long-term planning of an organization with the purpose of creating and capturing value (Leischnig et al. 2017). Thus, it is necessary to understand how the existing strategy implementation literature compliments the successful implementation of a digital business strategy. Second, the successful implementation, not its mere ideation, of a strategy is what decides whether a competitive advantage to the focal firm ensues (Neilson et al. 2008). Even the best formulated business strategies do not necessarily guarantee competitive advantage of a business unless they can be implemented successfully (Ho et al. 2014; Hrebiniak 2006; Noble 1999). According to Noble (1999), implementation is an essential piece in the formula for success of any business and especially for industries in which unique ideas and strategies are difficult to achieve. Drawing onto these two points, it is important to understand how the combination of management information systems and strategic management influences the implementation of a strategy in order to overcome the many difficulties that lie between the ideal of strategy alignment and the reality of implementation (Beer and Eisenstat 2000). On the one hand, the time it takes to implement a strategy often varies to a great extent 
(see Alexander 1985; Mankins and Steele 2005; Miller et al. 2004) and on the other hand the reported rate of failures ranges from 7 to 90 percent in literature (Cândido and Santos 2015). One potential explanation is the lack of research guidelines concerning the right strategy implementation approach (Cândido and Santos 2015; Noble 1999). If we link this to the digital business strategy implementation, it becomes evident that to bridge this gap, an inquiry into the dimensions that help to implement digital business strategy in a successful way is warranted. Considering the lack of understanding about the determinants of digital business strategy implementation, we investigate the research question of which specific strategy implementation actions influence the level of implementation of a digital business strategy.

In order to achieve this goal, we refer to one promising research model on strategy implementation, introduced by de Oliveira et al. (2019). The model "can serve as baseline for studies that seek to investigate the determinants or consequences of strategy execution" (p. 10). The model is based on two major components, namely actions (i.e. determinants) and results (i.e. consequences). As we investigate the implementation of a digital business strategy, the action component of de Oliveira et al.'s (2019) model serves as basis for the remainder of this study. The action component consists of five underlying dimensions: unfolding, coordination, communication, control and feedback, and development of human resources policies and employee competences. ${ }^{10}$

While employing this model in the context of DBS implementation, we gathered data within a large German manufacturing company. The company was founded more than 100 years ago, is publicly listed and conducts business in more than 140 countries. The majority of its production plants lie outside of Germany and the company has more than 100,000 employees worldwide. Its yearly revenue is close to 100 billion Euros. We carried out an online survey addressing all senior vice presidents and vice presidents. Of the 502 managers in our final sample, we attained an overall response rate of $38.1 \%$, which translates into 191 fully completed and usable responses.

\footnotetext{
${ }^{10}$ For the remainder of this dissertation these five dimensions are referred to as strategy implementation actions.
} 
Our findings can be summarized as follows. We find that all five action dimensions are significant indicators of strategy implementation actions. We further find that the strategy implementation actions significantly increase the implementation level of a digital business strategy. Lastly, we find that these former findings hold regardless of the daily work of a business unit or the digital business strategy already implemented in a business unit.

This paper provides several important contributions for literature and management. First, we empirically examine the impact of these dimensions on practiced strategy and provide quantitative evidence. The findings show that the proposed dimensions might serve as an important aspect in future studies on strategy implementation and digital business strategy. This addresses de Oliveira et al.'s (2019) call for research to test their proposed dimensions. This represents an important step towards obtaining a better understanding of the two fields and encourage future studies. Second, the study provides theoretical insights on the implementation of a digital business strategy. That is, we examine a set of key strategic action dimensions, which are essential for the success of digital business strategy implementation. We identify all the dimensions based on the strategy implementation actions deemed relevant by de Oliveira et al. (2019). Thereby, we follow the call for research to develop tools for effective strategy implementation (Pryor et al. 2007) and address the obstacle to strategy implementation of not having a model to guide implementation efforts mentioned by Hrebiniak (2006). The author argues that implementation becomes a labyrinth in case of missing guidance. Third, our findings provide valuable information on the strategy implementation process for management. As we identify important action dimensions, we provide guidelines for implementation actions once digital business strategy has been formulated. This can help to reduce the failure rate of implementation efforts with regards to digital business strategies in the future. Fourth, we show the effect of strategy implementation actions on the business unit level and thereby follow a call for research by study 1 . This is a notable contribution, since most other studies investigate strategy implementation on the organizational level.

In the next section we develop our theory and hypotheses, which is followed by the explanation of our method. After that we provide the results and conclude with a discussion of our results, managerial implications and study limitations. 


\subsection{Theoretical Background and Hypotheses}

\subsubsection{Digital Business Strategy}

The literature stream on digital business strategy is increasing ever since the publication of Mithas and Lucas (2010) and has continued to gain importance since the publication of the special issue by MIS Quarterly in 2013 on this topic. Scholars see the digital business strategy field as a combination of management information systems and strategic management research. While corporate strategies typically deal with the relevant industries and markets, a digital business strategy focuses solely on the business and is defined as an "organizational strategy formulated and executed by leveraging digital resources to create differential value" (Bharadwaj et al. 2013, p. 472). According to the authors, a digital business strategy therefore represents the combination of an organizational- and an IT strategy. This implies that IT strategy becomes more important and has to be seen as more than a mere functional level strategy. Even though the literature stream is growing, quantitative findings remain limited. While study 1 fails to find a direct effect of digital business strategy on performance, Leischnig et al. (2017) find an indirect effect through market intelligence capability, as well as through value creation and value capturing. Another quantitative study in the digital business strategy field by Wunderlich and Beck (2018) tests for group differences between low and high digital business strategy implementation. The authors find that a high level of digital business strategy implementation leads to organizational innovativeness and consequently increased performance.

In order to benefit from these performance improvements, most organizations nowadays implement a digital business strategy, as managers try to keep up with technological developments (Leischnig et al. 2017). These technological developments alter the competitive landscape of many industries. They form the new business infrastructure and affect the new organizational logic, as well as patterns of coordination within and across firms (Bharadwaj et al. 2013). In this new logic, it is difficult for many companies to anticipate threats early on and to adapt to changes quickly enough (Harreld et al. 2007). This time component is considered crucial by Bharadwaj et al. (2013), who - next to scope, scale, and sources of business value creation and value capture - see speed as one key theme of digital business strategy. The authors argue for speed as an important component, as product 
launches, decision making, supply chain orchestration, and network formation and adaption are rapidly accelerating in the digital context. An organization's ability to adequately address the fast-paced nature of innovations and the implementation stage is crucial to its performance and existence under digital business conditions. To respond to the outlined changes and remain competitive, it is thus crucial for organizations to effectively manage the strategy implementation process with regards to the implementation of a digital business strategy. This strategy implementation process is discussed in the next sections.

\subsubsection{Strategy Implementation Actions}

In the field of management studies most of the work focuses on strategy formulation and neglects the implementation phase, which leaves this field under-researched (e.g. Alexander 1985; Atkinson 2006; de Oliveira et al. 2019; Okumus 2003; Pryor et al. 2007). This results in most of the studies following a more consultancy-like style and missing out on academic requirements (de Oliveira et al. 2019). Consequently, the number of studies reporting strategy implementation guidelines, theoretical models or a clear definition to executives is limited (Atkinson 2006; de Oliveira et al. 2019; Pryor et al. 2007). This leads to executives spending most of their time on strategy formulation as they feel more comfortable in this process while neglecting the process of strategy implementation (de Oliveira et al. 2019). With a lack of focus from management and a missing agreed-upon and dominant framework, many implementation efforts fail (Okumus 2003). According to Mankins and Steele (2005) this results in companies typically only achieving an average of $63 \%$ of the financial value compared to the value previously anticipated in strategy formulation. ${ }^{11}$ In addition, a study by Cândido and Santos (2015) investigating several studies, reports that the failure rate of implementation efforts in the literature ranges from 7 to 90 percent. Since this range appears tremendously wide, the authors conclude that it is difficult to quantify the true number of failed implementation efforts, owing to several factors that impact this process. In any case, the rate of failure is still higher than desirable. A study by Miller et al. (2004), which investigates 55 different cases of strategic decision implementation finds that the

\footnotetext{
${ }^{11}$ As a main driver the authors outline defects and breakdowns in planning and execution such as allocating the right resources at the right time (7.5\% decrease in strategy's potential value), poor communication (5.2\% decrease in strategy's potential value), action planning $(4.5 \%$ decrease in strategy's potential value) and blurred accountability (4.1\% decrease in strategy's potential value).
} 
duration can range from 3 to 16 years. The authors nevertheless find no significant relation between the duration of implementing strategic decisions and the success of implementation efforts. Successful implementation is however crucial, as even the best strategy is useless without implementation (Aaltonen and Ikävalko 2002). Therefore, implementation expertise is pivotal for creating and maintaining a sustainable competitive advantage (Pryor et al. 2007).

Due to the lack of a commonly accepted definition for the strategy implementation process, we proceed with the definition of de Oliveira et al. (2019):

"Strategy [...] implementation is the process, and related procedures, of

(i) informing - and of being informed by - managers and employees about company challenges as well as of

(ii) translating the strategic plan (either explicitly stated or else just assumed by top level managers) into specific actions and

(iii) establishing consistence among distributed company efforts and among respective resource-allocation decisions, in search of coherent movement for alignment between organizational effort and strategic intention in pursuit of corporate objectives." (p. 9)

This definition implies that the aim of strategy implementation is to put the formulated strategy to work by informing and incorporating all relevant stakeholders. We thus consider failure as a process in which stakeholders are not informed, strategic actions are not in place, and misalignment between organizational effort and strategic intention exists. All of this will result in a strategy that is poorly implemented (Cândido and Santos 2015). In contrast, by successful implementation we mean that everything is implemented as intended within the expected time frame, all performance goals are met, and the method, as well as the outcome is accepted within the organization (Miller 1997).

The definition clearly shows that multiple factors must be considered simultaneously in order to implement a strategy successfully (Okumus 2003). Strategy implementation should not be considered as a one-time annual event (Kaplan and Norton, 2005) but rather as a multifaceted and complex organizational process (Noble 1999). This makes strategy implementation itself a period of high risk 
for any organization (Reed and Buckle 1988). During this period of high risk, organizations regularly face the same strategy implementation problems. Several studies investigated this phenomenon in order to prevent these problems in the future (e.g. Alexander 1985; Beer and Eisenstat 2000; Hrebiniak 2006). The study by Alexander (1985) surveyed 93 firms from different business sectors to assess implementation problems they experienced. The author found six implementation problems which occurred in more than $60 \%$ of the surveyed firms, namely: implementation duration was longer than planned; major unplanned problems occurred during implementation; coordination of activities was not effective; competing activities and crises distracted attention; capabilities of employees were not sufficient; and training and instruction given to lower level employees were not adequate. Another study investigating problems during the implementation process has been conducted by Beer and Eisenstat (2000). The researchers collected data of the implementation process within a number of organizations. The problems most often mentioned by employees in the organizations were: top-down or laissez-faire senior management style; unclear strategy and conflicting priorities; ineffective senior management team; poor vertical communication; poor coordination across functions, businesses or borders; and inadequate down-the-line leadership skills and development. The authors conclude that these problems can be solved by some, but not all organizations. One more study on the obstacles to effective strategy implementation has been conducted by Hrebiniak (2006). The author collected data from 443 managers that were involved in strategy implementation processes. Some of the overarching issues found were the fact that managers are trained to plan, not execute. Second, top-level managers delegate the implementation efforts to lower level employees, which reduces ownership and commitment in most of the processes. Third, the implementation process takes longer than the formulation process. This makes it harder for managers to focus on and control the implementation. Fourth, execution includes more stakeholders than strategy formulation. Here, it is important for organizations to link strategic objectives with day-to-day activities as well as people's incentive structures. All in all, most strategies fail during this important phase, resulting in important resources being wasted (Pryor et al. 2007). Implementation efforts therefore require guidelines and action plans in order to prevent an unstructured approach which only relies on initiatives of motivated individuals (Hrebiniak 2006). 
In order to provide some guidelines or action plans, researchers have been developing various frameworks since the early 1980s. These are however largely conceptual and/ or descriptive (Okumus 2001). One framework, the 5 P's model, has been developed by Pryor et al. (2007) and suggests that strategy implementation is reliant on the closed-loop ranging from purpose (strategic theory), principles (values and culture theory), processes (systems theories), people (behavioral theories) to performance (measurement and feedback theories). The authors thereby integrate theory and research from different business disciplines to represent the interdependencies involved during an effective implementation process in a more comprehensive and integrated structure. Another framework, the capable organization framework, has been suggested by Crittenden and Crittenden (2008). The authors argue that structural levers and managerial skills levers offer a toolkit for implementation efforts. The structural levers are actions (who, what, and when of cross-functional integration and company collaboration), programs (installing organizational learning and continuous improvement practices), systems (installing strategic support systems), and policies (establishing strategy supportive policies). The managerial skills levers are interacting (the exercising of strategic leadership), allocating (understanding when and where to allocate resources), monitoring (tying rewards to achievement), and organizing (the strategic shaping of corporate culture). The levers help identifying efforts that on the one hand facilitate formulation and implementation and on the other hand could negatively affect the implementation process (Crittenden and Crittenden 2008). One more model is the 'strategy implementation framework' created by Okumus (2003). The author established four categories $^{12}$, which are organized in a process-like sequence, albeit not suggesting that implementation is linear and prescriptive. The first category is strategic content and describes the strategy development process. The second category is strategic context, which differentiates between internal and external context. This category mainly deals with aspects like environmental uncertainty, organizational structure, culture and leadership. The third category describes the operational process which aggregates actions like operational planning, resource allocation, people, communication and control. The last category is referred to as outcome and

\footnotetext{
12 The four groups are based on 11 implementation factors which are key elements that must be considered during the implementation process. The 11 key elements are: strategy development, environmental uncertainty, organizational structure, organizational culture, leadership, operational planning resource allocation, communication, people, control, and outcome.
} 
investigates the results of the implementation process. According to the author, the framework helps executives and researchers to analyze the strategy implementation of past, current and future cases. Another model, the $8 \mathrm{~S}$ 's of Strategy Execution, has been developed by Higgins (2005)..$^{13}$ It is composed of the following elements: strategy and purposes, structure, systems and processes, style (leadership/management style), staff, resources, shared values (organizational culture), and strategic performance. A major problem in today's changing environment is that most organizations have difficulties aligning the aforementioned components. The model thus helps executives in focusing their attention on the relevant fields to ensure that the strategy works (Higgins 2005). This is just a selective listing of strategy implementation models and should therefore not be considered exhaustive. The models however clearly indicate that the focus in the academic literature lies on investigating the entire strategy implementation process without putting greater importance on specific aspects such as actions or required skills.

Even though the identification of the previously mentioned implementation problems and the development of implementation frameworks have improved the success rate of implementation efforts, the failure rate is still too high (Cândido and Santos 2015). One promising avenue of research to improve these failure rates has been proposed by de Oliveira et al. (2019). The authors introduced an operational model for the strategy implementation process, which serves as basis for this study. In their model, strategy implementation is set up as a construct consisting of an action dimension and a results dimension. For the remainder of this paper we will focus on the model's action dimension, as putting strategies into action is one of the most complex and difficult tasks (Aaltonen and Ikävalko 2002). Although the action dimension has been considered to some extent in most of the aforementioned frameworks, the framework by de Oliveira et al. (2019) is the first to put an emphasis on this dimension and organize all the relevant actions among conceptual dimensions. These conceptual dimensions will be presented in the next sections.

\footnotetext{
${ }^{13}$ The model is a refinement of the McKinsey 7S Framework introduced by Waterman Jr, Peters and Phillips (1980).
} 


\subsubsection{The effect of unfolding on strategy implementation actions}

The first conceptual dimension describes the actions needed to plan the implementation process. It defines the conversions of the formulated strategy into specific actions, responsibilities, and definition of goals. This promotes alignment of efforts among all stakeholders involved (de Oliveira et al. 2019, p. 4). This dimension can be linked to the operational planning actions of the model by Okumus (2003) earlier mentioned. Unfolding activities are crucial, since even the best implementation efforts cannot rescue a poorly conceptualized implementation plan. If the plan is too vague, it is of limited use as responsibilities or next steps might be unclear. If it is too detailed, departments are not able to respond to changing situations quickly enough (Alexander 1985). This is in line with findings by Mankins and Steele (2005) who - among others - propose two important rules for successful strategy implementation related to the unfolding dimension. First, for implementation success it is crucial for the implementation to keep it "simple but make it concrete". Second, executives must clearly specify priorities. This can be linked to the specific actions, related elements and definition of goals stated in the definition above. The definition of goals is an important aspect of implementing strategies, as they heavily influence the decisions made by employees. However, transforming the strategy into concrete goals is often perceived as difficult (Aaltonen and Ikävalko 2002). According to Reed and Buckley (1988), goal-setting is one of the most important activities during the implementation process, as goals have a significant positive effect on progress. In addition, unfolding helps to guard against individuals engaging in activities that harm the organization or who fail to carry out important tasks. Reed and Buckley (1988) state that these unfolding activities are needed at all necessary organizational levels and that executives have to produce a framework of key activities to identify critical success factors. In addition, it is important to anticipate potential problems, as successful implementation is characterized by preventing implementation problems in the first place (Alexander 1985). Organizations should spend enough time assessing the risks of the previously mentioned implementation problems and develop a systematic process to implement a strategy. Therefore, we argue the following:

H1a: The level of unfolding activities that a business unit conducts, is a positive indicator of strategy implementation actions. 


\subsubsection{The effect of coordination on strategy implementation actions}

The second conceptual dimension describes the actions needed to organize the implementation process. It defines the needed efforts of senior and middle-level management to mobilize employees and assign leaders for the implementation efforts. This improves understanding, commitment, constructive conflict resolution and cooperation (de Oliveira et al. 2019). This dimension can be linked to the previously mentioned obstacle of 'poor coordination across functions, businesses or borders' by Beer and Eisenstat (2000), which was cited in 9 out of 12 cases in their research. This highlights the attention that organizations have to put on this dimension and that one of the key tasks of coordination is to manage interdependencies among functional activities or organizational subunits (Roth, Schweiger, and Morrison 1991). In addition, the definition points out the importance of executives during the implementation process. Successful executives need to closely accompany the implementation process and spend at least as much time on it as they spend on formulating the strategy (Higgins 2005), instead of delegating it to lower-level employees as the study by Hrebiniak (2006) shows. There is common agreement that management is a key component in every implementation process (Nutt 1986). The study by O'Reilly, Caldwell, Chatman, Lapiz and Self (2010) shows that the likelihood of implementing a new strategy significantly increases when the employees feel that leaders across all levels support said new strategy. Another aspect that highlights managers' importance is the fact that all the implementation models mentioned earlier address the executive level (e.g., Crittenden and Crittenden 2008; Higgins 2005; Okumus 2003; Pryor et al. 2007). Another assignment of this dimension is to safeguard the equal understanding among all stakeholders, since successful strategy implementation rests on the precondition "that functional areas within the firm have a basic understanding of the strategy" (Rapert et al. 2002, p. 301). This dimension however is neglected by many organizations. The study by Kaplan and Norton (2005) finds that $95 \%$ of employees state that they are not aware of or do not understand their company's strategy. Overall, managers have to carefully consider their coordination activities and ensure equal involvement and understanding among all levels of the organization. Therefore, we argue the following: 
H1b: The level of coordination activities that a business unit conducts, is a positive indicator of strategy implementation actions.

\subsubsection{The effect of communication on strategy implementation actions}

The third conceptual dimension describes the distribution of information within the organization to further increase understanding among all employees. It defines the attempts needed to disseminate information about the strategy and the implementation efforts. This includes aspects such as corporate targets, actions, responsibilities, deadlines, expected goals, results attained, and adjustments over time. The aim is to further increase understanding of the process among the workforce (de Oliveira et al. 2019).

Many studies on strategy implementation have already emphasized the importance of communication (e.g., Aaltonen and Ikävalko 2002; Alexander 1985; Atkinson 2006; Beer and Eisenstat 2000; Kaplan and Norton 2005; Okumus 2003; Reed and Buckley 1988). According to Alexander (1985) CEOs in his study mentioned communication more often than any other feature as the most important aspect promoting implementation. Communication is identified as a key issue in promoting a clear understanding of the key roles and responsibilities of all stakeholders during the implementation. Employees are thereby made aware of their tasks and stay focused on key targets despite everyday pressure (Atkinson 2006). The importance of this dimension becomes apparent in the previously outlined implementation obstacles and frameworks. In enhancing the understanding of strategy, the communication aspect has been found to be a major problem in most implementation processes (e.g., Aaltonen and Ikävalko 2002; Mankins and Steele 2005). The study by Beer and Eisenstat (2000) states poor vertical communication as the most frequently mentioned "silent killer" of strategy implementation. A badly communicated strategy makes the definition of specific actions, as well as adequate resource planning impossible (Mankins and Steele 2005) and consequently leads to ineffective performance during the implementation process (Reed and Buckley 1988). The 'strategy implementation framework' presented earlier includes communication as a main activity during the operational process. Here, communication is seen as "the mechanisms that send formal and informal messages about the new strategy" (Okumus 2003, p.877). Communication fosters strategic 
consensus, which describes the concept of shared understanding and commitment to strategic directives between different individuals and groups within an organization (Noble 1999). The study by Rapert et al. (2002) shows that frequent communication leads to strategic consensus, which in turn leads to increased functional and organizational performance. According to the authors, strategic consensus is fostered especially through the frequent communication between management, as it develops shared attitudes, understanding, and values. Overall, communication has to be treated as an important dimension during the implementation process as it can otherwise turn out to be a major barrier to successful strategy implementation. Therefore, we argue the following:

H1c: The level of communication activities that a business unit conducts, is a positive indicator of strategy implementation actions.

\subsubsection{The effect of control and feedback on strategy implementation actions}

The fourth conceptual dimension introduces necessary monitoring and modification activities, which address unforeseeable circumstances during the implementation process. It defines monitoring different developments in the internal and external environment over time. According to de Oliveira et al. (2019), this includes the internally achieved results or potential changes that may affect the implementation process (i.e. adjustment of actions or specific elements such as responsibilities, deadlines and resources).

Many researchers in early management studies treated implementation as a fairly mechanistic control function (Noble 1999). In recent years however less than $15 \%$ of companies regularly benchmark their business results against performance forecast on the business unit level. This might give an explanation as to why so many companies fail in implementing their strategies (Mankins and Steele 2005). One important purpose of the control and feedback function is to monitor uncontrollable factors. Particularly, the uncontrollable factors in the external environment have shown to have an adverse effect on implementation, as highlighted in the aforementioned obstacles. They were identified as a problem in $60 \%$ of the strategic decision implementations (Alexander 1985). In addition, this dimension helps to overcome the obstacles brought about by the fact that the implementation process 
takes longer than its formulation, which leads to managers losing track of the problem. Control and feedback mechanisms can be used to translate long-term needs into short-term objectives (Hrebiniak 2006). It thereby provides the feedback management needs to keep up with the external and internal environment. As this dimension can prevent a variety of problems, it has been part of all three models outlined earlier. In the 5 P's model by Pryor et al. (2007) it is the main driver of the performance component. This component of the model helps to measure the implementation process and gives feedback to the stakeholders involved. The authors argue that the measures should not be complex but rather relevant and understandable. This helps employees to understand and evaluate their own performance and informs managers on the implementation progress and on which adjustments need to be made. In the capable organization framework, the control and feedback dimension is a component in the managerial skill 'monitoring'. This skill is used to tie rewards to achievements (Crittenden and Crittenden 2008). An experiment by Brüggen and Moers (2007) shows that financial incentives, compared to a fixed wage, can help in directing efforts and increasing overall efforts directed at the tasks compared to paying a fixed wage. This can help managers in directing employees' time and effort on the tasks that are beneficial for the implementation. However, this connection cannot be made with adequate precision, if organizations show deficiencies in their control and feedback dimension. Lastly, this dimension plays a pivotal role in the strategy implementation framework by Okumus (2003). On the one hand, it helps organizations to correctly interpret the strategic context (i.e. internal and external). On the other hand, it improves the operational process, as one significant element within operations is the control and feedback component. Nevertheless, this dimension can only be carried out successfully, if the organization has effective monitoring systems in place. Organizations need to have a welldesigned, functioning management control system. The establishment of an effective strategic control system and the combination with other management and operational control systems is crucial for the successful implementation of strategy (Atkinson 2006). Second, organizations need to have an IT control system in place that is able to provide real-time performance tracking. It enables continuous monitoring of resource deployment patterns against the plan and uses continuous feedback to challenge planning forecasts and change resources (Mankins and Steele 2005). Overall, it is important to implement the right control and feedback 
functions in order to promote the strategy implementation process. Therefore, we argue the following:

H1d: The level of control and feedback activities that a business unit conducts, is a positive indicator of strategy implementation actions.

\subsubsection{The effect of development of human resources policies and employee competences on strategy implementation actions}

The fifth conceptual dimension aims to create the necessary conditions from an $\mathrm{HR}$ and skills perspective to ensure a successful implementation effort. It defines the joint efforts of the HR area with stakeholders involved in the strategy implementation process. The aim is to align HR policies with the new strategy and attract the needed competences (de Oliveira et al. 2019). Similar to the four previous dimensions, this last dimension has likewise been mentioned with regards to the problems and models outlined earlier. The study by Alexander (1985) names two implementation problems, which provide a link to the development of human resources policies and employee competences. First, the difficulty that capabilities of employees involved with the implementation were insufficient has been mentioned in $63 \%$ of the strategic decision implementations. Here, the adaption of human resource policies like wage structure or hiring criteria might be an important aspect to overcome this problem in order to attract the right employees for strategy implementation jobs. Second, the study shows that in $62 \%$ of cases, the training and instructions given to lower level employees were inadequate. This implementation problem is addressed by the action dimension as well. Both "silent killers" mentioned are in line with the findings by Beer and Eisenstat (2000) stated earlier, emphasizing that down-the-line leadership skills and development are inadequate in many organizations. The authors argue that lower-level managers have not been sufficiently trained to lead change associated with a new strategy. However, this lack of training cannot only be linked to lower level managers as Hrebiniak's (2006) previously outlined findings show. The study shows the fact that managers are trained to plan, not execute, constitutes an essential problem. Even though the author attribute this problem mainly to the fact that strategy and planning is taught separately at most business schools, the action dimension at hand should play a crucial role in overcoming this issue. Potential solutions to address these 
implementation problems have already been discussed in several implementation frameworks. The capable organization framework includes programs as one structural lever. The main task of this lever is to install organizational learning and continuous improvement practices (Crittenden and Crittenden 2008). The 'strategy implementation framework' by Okumus (2003) highlights people as a core layer in the operational process. The author states that a key enabler for a successful strategy implementation are the recruitment of relevant workforces, the acquisition and development of new skills and knowledge, the offering of adequate training activities to develop and prepare all employees involved, and the advancement of human resource policies and practices to improve the implementation of new strategies. This is in line with the staff component introduced in Higgins' (2005) framework. The component highlights the prominence organizations attach to match the number and types of employees on the job with the requirements given by the implementation challenge. In short, this dimension clearly demonstrates that it is important to align HR practices and employee competences with the strategy implementation requirements in order to ensure a successful process. Therefore, we argue the following:

H1e: The level of development of human resources policies and employee competences activities that a business unit conducts, is a positive indicator of strategy implementation actions.

\subsubsection{The effect of strategy implementation actions on digital business strategy}

The previous literature review points out that specific actions can have a pivotal impact on the overall success of strategy implementation efforts. Managers have to deliberately execute and guide these actions. In addition, the five dimensions indicate that strategy implementation is a multifaceted phenomenon. Organizations should apply similar efforts on all dimensions in order to ensure a successful strategy implementation. They should furthermore consider that there is a complex interplay between all dimensions (de Oliveira et al., 2019).

According to Porter (1996), an organization's corporate strategy in general follows three underlying principles. The first principle states that organizations formulate strategies through defining a set of activities, which will help them to obtain a unique and valuable market position. This definition determines all future activities, 
as it decides whether an organization performs activities differently, or whether it performs different activities compared to its rivals in order to create a unique mix of values. Here, organizations have to choose between different options like serving few needs of many customers, serving broad needs of few customers, or serving broad needs of many customers in a narrow market. In case of a digital business strategy, this principle serves a comparable purpose. Organizations need to define their activities involving relationships to firms, industries, IT infrastructure, and the external environment (Bharadwaj et al. 2013). In general, as digital business strategy can help to redefine a market's competitive landscape, organizations focus on their digital strategy decisions in order to shield themselves from the erosion of competitive advantage (Mithas et al. 2013). Activities in digital business strategy are thus highly influenced by the interaction of the firm's current level of digital investments (i.e. leading vs. lagging) with turbulence, concentration, and growth in the competitive environment. This defines the degree to which firms deviate from industry norms in order to generate a unique and valuable position (Mithas et al. 2013). Digital business strategy hence is not different from business strategy in the first principle. The second principle states that strategy involves deliberating and choosing between different options. Strategy needs to set a clear direction regarding decisions like revenue growth or cost savings. Equal decisions need to be reached with regards to a digital business strategy. A study by Mithas et al. (2012) compares the effect of IT investments on sales and profitability compared to other discretionary investments like advertising and R\&D expenditures. The authors find a higher effect for IT investments compared to other investments. This effect was stronger for IT investments focusing on revenue growth as compared to those focused on cost reduction. Again, this indicates that digital business strategy has to follow Porter's (1996) principles and thus needs to make compromises on important options. The third principle states that strategy aligns a company's activities. A strategy is successful, if an organization is able to conduct many interdependent activities simultaneously and in an integrated manner. In case of digital business strategy, this principle is of even higher importance. The example of increased speed of product launches highlights this fact. By adding a digital business dimension to products, an organization finds itself in a network with complementary products and services from other organizations (e.g. Apple is highly dependent on external app developers for their Appstore, Amazon is highly dependent on publishing companies for their 
Amazon Kindle). An organization therefore needs to coordinate its activities not only within an organization but also with other organizations (Bharadwaj et al. 2013). Once more, this showcases similarities between business strategy and digital business strategy, as aligning the different activities remains a core principle. As the previous discussion shows that digital business strategy follows the same principles as business strategy, we assume that strategy implementation actions defined for business strategy should be equally beneficial when implementing a digital business strategy. Therefore, we argue the following:

H2: Strategy implementation actions positively influence the Implementation level of a digital business strategy.

The predicted hypotheses are shown in Figure 4.

\section{Figure 4 \\ Hypothesized Structural Model}

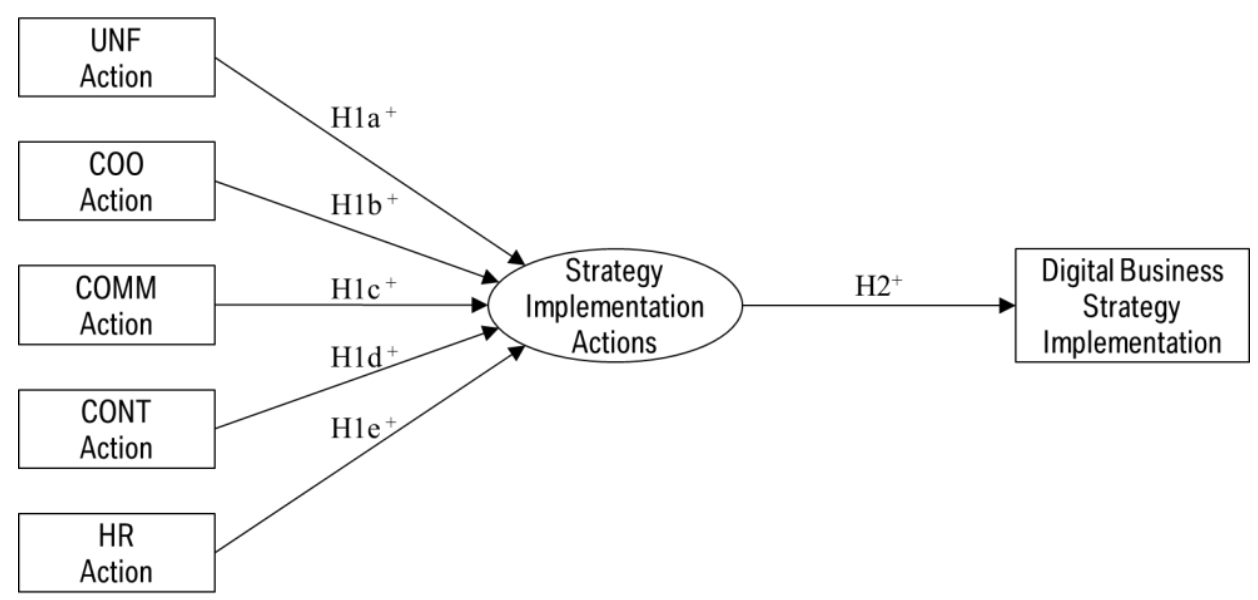

\begin{tabular}{ll}
\hline UNF & Unfolding \\
COO & Coordination \\
COMM & Communication \\
CONT & Control and feedback \\
HR & Development of human resource policies and employee competences
\end{tabular}

\subsection{Method}

This section gives a detailed overview of the sample, data collection and measurement of variables used. 


\subsubsection{Sample and Data Collection}

The sample consists of all senior vice presidents and vice presidents of a large German manufacturing organization $(n=502)$. The organization targets the premium segment and was founded more than 100 years ago. It is publicly listed and conducts business in more than 140 countries. Many of its production plants lie outside of Germany and the company has more than 100,000 employees worldwide. Its yearly revenue is close to 100 billion Euros. The organization introduced its digital business strategy two years prior to the data gathering process. Exclusively addressing the management of an organization is reasonable in this case as their expertise and knowledge is crucial in the implementation process (Okumus 2003).

The manufacturing industry represents a highly interesting context due to several reasons. First, the McKinsey study by Bughin et al. (2017) shows that manufacturing firms in particular lag behind other sectors with regards to their degree of digitalization. Second, most of the firms in the manufacturing industry have to tremendously adapt their product offerings, especially with regards to the addition of digital components such as connectivity, location-based services or updateability. Digitalization thus transforms formerly pure-play manufacturing companies into firms that are both manufacturers and service providers. This has wide-ranging implications on core functions like product development, IT, manufacturing, logistics, marketing, sales, and after-sale. Change is thus needed in domains such as internal processes, products and customer interaction (Porter and Heppelmann 2015). Large corporations that neglect new technologies or ignore the need for change are likely to fall behind (Sebastian et al. 2017). Third, large manufacturing organizations are heavily exposed to fluctuations in the world market, as well as to developments like changing regulations, customer expectations and competition. It is therefore important for them to implement strategic decisions quickly. Lastly, large manufacturing organizations provide the opportunity to obtain a large sample of test subjects across diverse departments and countries with duties ranging from production, development, human resources, finance, strategy to sales. The fact that our sample covers the whole organization is essential for testing the hypothesis stated, as implementation requires the interplay across different functional areas and activities (de Oliveira et al. 2019). Researchers therefore should not merely focus on specific functional areas of the organization (Okumus 2003) but study the 
implementation in the context of established organizations (Crittenden and Crittenden 2008).

Many scholars emphasize the important role of managers during strategy implementation (e.g., Alexander 1985; Beer and Eisenstat 2000; Floyd and Wooldridge 1992; Ho et al. 2014; Mankins and Steele 2005; Okumus 2003). Implementation is largely influenced by the degree of management intervention that aims to align organizational actions with strategic intention (Floyd and Wooldridge 1992). In addition, the success of implementation efforts is strongly correlated with the time managers spend on implementation, as insufficient time and effort results in poor implementation outcomes (Higgins 2005). Therefore, our sample represents a good fit for the hypothesis.

A structured questionnaire including 31 questions formed the principal means of data collection. In order to adequately address all managers globally, survey materials were presented in English (see Appendix I). ${ }^{14}$ Pre-tests of the final survey were conducted with 15 department heads. Of the 502 managers in our final sample we attained an overall response rate of $38.1 \%$ which translates into 191 fully completed and usable responses. The main contact person in our sample organization was the vice president of strategy digitalization who helped us to increase the response rate by addressing our sample participants personally.

\subsubsection{Measurement and Validation}

An online survey asked our sample participants to report their perception regarding strategy implementation actions taken, as well as their assessment of the implementation progress of the digital business strategy. As a well-accepted practice in research we used seven-point Likert-scale answering schemes for all questions. Only questions addressing the respondent's demographics deviated from this scheme. Due to restrictions imposed by the study organizations (reasons of anonymity) we have only been able to gather information about their current functional responsibility.

Strategy Implementation Actions: We measure this concept by using the action dimension of the strategy implementation construct developed by de Oliveira

\footnotetext{
${ }^{14}$ The questions including the different answering schemes are shown in Appendix 1 at the end of this dissertation.
} 
et al. (2019). The authors conceive of strategy implementation action as a reflective second-order construct consisting of unfolding, coordination, communication, control and feedback, and development of human resources policies and employee competences. In order to measure the initial index at the business unit level, we added the term "In my business unit..." at the beginning of every question. In addition, we removed all questions that solely addressed the activities of managers instead of the whole business unit. ${ }^{15}$ This was a result of the pilot test, as managers were confused who they had to evaluate. Respondents were asked to rate the level of their business unit's strategy implementation action based on a seven-point interval scale ( $1=$ 'strongly disagree' to $7=$ ='strongly agree'). The final questions are shown in Appendix I.

Digital Business Strategy: The aim of this variable is to measure the level of implementation of the digital business strategy within individual business units. We use the measure introduced by study 1 . Since a clear definition of the construct has yet to be developed, the authors adjusted an initial version of Leischnig et al. (2017) through a two-stage research approach. In the first stage study 1 conducted expert interviews in order to understand the completeness of the digital business strategy measure. In the second stage the newly developed index by means of a survey was tested. As the measure has already been applied on the business unit level, no adjustments were necessary. In line with study 1 a seven-point interval scale ( $1=$ 'strongly disagree' to $7=$ =strongly agree') has been used. The final questions can be found in Appendix I.

\subsection{Results}

The following section presents the results using structural equation modeling (SEM). SEM was used to examine our conceptual model as it is a prevalent estimation technique to test theory driven conceptual models against empirical data (Chen et al. 2008; Gefen et al. 2000), and therefore deemed suitable for our research setting. In addition, it is the preferred method when integrating variables that have not been

\footnotetext{
${ }^{15}$ Following questions have been removed: Involve top management in the execution of strategy (coordination dimension); Engage managers in the communication efforts about strategy and its execution (communication dimension); Make managers accountable for the analysis of collected data, Engage managers and employees in the definitions of adjustments (to execution-related actions, goals or deadlines), Involve top management whenever a change in strategy is necessary (control and feedback)
} 
directly measured (i.e. latent variables), as it analyzes multiple relationships simultaneously (incl. latent variables). In this study, we use the AMOS 24.0 software program (Arbuckle and Wothke 1999) to conduct the statistical analysis. This is a covariance-based SEM (CB-SEM) approach (Byrne 2010). This approach is considered suitable in case of confirming theoretical assertions in a more conservative and rigorous way (Hair et al. 2011; Byrne 2010). Considering that our proposed relationships in the conceptual model are strongly grounded in the current theoretical frameworks (Bharadwaj et al. 2013; de Oliveira et al. 2019; Leischnig et al. 2017), we selected the CB-SEM approach to test our conceptual model. Table 4 shows descriptive statistics of the directly measured variables. Prior to running the SEM method, a confirmatory factor analysis has been conducted.

\section{Table 4}

Descriptive Statistics

\begin{tabular}{lllllll}
\hline Variable & Obs. & Min & Mean & Median & Max & Std. Dev. \\
\hline DBSI & 191 & 2.70 & 5.39 & 5.40 & 7 & 0.858 \\
Strategy & Implementation & Actions & & & & \\
UNF & 191 & 1 & 5.01 & 5.17 & 7 & 1.101 \\
COO & 191 & 1.25 & 4.97 & 5 & 7 & 1.070 \\
COMM & 191 & 2 & 5.40 & 5.33 & 7 & 0.895 \\
CONT & 191 & 2.75 & 5.58 & 5.75 & 7 & 0.755 \\
HR & 191 & 1 & 4.74 & 5 & 7 & 1.209 \\
\hline DBSI & Digital Business Strategy Implementation & & & \\
UNF & Unfolding & & & & \\
COO & Coordination & & & \\
COMM & Communication & & & \\
CONT & Control and feedback & & & \\
HR & Development of human resource policies and employee competences &
\end{tabular}

\subsubsection{Measurement model}

Prior to calculating the SEM results, we evaluated the single components of the measurement model. In the first step, a principal component analysis has been carried out to evaluate the variables directly measured by the different items. Secondly, the latent variable, strategy implementation actions, has been evaluated using the first stage of the two-stage process recommended by Schumacker and Lomax (1996). In this step, the single latent variable (i.e. strategy implementation actions) is modeled as a measurement model and examined using SEM. The second stage will be shown in the structural model section. 
The principal component analysis has been conducted for the variables unfolding, coordination, communication, control and feedback, development of human resources policies and employee competences, and digital business strategy implementation. The results in Appendix $\mathrm{J}$ are shown after an orthogonal rotation. The variation an item explains in a latent variable is defined by the standardized factor loadings. This value should not be less than 0.5 and preferably exceed 0.7 (Hair et al. 2006). In addition, if the Eigenvalue exceeds 1, the single items can be treated as a factor. The indicator Average Variance Extracted (AVE) describes the average of the squared factor loadings and should be greater than 0.5 in order to imply acceptable convergent validity (Hair et al. 2006). The consistency of the scale is shown by the reliability coefficient Cronbach's alpha (Hair et al. 2006). A lower limit for this indicator is 0.7 (Robinson et al. 1991). Altogether the variables unfolding, coordination, communication, control and feedback, development of human resources policies and employee competences, and digital business strategy implementation show acceptable fit. Most of the factor loadings exceed the preferred level of 0.7 and all factor loadings besides one are above the lower threshold of 0.5. In addition, the eigenvalue of all variables is above the lower limit of 1 . The variables communication and control and feedback however do not meet all requirements. Communication scores 0.619 on the Cronbach's alpha and control and feedback scores 0.497 on AVE and 0.6563 on Cronbach's alpha. Although these values are slightly below the limit, we agreed to retain them in the model for two reasons. First, from a theoretical perspective both variables are an essential part of the latent construct. Second, the two variables fulfill all the other limits outlined earlier. For the variables unfolding, coordination, development of human resources policies and employee competences all fit indices are met. For the variable digital business strategy implementation one factor loading and the AVE are marginally below the 0.5 limit. As the Cronbach's alpha however is well above the 0.7 threshold and indicates good fit, we decided to retain all items. Thus, all items are loaded onto a single factor for every variable. The correlation coefficients are shown in Table 5. The confirmatory factor analysis revealed a good fit based on the fit indicator explained in the next section. 


\section{Table 5}

Correlation Coefficients ( $n=191)$

\begin{tabular}{lllllll}
\hline & DBSI & UNF & COO & COMM & CONT & HR \\
\hline DBSI & 1.0000 & & & & & \\
UNF & $0.6569^{*}$ & 1.0000 & & & & \\
COO & $0.6772^{*}$ & $0.8174^{*}$ & 1.0000 & & & \\
COMM & $0.5448^{*}$ & $0.6581^{*}$ & $0.6287^{*}$ & 1.0000 & & \\
CONT & $0.5219^{*}$ & $0.5957^{*}$ & $0.5708^{*}$ & $0.5502^{*}$ & 1.0000 & \\
HR & $0.5504^{*}$ & $0.7880^{*}$ & $0.6659^{*}$ & $0.5430^{*}$ & $0.4823^{*}$ & 1.0000 \\
\hline DBSI & Digital Business Strategy Implementation & & & \\
UNF & Unfolding & & & & \\
COO & Coordination & & & & \\
COMM & Communication & & & \\
CONT & Control and feedback & & & & \\
HR & Development of human resource policies and employee competences & \\
$*$ & Significant at $p$-value $<0.01$ & & & &
\end{tabular}

\subsubsection{Structural Model}

In the second stage we calculated the SEM. Similar to the last step in the measurement model analysis, we used the AMOS 24.0 software program (Arbuckle and Wothke 1999) to estimate the base model shown in Figure 4. The bootstrap method helped us to test for significance. The bootstrap procedure has been conducted with 2,000 samples and a bias-corrected confidence interval of 90 . The value of the measured variable resulted from calculating the averages of the single items used per variable. The value for the latent variable, strategy implementation actions, has been calculated using AMOS. Since the distinct number of parameters to be estimated is 12 , the subject-to-parameter ratio of 15.92 is above the rule of thumb of 5:1 (Hair et al. 2006). As researchers have not found this single criterion indicating a model's validity, we report several fit indices which give a good indication and are in line with previous research. Table 6 shows the results of the structural equation model as well as the model fit indices. All in all, the indices indicate a good model fit. The chi-square value of 23.164 is significant at the 1 percent level $(\mathrm{df}=9$, $\mathrm{p}=0.006$ ) which is not optimal, but is mainly owed to the sample size. In order to remedy this shortcoming, we additionally used the CMIN/DF ( $\chi 2$ / df), as the chisquare statistic is affected by large sample sizes. Although a clear cutoff level has not been defined by researchers, an indicator ranging from 2 to 5 is generally accepted (e.g., Carmines and Mclver 1981; Marsh and Hocevar 1985). The value of 2.574 therefore meets this standard. The Root Mean Square Error of Approximation 
(RMSEA) is an additional measure that corrects for sample size and model complexity (Browne and Cudeck 1993). The index ranges from 0 to positive infinity with 0 indicating excellent model fit and appropriateness for confirmatory contexts (Rigdon 1996). Even though the threshold indicating good fit is still debated amongst researchers, most consider values below 0.1 acceptable (e.g., Browne and Cudeck 1993; Chen et al. 2008; Hair et al. 2006). The RMSEA of 0.091 at hand therefore indicates good fit. In line with the RMSEA, the Goodness-of-Fit Index (GFI) is an absolute fit measure. The purpose of both measures is to calculate the fit between the specified model and the observed data. As a rule, a value greater than 0.9 indicates good model fit (Hair et al. 2006). Since the results of the SEM report a GFI value of 0.957 , the model has strong explanatory power. The last fit indicator reported is the Comparative Fit index (CFI). This index represents the model's fit relative to an alternative baseline model and is therefore and incremental fit index (Hair et al. 2006). The lower threshold for the CFI is 0.9 with a preferred value of above 0.95 for a good fit indication (Hu and Bentler 1999). The obtained value of 0.981 hence emphasizes good fit of our model. The structural model analysis shows that besides the p-value, all indices indicate a good model fit. Consequently, all implications taken from the SEM results are based on a fundamental model and deemed generalizable. The final structural model is shown in Figure 5. 


\section{Figure 5}

Final Model

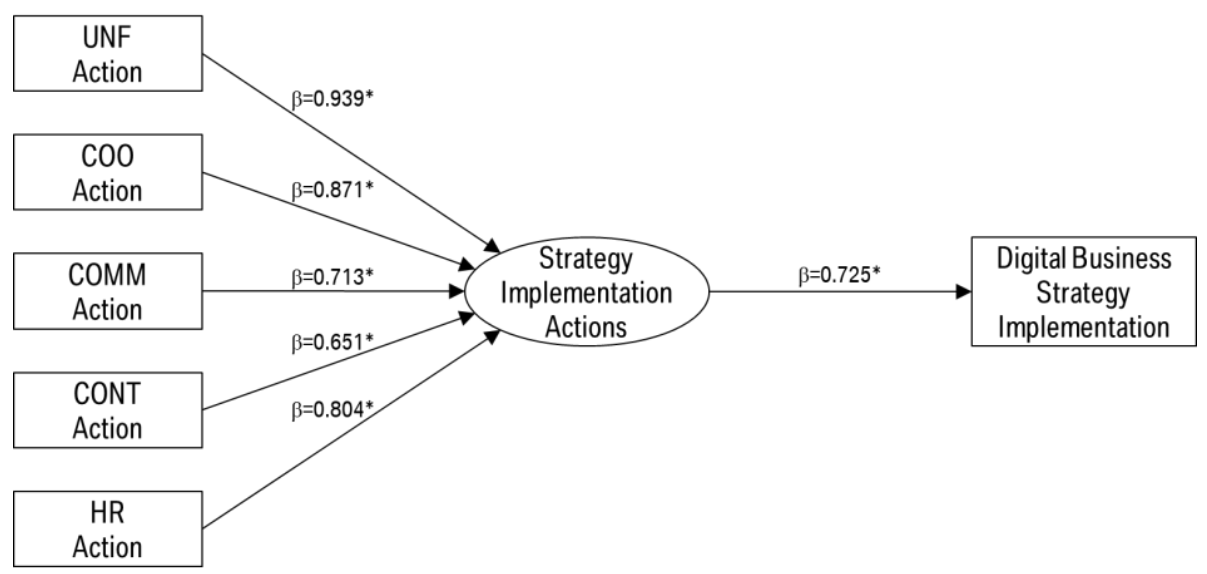

\begin{tabular}{ll}
\hline \multicolumn{2}{l}{ The standardized coefficients are presented. } \\
UNF & Unfolding \\
COO & Coordination \\
COMM & Communication \\
CONT & Control and feedback \\
HR & Development of human resource policies and employee competences \\
${ }^{*}$ & Significant at $p$-value $<0.01$
\end{tabular}

\subsubsection{Hypothesis Testing}

Table 6 presents a summary of the SEM results. Hypothesis 1a-e predicted the reflective effect of the different action dimensions on strategy implementation actions. The results indicate that the weights of all second-order estimates are positive and significant. Thus, hypotheses $1 \mathrm{a}-\mathrm{e}$ are significant. The strongest effect has been found for the unfolding dimension $(\beta=.939, p<0.01)$ followed by coordination $(\beta=.871, p<0.01)$, development of human resources policies and employee competences $(\beta=.804, p<0.01)$, communication $(\beta=.713, p<0.01)$, and control and feedback $(\beta=.651, p<0.01)$ respectively. Hypothesis 2 predicted the effect of strategy implementation actions on the implementation of a digital business strategy. The results show a positive and significant relationship between strategy implementation actions and the implementation of a digital business strategy $(\beta=.725, p<0.01)$. Thus, hypothesis 2 is supported. This in line with previous literature and offers some highly appealing implications for academics and practitioners alike. 


\section{Table 6 \\ Parameter Estimates ( $n=191)$}

\begin{tabular}{llllll}
\hline \multicolumn{4}{l}{l Measurement Model Estimates } & & \\
\hline Path & & & Direction & Coefficient & Hypothesis \\
\hline UNF & $\rightarrow$ & SIA & + & $0.939^{*}$ & Supported \\
COO & $\rightarrow$ & SIA & + & $0.871^{*}$ & Supported \\
COMM & $\rightarrow$ & SIA & + & $0.713^{*}$ & Supported \\
CONT & $\rightarrow$ & SIA & + & $0.651^{*}$ & Supported \\
HR & $\rightarrow$ & SIA & + & $0.804^{*}$ & Supported \\
\hline \multicolumn{2}{l}{ Structural Model } & & & & \\
\hline Independent & Dependent & Direction & Coefficient & Hypothesis \\
variable & & variable & & & \\
\hline SIA & DBSI & + & $0.725^{*}$ & Supported \\
\end{tabular}

\begin{tabular}{ll}
\hline Model fit & \\
\hline $\mathrm{X}^{2}$ & 23.164 \\
$p$-value & 0.006 \\
DF & 9 \\
CMIN/DF & 2.574 \\
RMSEA & 0.091 \\
GFI & 0.957 \\
CFI & 0.981 \\
\hline
\end{tabular}

The standardized coefficients are presented.

SIA Strategy implementation actions

UNF Unfolding

$\mathrm{COO} \quad$ Coordination

COMM Communication

CONT Control and feedback

HR Development of human resource policies and employee competences

DBSI Digital business strategy implementation

* $\quad$ Significant at $p$-value $<0.01$

\subsubsection{Further Analysis}

To determine the robustness of the SEM results presented, we conducted several additional analyses. In order to reinforce the SEM results of the base model, the following section conducts analyses including only parts of the sample. The methodology remains unchanged.

First, we divided the observations regarding the implementation of the digital business strategy. This was done by using the median of the digital business strategy variable to split the sample in half. The cutoff value is 5.4 with every observation higher being assigned to the digital business strategy implementation high group. 
Based on this cutoff level, 95 observations have been assigned to the high implementation group and 96 observations to the low implementation group. The results are presented in Appendix $\mathrm{K}$ and $\mathrm{L}$. The results of both models indicate moderately acceptable model fit (SEM DBSI high $-\chi 2=27.497, \mathrm{df}=9, \mathrm{p}=0.001$, $\mathrm{CMIN} / \mathrm{DF}=3.055$, RMSEA $=0.148, \mathrm{GFI}=0.921, \mathrm{CFI}=0.915$; SEM DBSI low $\chi 2=15.032, \quad \mathrm{df}=9, \quad \mathrm{p}=0.090, \quad \mathrm{CMIN} / \mathrm{DF}=1.670, \quad \mathrm{RMSEA}=0.084, \quad \mathrm{GFI}=0.949$, $\mathrm{CFI}=0.982$ ). Overall, the weights of all relations do not differ significantly from the original model. In both cases the relation between the different action dimensions and strategy implementation actions remain significant and positive (SEM DBSI high - unfolding: $\beta=.876, p<0.01 /$ coordination, $\beta=.721, p<0.01 /$ communication: $\beta$ $=.560, p<0.01 /$ control and feedback: $\beta=.707, p<0.01 /$ development of human resources policies and employee competences: $\beta=.693, p<0.01$; SEM DBSI lowunfolding: $\beta=.941, p<0.01 /$ coordination: $\beta=.892, p<0.01 /$ communication: $\beta=$ $.685, p<0.01 /$ control and feedback: $\beta=.530, p<0.01 /$ development of human resources policies and employee competences: $\beta=.828, p<0.01$ ). Hypotheses $1 \mathrm{a}$ e remain supported. Regarding hypothesis 2 , the results likewise show a significant and positive relation (SEM DBSI high: $\beta=0.56$, p-value < 0.01; SEM DBSI low: $\beta=0.62$, p-value $<0.01$ ). Overall, hypothesis 2 remains supported, which demonstrates that the results can be generalized to all business units irrespective of their level of digital business strategy implementation.

Second, we clustered the observations according to the business units' function. The first group $(n=70)$ is named "central functions" and includes business units that handle activities like human resources, controlling, finance, quality management, strategy or legal. The second group $(n=121)$ is named "operational functions" and includes business units that handle - amongst others - activities like research and development, purchasing, production, logistics or sales. The results are shown in Appendix $\mathrm{M}$ and $\mathrm{N}$. In line with the results of the level of digital business strategy implementation, the results remain similar to the original model and the model fit indices for both models show acceptable fit (SEM central functions $\chi 2=31.172, \mathrm{df}=9, \mathrm{p}=0.000, \mathrm{CMIN} / \mathrm{DF}=3.464, \mathrm{RMSEA}=0.189, \mathrm{GFI}=0.871, \mathrm{CFI}=0.917$; SEM operating functions $-\chi_{2}=11.522, \mathrm{df}=9, \mathrm{p}=0.242, \quad \mathrm{CMIN} / \mathrm{DF}=1.280$, RMSEA=0.048, GFI=0.966, CFI=0.995). In terms of hypotheses $1 \mathrm{a}$-e the results are significant and positive (SEM central functions - unfolding: $\beta=.912, p<0.01$ / coordination, $\beta=.878, p<0.01 /$ communication: $\beta=.709, p<0.01 /$ control and 
feedback: $\beta=.761, p<0.01 /$ development of human resources policies and employee competences: $\beta=.714, p<0.01$; SEM operating functions - unfolding: $\beta$ $=.950, p<0.01 /$ coordination: $\beta=.876, p<0.01 /$ communication: $\beta=.714, p<0.01$ / control and feedback: $\beta=.593, p<0.01 /$ development of human resources policies and employee competences: $\beta=.831, p<0.01$ ). Thus, hypotheses 1 a-e are supported for both models. The relation between the strategy implementation actions and digital business strategy implementation remains positive and significant without significantly differing between the samples (SEM central functions: $\beta=0.730, p$-value $<0.01$; SEM operating functions: $\beta=0.726, p$-value $<0.01$ ). Hypothesis 2 remains supported. Again, the additional analysis suggests that the results are generalizable to a diverse set of functions. Managers cannot concentrate on single business functions when following the strategy implementation actions.

\subsection{Discussion and Conclusion}

Digital developments are an important topic on the agenda of researchers and executives alike. While digitalization impacts the scope of many literature streams, it is a crucial component for organizations to remain competitive. This study's aim was to answer the question of how specific strategy implementation actions influence the level of implementation of a digital business strategy. The research in both fields, strategy implementation and digital business strategy, is still in its infancy. While digital business strategy is a newly developing phenomenon in organizations, the field of strategy implementation lags other research fields, as most of the studies to date have focused on the formulation process (Alexander 1985; Noble 1999; Pryor et al. 2007). In this study, we find that first, the strategy implementation dimensions (unfolding, coordination, communication, control and feedback, and development of human resources policies and employee competences) have a significant positive impact on strategy implementation actions. Second, strategy implementation actions have a significant positive effect on the implementation of a digital business strategy. Third, the additional analysis showed that these results hold regardless of the type of business unit or the level of implementation within the business unit. Responding to calls for research, this study gives guidelines on how to implement a digital business strategy in organizations and extends the understanding of the model proposed by de Oliveira et al. (2019). 
Our study contributes to literature in several ways. First, the findings complement the digital business strategy field and add important findings to the fields of management information systems and strategic management. In that way, we show how findings from the two fields hold in the newly emerging field of digital business strategy. In particular, we show how a framework from the field of strategic management can be applied to digital business strategy. This adds quantitative evidence to the emerging field of digital business strategy, which is an exception in a mainly theoretical and qualitatively driven field. Overall, this is an important step towards obtaining a better understanding of the digital business strategy concept. Second, our research focuses on the under-researched area of strategy implementation instead of more common research fields like evaluating the effect of a strategy or investigating the formulation process. We tested strategy implementation actions and added quantitative evidence to the field of strategy implementation, which currently remains limited. The findings show the importance of the implementation stage and indicate that researchers should pay more attention to the field, as it can help to bridge the gap between an appropriately formulated strategy and the resulting performance. Third, the results clarify the importance of analyzing constructs beyond the firm level by investigating the business unit level. This provides more specific insights into processes and activities within an organization.

Our findings provide several contributions to management as well. First, our study tests and identifies strategy implementation actions that help managers in implementing a digital business strategy. Our findings show that strategy implementation activities should be made a core element in every strategy process. Managers have to spend more time and effort on the implementation process and refrain from solely focusing on the formulation process. Our findings thus showcase how managers can implement a digital business strategy that addresses the threats associated with disruption through digital technologies identified by Kane et al. (2016). In addition, the findings help managers to prevent negative outcomes such as depressed stock prices, growth challenges, or cost and quality issues following the implementation of digital initiatives described by Davenport and Westerman (2018). Second, our findings offer a structured and detailed approach to management that paves the way for a successful implementation of digital business strategy. Managers have to carefully consider the relevance of each of the 
implementation dimensions and subsequently tailor and apply them to their organization and business units. The results produce guidelines for managers in the implementation stage. In the first activity, unfolding, it is important that managers translate the formulated strategy into specific actions and define goals, thus generating an implementation plan. In the second activity, coordination, it is important that managers align the efforts of all management levels in order to mobilize employees and establish clear responsibilities. This promotes aspects like understanding, commitment, and conflict prevention. In the third activity, communication, it is required that managers disseminate information regarding aspects like objectives, required actions and responsibilities. In the fourth activity, control and feedback, managers have to monitor the achieved results and observe the external and internal environment in order to adjust the plan in case this becomes necessary. In the fifth activity, development of human resource policies and employee competences, our results show that it is pivotal for managers to link the activities of the human resources department with those who implement the strategy to ensure a successful implementation. Third, our study gives important insights on the effect of implementation activities within the firm. Since our unit of analysis is the business unit, we provide more detailed information for management. The additional analysis shows that managers can treat all business units equally when applying the strategy implementation actions, regardless of the level of digital business strategy already implemented (i.e. high digital business strategy versus low digital business strategy) or their daily activities (i.e. central functions versus operating functions). Fourth, our study shows that a successful implementation of a digital business strategy requires the integrated efforts of all employees. On the one hand, it is important that managers establish a well-formulated implementation plan and follow the five implementation activities. On the other hand, it is equally important that employees follow the plan and direct their efforts in the best way possible in order to ensure a successful implementation of the digital business strategy.

Nonetheless, our research findings should be considered in light of several limitations. First, while we find that the strategy implementation actions significantly influence the implementation level of a digital business strategy, we did not investigate whether the sequence of implementation actions has an impact on the successful implementation of a digital business strategy. Future studies can test the 
research question raised in this paper by using a time-series approach with sequential starting dates per activity. Second, all our findings are based on data from one organization. On the one hand, this has the benefit of controlling for factors like variance in quality of strategy, different levels of environmental pressure or organizational size. On the other hand, we are limited in testing for across-industry differences, for different types of a digital business strategy, and the effect of different external influences which differ between industries. Future studies could address these limitations by testing the effect of strategy implementation actions on the implementation of a digital business strategy across different industries. Third, all the measures in our model are subjective and based on perception of management, as no objective measures have been made publicly available. Moreover, all the data is based on an online survey and thus possess the typical limitations such as sampling issues and self-selection bias (Wright 2005). Future research can test the proposed model by using both subjective and objective measures. 


\section{Appendices Chapter 3}

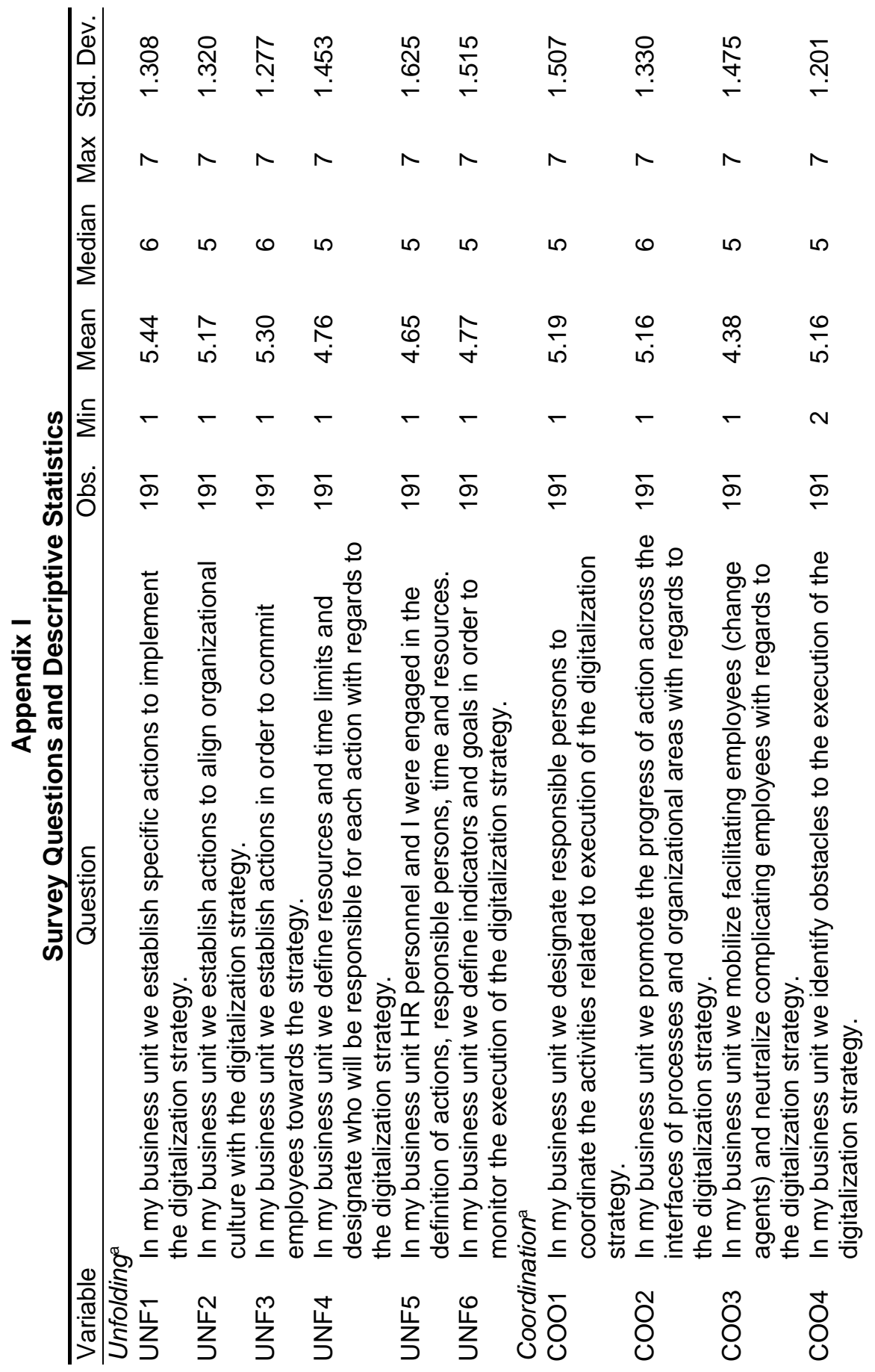




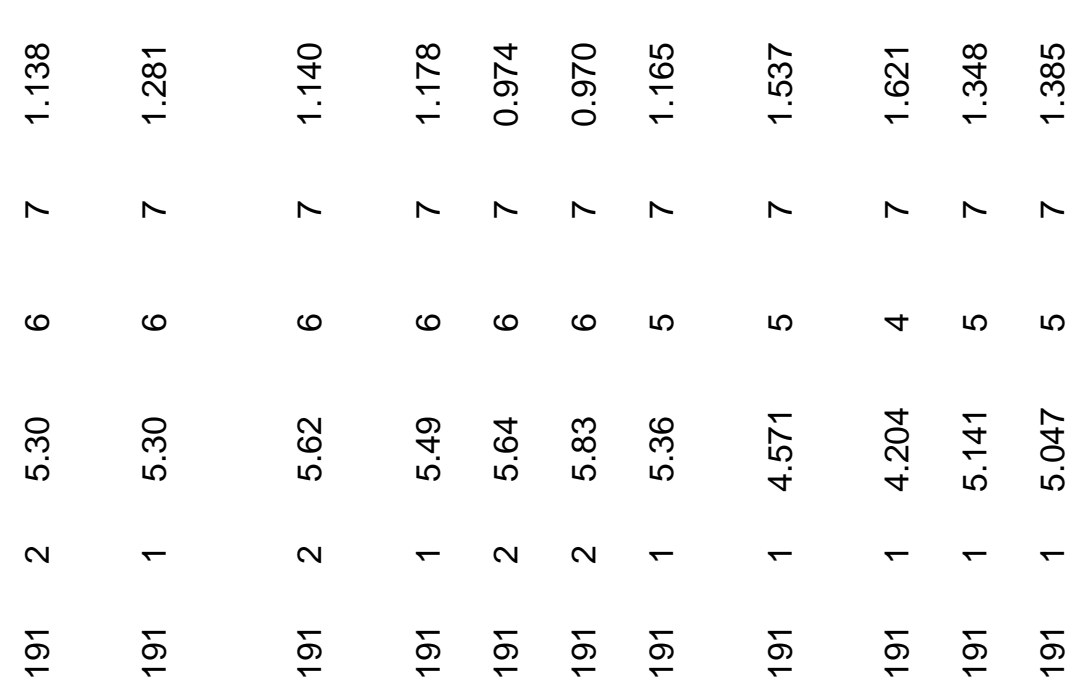

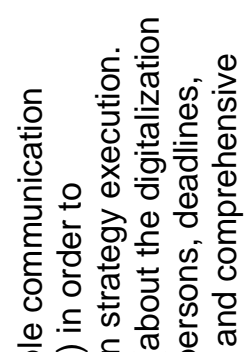

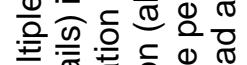

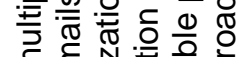

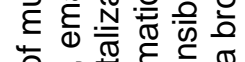
¿ क 늉 흥 은 응.

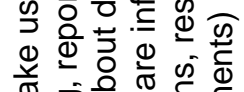

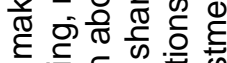
음 음 \丶

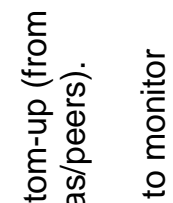

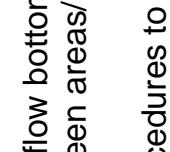
亏 की तั के

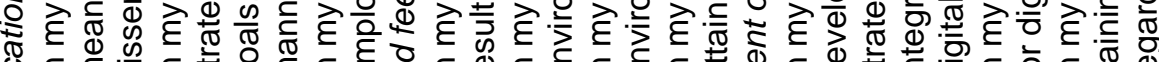
을 踣产

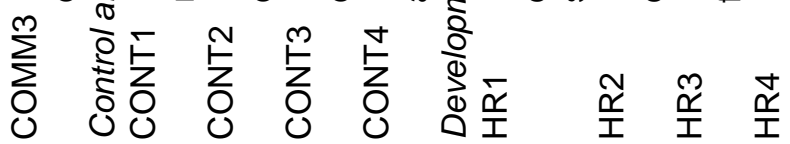




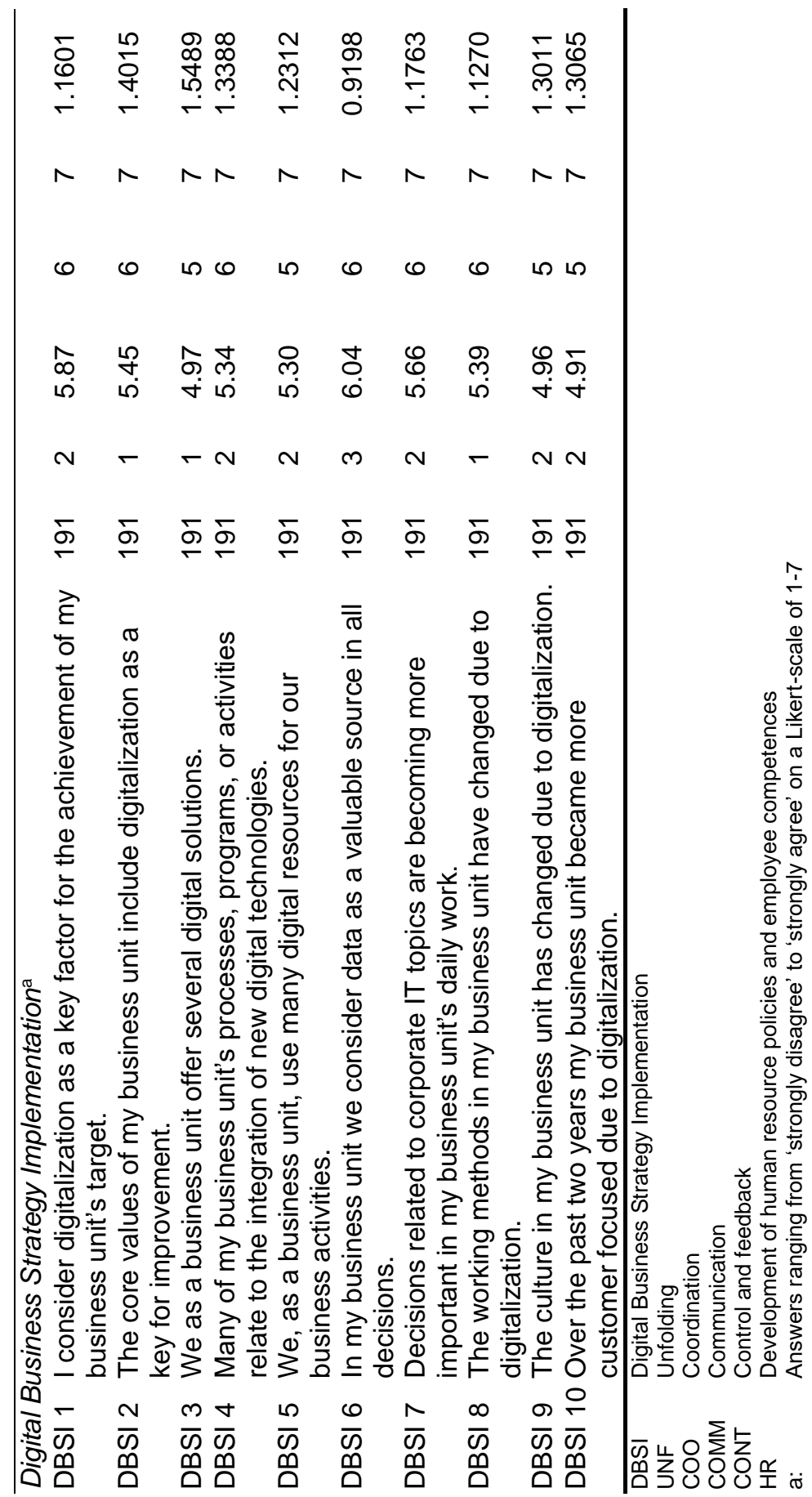




\section{Appendix $\mathbf{J}$}

Standardized factor loadings $(n=191)$

\begin{tabular}{|c|c|c|c|c|c|c|}
\hline & UNF & $\mathrm{COO}$ & COMM & CONT & $\mathrm{HR}$ & DBSI \\
\hline UNF 1 & 0.8331 & & & & & \\
\hline UNF 2 & 0.8223 & & & & & \\
\hline UNF 3 & 0.8356 & & & & & \\
\hline UNF 4 & 0.8008 & & & & & \\
\hline UNF 5 & 0.5848 & & & & & \\
\hline UNF 6 & 0.8099 & & & & & \\
\hline COO 1 & & 0.7644 & & & & \\
\hline $\mathrm{COO} 2$ & & 0.8064 & & & & \\
\hline COO 3 & & 0.7670 & & & & \\
\hline $\mathrm{COO} 4$ & & 0.7671 & & & & \\
\hline COMM 1 & & & 0.7635 & & & \\
\hline COMM 2 & & & 0.8053 & & & \\
\hline COMM 3 & & & 0.6882 & & & \\
\hline CONT 1 & & & & 0.6944 & & \\
\hline CONT 2 & & & & 0.6677 & & \\
\hline CONT 3 & & & & 0.7598 & & \\
\hline CONT 4 & & & & 0.6939 & & \\
\hline HR 1 & & & & & 0.8209 & \\
\hline HR 2 & & & & & 0.8129 & \\
\hline HR 3 & & & & & 0.7872 & \\
\hline HR 4 & & & & & 0.8601 & \\
\hline DBSI 1 & & & & & & 0.7159 \\
\hline DBSI 2 & & & & & & 0.8057 \\
\hline DBSI 3 & & & & & & 0.6401 \\
\hline DBSI 4 & & & & & & 0.7497 \\
\hline DBSI 5 & & & & & & 0.6706 \\
\hline DBSI 6 & & & & & & 0.4596 \\
\hline DBSI 7 & & & & & & 0.6050 \\
\hline DBSI 8 & & & & & & 0.6942 \\
\hline DBSI 9 & & & & & & 0.7194 \\
\hline DBSI 10 & & & & & & 0.7180 \\
\hline Eigenvalue & 3.7077 & 2.4113 & 1.7051 & 1.9868 & 2.9643 & 4.6753 \\
\hline AVE & 0.6180 & 0.6028 & 0.5684 & 0.4967 & 0.6736 & 0.4675 \\
\hline CR & 0.9055 & 0.8585 & 0.7973 & 0.7975 & 0.8918 & 0.6271 \\
\hline Cron. Alpha & 0.8665 & 0.7765 & 0.6194 & 0.6563 & 0.8356 & 0.8708 \\
\hline
\end{tabular}

All values are based on an orthogonal rotation.

UNF Unfolding HR Development of human resource policies and

COO Coordination employee competences

COMM Communication DBSI Digital Business Strategy Implementation

CONT Control and feedback 


\section{Appendix K}

Parameter Estimates DBSI High $(n=95)$

\begin{tabular}{llllll}
\multicolumn{5}{l}{ Measurement Model Estimates } \\
\hline Path & & & Direction & Coefficient & Hypothesis \\
\hline UNF & $\rightarrow$ & SIA & + & $0.876^{*}$ & Supported \\
COO & $\rightarrow$ & SIA & + & $0.721^{*}$ & Supported \\
COMM & $\rightarrow$ & SIA & + & $0.560^{*}$ & Supported \\
CONT & $\rightarrow$ & SIA & + & $0.707^{*}$ & Supported \\
HR & $\rightarrow$ & SIA & + & $0.693^{*}$ & Supported \\
\hline Structural Model & & & & \\
\hline Independent & Dependent & Direction & Coefficient & Hypothesis \\
variable & & variable & & & \\
\hline SIA & DBSI & + & $0.555^{*}$ & Supported \\
\hline
\end{tabular}

\begin{tabular}{ll}
\hline Model fit & \\
\hline $\mathrm{X}^{2}$ & 27.497 \\
$p$-value & 0.001 \\
DF & 9 \\
CMIN/DF & 3.055 \\
RMSEA & 0.148 \\
GFI & 0.921 \\
CFI & 0.915 \\
\hline
\end{tabular}

The standardized coefficients are presented.

SIA Strategy implementation actions

UNF Unfolding

$\mathrm{COO}$ Coordination

COMM Communication

CONT Control and feedback

HR Development of human resource policies and employee competences

DBSI Digital business strategy implementation

Significant at $p$-value $<0.01$ 


\section{Appendix L \\ Parameter Estimates DBSI Low ( $n=96)$}

\begin{tabular}{llllll}
\multicolumn{4}{l}{ Measurement Model Estimates } & & \\
\hline Path & & & Direction & Coefficient & Hypothesis \\
\hline UNF & $\rightarrow$ & SIA & + & $0.941^{*}$ & Supported \\
COO & $\rightarrow$ & SIA & + & $0.892^{*}$ & Supported \\
COMM & $\rightarrow$ & SIA & + & $0.685^{*}$ & Supported \\
CONT & $\rightarrow$ & SIA & + & $0.530^{*}$ & Supported \\
HR & $\rightarrow$ & SIA & + & $0.828^{*}$ & Supported \\
\hline Structural Model & & & & \\
\hline Independent & Dependent & Direction & Coefficient & Hypothesis \\
variable & & variable & & & \\
\hline SIA & DBSI & + & $0.620^{*}$ & Supported \\
\end{tabular}

\begin{tabular}{ll}
\hline Model fit & \\
\hline$X^{2}$ & 15.032 \\
$p$-value & 0.090 \\
DF & 9 \\
CMIN/DF & 1.670 \\
RMSEA & 0.084 \\
GFI & 0.949 \\
CFI & 0.982 \\
\hline
\end{tabular}

The standardized coefficients are presented.

SIA Strategy implementation actions

UNF Unfolding

$\mathrm{COO}$ Coordination

COMM Communication

CONT Control and feedback

HR Development of human resource policies and employee competences

DBSI Digital business strategy implementation

* $\quad$ Significant at $p$-value $<0.01$ 


\section{Appendix M}

Parameter Estimates Central Functions $(n=70)$

\begin{tabular}{llllll}
\hline \multicolumn{4}{l}{ Measurement Model Estimates } & & \\
\hline Path & & & Direction & Coefficient & Hypothesis \\
\hline UNF & $\rightarrow$ & SIA & + & $0.912^{*}$ & Supported \\
COO & $\rightarrow$ & SIA & + & $0.878^{*}$ & Supported \\
COMM & $\rightarrow$ & SIA & + & $0.709^{*}$ & Supported \\
CONT & $\rightarrow$ & SIA & + & $0.761^{*}$ & Supported \\
HR & $\rightarrow$ & SIA & + & $0.714^{*}$ & Supported \\
\hline Structural Model & & & & \\
\hline Independent & Dependent & Direction & Coefficient & Hypothesis \\
variable & & variable & & & \\
\hline SIA & DBSI & + & $0.730^{*}$ & Supported
\end{tabular}

\begin{tabular}{ll}
\hline Model fit & \\
\hline $\mathrm{X}^{2}$ & 31.172 \\
$p$-value & 0.000 \\
DF & 9 \\
CMIN/DF & 3.464 \\
RMSEA & 0.189 \\
GFI & 0.871 \\
CFI & 0.917 \\
\hline
\end{tabular}

The standardized coefficients are presented.

SIA Strategy implementation actions

UNF Unfolding

COO Coordination

COMM Communication

CONT Control and feedback

HR Development of human resource policies and employee competences

DBSI Digital business strategy implementation

Significant at $p$-value $<0.01$ 
Appendix $\mathbf{N}$

Parameter Estimates Operating Functions ( $n=121)$

\begin{tabular}{llllll}
\multicolumn{4}{l}{l Measurement Model Estimates } & & \\
\hline Path & & & Direction & Coefficient & Hypothesis \\
\hline UNF & $\rightarrow$ & SIA & + & $0.950^{*}$ & Supported \\
COO & $\rightarrow$ & SIA & + & $0.876^{*}$ & Supported \\
COMM & $\rightarrow$ & SIA & + & $0.714^{*}$ & Supported \\
CONT & $\rightarrow$ & SIA & + & $0.593^{*}$ & Supported \\
HR & $\rightarrow$ & SIA & + & $0.831^{*}$ & Supported \\
\hline Structural Model & & & & \\
\hline Independent & Dependent & Direction & Coefficient & Hypothesis \\
variable & & variable & & & \\
\hline SIA & DBSI & + & $0.726^{*}$ & Supported \\
\hline
\end{tabular}

\begin{tabular}{ll}
\hline Model fit & \\
\hline$X^{2}$ & 11.522 \\
$p$-value & 0.242 \\
DF & 9 \\
CMIN/DF & 1.280 \\
RMSEA & 0.048 \\
GFI & 0.966 \\
CFI & 0.995 \\
\hline
\end{tabular}

The standardized coefficients are presented.

SIA Strategy implementation actions

UNF Unfolding

$\mathrm{COO}$ Coordination

COMM Communication

CONT Control and feedback

HR Development of human resource policies and employee competences

DBSI Digital business strategy implementation

* $\quad$ Significant at $p$-value $<0.01$ 


\title{
4. THE EFFECT OF DISAGGREGATED PERFORMANCE MEASURES ON MISREPORTING AND THE INFLUENCE OF PERFORMANCE TARGETS ${ }^{16,17}$
}

\begin{abstract}
In this paper we investigate how disaggregation of performance reporting affects misreporting and whether this relationship is influenced by performance targets. These aspects play an important role in the performance reporting process. The correctness achieved during the performance reporting process is crucial for managing and controlling organizations successfully. The impact of disaggregation regarding the level of information reported by employees however remains unclear. The results presented in this study are based on a laboratory experiment. During the experiment participants were asked to solve multiplication tasks and report their performance anonymously. The reporting scheme differed depending on the treatment group. We find that individuals prefer honesty and misreport significantly less in case of disaggregated performance measures. In case of performance targets, the findings indicate that they equalize the prior finding to some extent leading to a more similar level of misreporting between the different aggregation levels.
\end{abstract}

\footnotetext{
${ }^{16}$ This chapter is based on a working paper co-authored with Alexander Brüggen, and Axel Schulz.

${ }^{17}$ Acknowledgements: I would like to thank Todd Thornock (discussant) and Wendy Bailey (discussant), as well as participants at the 2018 AAA Annual Meeting and 2018 ABO Research Conference for their helpful comments and suggestions.
} 


\subsection{Introduction}

The purpose of this study is to investigate how disaggregation of performance reporting affects misreporting and whether this relationship is influenced by performance targets that generally accompany performance reporting. This study defines misreporting as the difference between the true performance achieved and the reported performance. Disaggregation is defined as the number of potential times individuals can engage in misreporting.

Performance measures and reporting of performance play an essential role for assessing performance in organizations as well as for managing and controlling their activities. In most cases organizations rely on the honesty of employees, who have private information that is valuable to the firm. Therefore, promoting honesty during the reporting process is a central function of management control systems. One important decision for organizations to consider in this process relates to the level of aggregation at which performance is reported. For example, business unit performance can be reported as aggregate information at the profit level or at a more disaggregated level as revenue and cost separately. Further, hours worked per week on each project might be reported separately (disaggregated) or as a sum for all projects (aggregated). With an increase of data processing technology and the possible ability to develop performance measures throughout many areas of managerial decisions, organizations are tempted to develop and provide large numbers of performance measures, disaggregating performance information further. While information that is more aggregated has the benefit of avoiding information overload, information that is more disaggregated can be beneficial in providing more detailed information for specific actions. In line with this, Hölmstrom (1979) demonstrated that all (costless) signals that are informative about an agent's hidden action should be used in an optimal contract. In contrast, however, Chenhall and Morris (1986) found that aggregated performance information is considered to be useful for managers in more uncertain environments because aggregated information reflects managerial effort better, with less disturbance from uncertainty. Banker and Datar (1989) further established a cost argument for the design of performance measures. In particular, they found that "the demand for aggregation in evaluating managerial performance arises because reporting all the basic transactions and other nonfinancial information about performance is costly and impracticable" (Banker and Datar 1989, p. 21). While the cost of capturing and 
reporting data is ever decreasing with the increased capacity of data processing, the cognitive cost for managers to integrate reported information in decision making remains a concern. Despite the optimal amount of data available, data is most useful when it is accurate (Mendoza 2020). In order to ensure the accuracy of data available, this study aims at finding the optimal level of data quantity reported in the performance reporting process.

Since performance measurement is defined as the metric used to quantify actions of employees (Neely, Gregory, and Platts 1995), we focus on performance reporting, which is the process of communicating employees' actions via quantified information (the way information is being reported), because it is the metric used to quantify actions of employees (Neely et al. 1995). Thereby, we follow a long-lasting call of Neely et al. (1995) for research to investigate how information should be displayed in performance reporting design to encourage appropriate behavior as well as how the data that are generated should be displayed. In addition, we focus on misreporting at the employee level, which largely differs in motives compared with misreporting at the executive level. In this way, our work is distinct from studies focusing on misreporting of executives, who are motivated to manage earnings to protect their compensation plans (e.g., Bollen and Pool 2009; Burns and Kedia 2006).

While several studies have investigated the effect of aggregation and disaggregation on individual behavior (e.g. Bonner, Clor-Proell, and Koonce 2014; Mendoza 2020; Nikias, Schwartz, Spires, Wollscheid, and Young 2010; Thaler 1985), the effect on an individual's performance reporting behavior is largely unknown. Where performance measurement involves an element of self-reporting, lower levels of aggregation potentially present the self-reporting individual with a greater number of opportunities to misreport (i.e., for each measured element, there is a separate opportunity to misreport). Although prior studies have examined the effect of reporting frequency on employee behavior (e.g., Hecht, Hobson, and Wang 2016), their focus has been on intertemporal effects. In contrast, our study focuses on misreporting at one point in time and investigates the effect of the number of opportunities the individual has to misreport at that particular point in time. Specifically, our study investigates whether disaggregation reduces the reliability of reporting due to an increased level of misreporting. 
Research into misreporting has a long history (e.g., Chow et al. 1988; Merchant 1985). In this study we use two different streams of literature to explain the effects associated with different levels of aggregation on misreporting. The first stream of literature deals with mental accounting and the perceived value individuals experience from earning a gain via misreporting. In this context individuals act irrational and experience a high level of psychological value from disaggregated gains (Thaler 1985). The second stream of literature deals with the disutility (i.e. psychological costs) individuals experience from misreporting. We utilize a psychological theory of dishonesty (Mazar et al. 2008), which states that individuals have an internal reward system associated with being honest. Individuals actively engaging in dishonest reporting experience dissonance between their actions and their view of themselves as honest (preference for honesty). We argue that it is not only the amount of dishonesty but also the frequency of being dishonest that matters in this context. As the number of lies necessary to reach the same magnitude of payoff from lying increases (i.e., more smaller lies vs. fewer larger lies), the act of lying itself further contributes to the dissonance experienced. Based on this reasoning, we argue that the probability that subordinates will misreport more is increased when the performance reporting involves more aggregated performance measures.

Performance measures are commonly used in conjunction with targets. One aspect of target setting is that the target serves as a reference point (Heath et al. 1999). While individuals derive internal targets based on their own expectation or aspiration level, external targets that are set by a superior or an organization reflect the organization's expectations. As such, external targets can reduce the amount of lying because reported performance exceeding the target may be viewed with suspicion by the superior. At the same time, it could increase lying in reporting up to the target because the target could be viewed as "giving permission" to report the level that is expected. While these effects are very different, we expect that a target reduces excessive misreporting. In the context of aggregation, we argue that targets interact with the degree of aggregation and result in similar levels of misreporting across high and low levels of aggregation.

To test our propositions, we run an experiment in which we manipulate the level of performance reporting aggregation and the provision of a nonbinding target. ${ }^{18}$ In

\footnotetext{
${ }^{18}$ No consequences for the participants were attached to the targets.
} 
line with our expectations, we find that individuals misreport more when they report aggregate performance compared with disaggregate performance. Further, our results show that the provision of a target interacts with the aggregation of performance reporting.

Our study contributes to the literature in several ways. We document that the level of aggregation directly affects the level of misreporting, with more disaggregated measures reducing the amount of misreporting. Further, targets play an important role in reducing the difference in misreporting observed between the disaggregated and aggregated performance measurement groups. Finally, this paper adds important insights to several studies investigating the behavior of individuals in more or less aggregated reporting settings (e.g. Bonner et al. 2014; Mendoza 2020; Nikias et al. 2010). The study by Nikias et al. (2010) can be considered closely related to the study at hand. While their study focuses on the reporting behavior during the budgeting process (i.e. the potential for slack creation), we analyze the ex post performance reporting process. As aggregation triggers important behavioral motives (Nikias et al. 2010), there is reason to assume that these behavioral motives might differ between the reporting of performance numbers compared to budgeting numbers. The study by Mendoza (2020) likewise investigates reporting behavior by means of different experiments. In the study's setting participants are triggered to underreport (i.e. practice of auditors to underreport their working hours). Our study is different from Mendoza (2020) as our participants have a motive to overreport. We thereby follow a call for research by Mendoza (2020) to investigate the effect of aggregation and disaggregation in the gain setting. Currently, it is unclear how this difference affects the behavioral motives of individuals. Consequently, we demonstrate how performance targets affect misreporting with regards to different levels of aggregation.

Our study also has important managerial implications for the design of performance measurement systems. The results indicate that people misreport in case they have an opportunity and incentives to engage in unethical behavior even though the results show an individual's preference for honesty. Bearing this in mind, the results provide practitioners with guidelines that limit the potential level of misreporting. In particular, the results highlight the importance of disaggregated performance reporting mechanisms since they reduce the amount of misreporting 
by individuals. In case disaggregated performance reporting is not feasible, the study emphasizes the role of performance targets as they reduce the level of misreporting in an aggregated performance reporting setting.

Our study proceeds as follows. The next section develops our theory and hypotheses. Then, we explain our method. After that we provide the results, and the final section concludes our study.

\subsection{Theory and Hypotheses Development}

\subsubsection{Misreporting}

Early studies in accounting have largely focused on misreporting in the form of budgetary slack. The literature has provided strong evidence for the tendency of individuals to understate their future performance and thus create slack in their budgets (Chow et al. 1988; Merchant 1985; Young 1985). While the literature on budgetary slack typically deals with underreporting of performance (e.g. Mendoza 2020), the literature examining incentives and misreporting tends to focus on individuals overreporting past performance to increase their compensation (Fisher, Maines, Peffer, and Sprinkle 2002). In their study, Fisher et al. (2002) combined two functions of a budget: the allocation of resources, which induces slack building, and the use of budgets as a performance evaluation mechanism, which triggers overstatement of performance. Our study defines misreporting as the difference between the true performance achieved and the reported performance.

Detecting dishonest acts of their employees remains difficult for organizations (Coyne and Bartram 2000), yet dishonesty does not always prevail because honesty itself has a certain utility for individuals. Although Baiman and Lewis (1989) found that preferences for honesty are generally weak, Evans, Hannan, Krishnan, and Moser (2001) showed that participants in their experiment on reporting behavior almost never lied to the maximum. There are a number of potential explanations for how individuals derive utility from being honest and thus do not lie to the maximum. One such explanation is based on the theory of self-concept maintenance (Mazar et al. 2008). According to this theory, people are motivated by two competing forces, namely, opportunistic behaviour that might generate a beneficial outcome versus maintenance of a positive self-concept as an honest person. This self-concept of 
being honest forms an upper boundary with regard to misreporting (Mazar et al. 2008).

\subsubsection{Information Aggregation}

The level of information aggregation that is captured by a performance measure is an important consideration for designers of such measures. The effect of information aggregation has been examined in terms of the number of performance measures included in a performance measurement system (e.g., Lillis 2002), such as whether to include one measure or several measures, as well as the level of aggregation (e.g., Kachelmeier, Williamson, and Zhang 2017), such as whether to include individual or group-based measures. The focus of our study is on disaggregated reporting versus aggregated reporting at a particular point in time. With the advances in information technology, shortening the measurement period has become more feasible in many companies, with the extreme end being continuous live monitoring. While hurdles on the technological side are decreasing, the mental costs for the recipient of the information (i.e., the superior) increase rather than decrease with the shortened measurement period and the consequently increased number of observations to be considered.

To the extent that the subordinate is required to self-report with regard to the performance measure, a situation of moral hazard arises whereby conventional agency theory predicts that the self-interested subordinate (agent) will engage in some level of misreporting, if information asymmetry is present (Baiman 1990). While conventional agency models do not consider a preference for honesty as part of the individual's utility, subsequent research by Luft (1997) and Evans et al. (2001) has empirically found that individuals do not engage in complete wealth maximization. The explanation for this finding is investigated by two distinct literature streams namely, mental accounting and psychological costs.

The first literature stream, mental accounting, investigates the effect of aggregation on individuals' behavior. This literature stream has its origin in the prospect theory developed by Kahneman and Tversky (1979). While prospect theory describes the behavior of individuals during a single outcome event, mental accounting investigates individual behavior in case of multiple events. The theory implies that individuals perceive financial events as either a gain or a loss into their 
mental accounts. These are either single mental accounts or multiple mental accounts (Thaler 1985). In line with prospect theory, the value function is s-shaped and defines itself over gains and losses instead of total wealth. As shown in Figure 6 individuals value smaller gains proportionally higher than larger gains compared to the overall wealth (the distance between gain $a$ and gain $b$ is proportionally higher than the increase between $v_{a}$ and $v_{b}$ ). The accounting system therefore influences individuals' behavior in an irrational way leading to people preferring the segregation of multiple gains in their mental accounts despite not leading to a difference in the overall value (Thaler 1985). In case of disaggregated performance measures this concavity of the value function over gains leads to an individual experiencing higher psychological value for several disaggregated smaller misreported values compared to one aggregated value although the economic wealth achieved is smaller (i.e. $2 \times v_{a}$ $>v_{b}$ while $2 \times a<b$ ). In order to reach the same perceived psychological value, individuals have to either misreport to a large extent or it is mathematically impossible as shown in the example in Figure 6 (i.e. it is impossible to misreport a value that is high enough to achieve a psychological value of $2 \times v_{a}$ ). Since mental accounting implies that people engage in irrational decisions in line with the concave value function, we assume that people misreport significantly less in the disaggregated setting as they experience high psychological value from significantly lower levels of misreporting. This is in line with findings by Bonner et al. (2014) and Mendoza (2020), who all find more ethical behavior in disaggregated settings. 


\section{Figure 6}

Prospect Theory Value Function

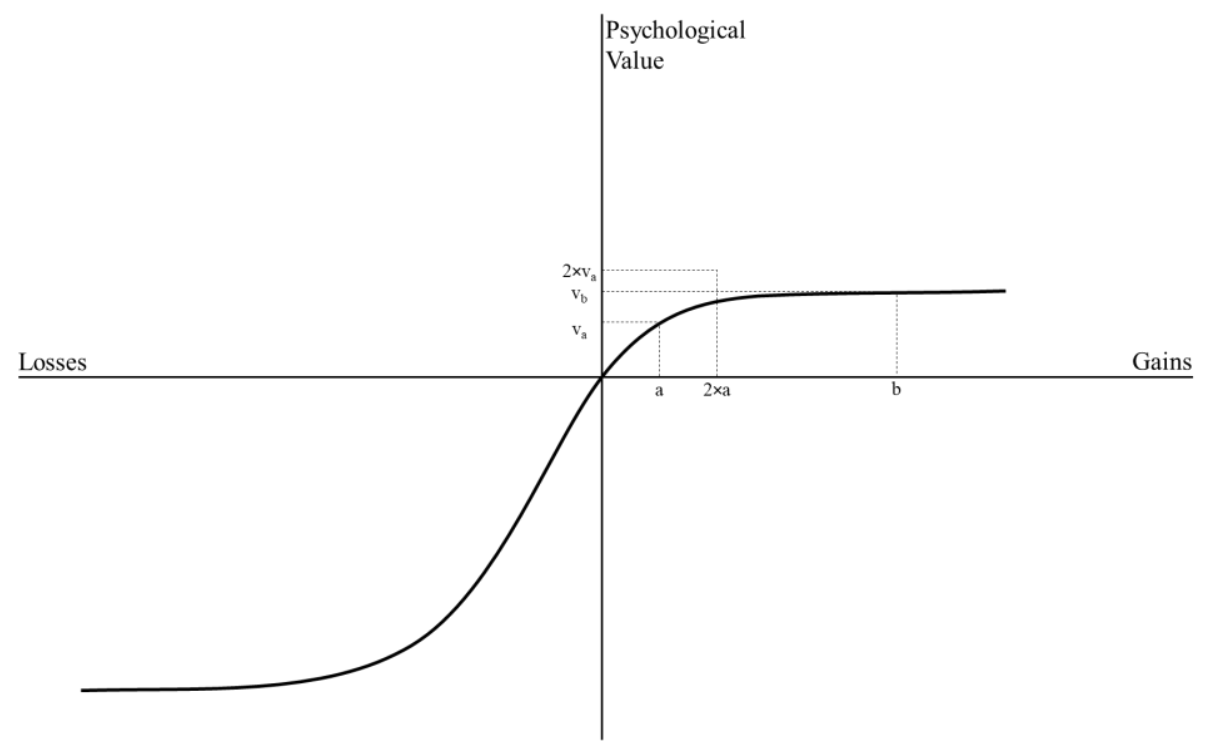

The second literature stream addressing this effect is related to psychological costs experienced by individuals in different contexts. While the preference for honesty has been shown to act as a counter force to wealth-maximizing motives arising from being dishonest and thus to misreporting, a psychological theory of dishonesty (Mazar et al. 2008) speaks more directly to the process by which the need to maintain a self-image of being honest (i.e., preference for honest) interacts with opposing forces to create dissonance, such as wealth maximization from dishonest actions. According to this theory of self-concept maintenance, dissonance increases as the level of dishonesty associated with the level of the action increases (as such, it adds to the psychological cost of dishonesty), and it declines as the level of dishonesty associated with the level of the action decreases.

Based on the concept of a psychological cost associated with dishonesty and thus with misreporting, we postulate that the increased occurrence of lying that is necessary for more disaggregated performance measures increases psychological cost (without a corresponding increased benefit from misreporting because the total 
monetary benefit does not change). Large unethical actions are harder to bear than small unethical actions (Schweitzer and Hsee 2002). This indicates that, compared with lying on an equivalent aggregated measure, the proportional amount of lying on disaggregated measures that is needed to reach the same overall level of misreporting is extraordinarily high, which increases the perceived level of dishonesty. As mentioned earlier, this need for more lying has a strong effect on people's perceived magnitude of dishonesty (Mazar et al. 2008) and increases the dissonance experienced by the subordinate during self-reporting. As such, it reduces the absolute amount of misreporting that occurs for more disaggregated performance measures. Based on the findings of both literature streams, we argue the following:

Hypothesis 1: The level of misreporting will increase under aggregated performance reporting.

\subsubsection{Performance Target}

Research into the effects of target setting has a long research tradition (see Locke and Latham 1990 for review). According to the literature, target setting is one of the more effective managerial tools (Locke and Latham 1990). Schweitzer, Ordóñez, and Douma (2004) show that targets significantly increase productivity, but their study also indicates that this management tool has to be used with caution because targets are associated with false reports and unethical behavior. Participants in their experiment showed two interesting patterns. First, they "were more likely to overstate their productivity when they were close to, rather than far from, reaching their [targets]" (p. 429), and second, they were more likely to overstate their productivity in a setting that included a target compared with a setting that lacked a target, even when the target was not linked to a monetary or social reward. Nevertheless, the study by Newman (2014) tests the effects of different types of target tightness ${ }^{19}$ on reporting honesty. In the experiment, participants were asked to report the costs of a project in the presence of a cost targets. The results indicate that using targets has no downside and that moderate and loose targets have a positive effect on honesty.

In addition, organizationally set targets have been shown to provide a reference point for the individual when evaluating subsequent information (e.g., Heath et al.

\footnotetext{
${ }^{19}$ The author tests for loose, moderate, and tight targets.
} 
1999), which can cause anchoring effects. An anchoring effect is a very fundamental heuristic, which biases judgments toward an initially presented value (Tversky and Kahneman 1974). The anchoring effect has been documented in many different studies (see Furnham and Boo 2011). For example, Bollen and Pool (2009) found that zero is a strong anchor for fund managers, triggering even misreporting of returns. In the earlier outlined value function, this anchor can be considered equal to the $x$ - and $y$-axis origin. A small proportion of misreporting above the target hence already leads to a perceived psychological value by any individual.

In line with the psychological cost discussion stated earlier, we argue that a target not only provides an anchor but also signals what is viewed as reasonable performance and hence further contributes to the cognitive dissonance experienced by an individual when reported performance deviates significantly from actual performance. We postulate that the effect of this anchor can be either positive or negative. In cases in which individuals have a lower tendency to misreport, we argue that they increase their misreporting because the anchor "gives permission" to misreport and thus reduces the psychological cost experienced. In cases in which individuals have a higher tendency to misreport, we argue that they decrease their misreporting because the anchor adds additional psychological cost to misreporting. In either case, we argue that an anchoring effect influences an individual's behavior to not misreport a number far beyond the target. This argument in combination with the target, which indicates the $x$ - and $y$-axis origin in the value function and thereby changes the perceived value by an individual, leads to a change in the previously described relationship between aggregation and misreporting. Therefore, we argue the following:

Hypothesis 2: The increase of misreporting under aggregated performance reporting is negatively moderated by the provision of a target.

\subsection{Method}

We ran an experiment with 119 students from a European university. All experimental materials were presented in English, which is consistent with the university's language of instruction. The experiment was carried out in a computer- 
based laboratory using Z-Tree software (Fischbacher 2007). ${ }^{20}$ Upon arrival, participants received an anonymous three-digit experimental identification number and were randomly assigned to the different experimental treatments. The participants did not know each other, and it was not possible for the instructors to track the experimental identification number back to the participant's name. The 119 participants were divided into five different sessions, which were all carried out on the same day. ${ }^{21}$

\subsubsection{Experimental Design and Variable Measurement}

During the experiment participants had to solve multiplication problems. We employed a $2 \times 2$ between-subjects design in which we manipulated the way that participants reported their performance (aggregated versus disaggregated) and the absence or presence of a nonbinding performance target. In total, 60 people were presented with the aggregated setting, and 32 of them were also provided with a performance target. Of the 59 participants that were assigned to the disaggregated setting, 30 were given a performance target. The given treatment remained the same throughout the experiment.

In our aggregate treatments, participants had to report their overall performance for all three rounds as a sum. That is, participants reported one number. In our disaggregated treatment, participants had to report their performance for each round; that is, they reported three numbers. In both treatments, participants selfreported their performance after completing the final round. Before participants submitted their reports, we provided them with information on the actual performance of correctly solved multiplication problems per round. This information was provided to participants in all treatments. Based on this information, participants were asked to report their own performance. Participants were not informed during the experiment that the maximum value that could be reported was $300(24 €)$. This information was only given to the participants if they reported a performance higher than 300. From the instructions, they knew that their compensation would be 100 percent variable depending on the number of correctly solved multiplications that they reported. For each correctly reported multiplication, participants were paid

\footnotetext{
${ }^{20}$ Screenshots of the information displayed to participants in the Z-Tree software are shown in Appendix 2 at the end of this dissertation.

${ }_{21}$ There were no significant effects between the different experiment sessions.
} 
$0.08 €$. Misreporting incurred no economic or social cost, such as a penalty or reputation damage.

In our target treatments, we informed participants in the instructions as well as before they reported their performance that their objective was to solve at least 70 multiplication problems in total. In the no-target treatments, this information was not provided. No consequences were attached to the target so that it was not binding. We derived the target from a pilot test with 13 participants. ${ }^{22}$

As previously outlined, we measured our independent variables as follows. The variable Aggregate is a dummy variable that equals one for the treatments in which participants had to report all rounds together in one number and zero otherwise. The variable Target is a dummy variable that equals one for the treatments with a performance target and zero otherwise. The dependent variable, Misreporting, is measured as the difference between the true performance and the reported performance.

\subsubsection{Procedure}

Upon arrival, participants drew a random identification number to log into the computer system. After logging into the Z-Tree computer system, the participants received instructions. Thereafter, participants had to pass a quiz to ensure that they understood the information that we provided.

Once participants passed the quiz, they could start with the first round of multiplication problems. All multiplication problems were randomly generated by the software. The first factor ranged between 10 and 30 and the second factor between 5 and 20 . These ranges were held constant for all participants in the same session but differed between the five sessions. In total, three rounds lasting 5 minutes each were conducted. Participants were not allowed to use mobile phones, calculators, or writing materials.

The computer screen always showed their actual performance. After three rounds, participants were asked to report their performance. The participants then

\footnotetext{
22 The mean performance in the pilot test was 68 correctly solved multiplication problems, and the median performance was 74 . Based on the pilot study results, we chose 70 as the number of problems that at least half of our participants would be able to correctly solve to meet the target.
} 
had to complete a post-experimental questionnaire including demographics, manipulation checks, and questions designed to learn more about participants' (misreporting) behavior. Participants received their compensation upon completion of the exit questionnaire. The experiment lasted about 40 minutes.

\subsection{Results}

\subsubsection{Descriptive Statistics}

Participants in the experiment had a mean age of 20.76 years; 69 (58 percent) were females and 50 were males. On average, they earned $€ 9.76$ and solved 53 tasks correctly. The mean reported performance, however, was 122 with a resulting mean of misreporting of 69 . These results are consistent with previous findings that participants do not lie to the maximum extent possible (Evans et al. 2001). Overall, only 12 participants (10 percent), five in the aggregated setting and seven in the disaggregated setting, reported the maximum level possible. Figure 7 shows the distribution of the different levels of misreporting among all participants, among participants in the aggregated setting, and among the disaggregated setting. The different panels show that misreporting behavior of individuals is pronounced toward two extremes. On one extreme, some participants misreported to a large extent for their own benefit, but on the other extreme, some participants had a strong preference for honesty and did not misreport at all. This outcome indicates that our dependent variable is not normally distributed. 


\section{Figure 7}

\section{Distribution of the level of misreporting among participants}

Panel A: All participants

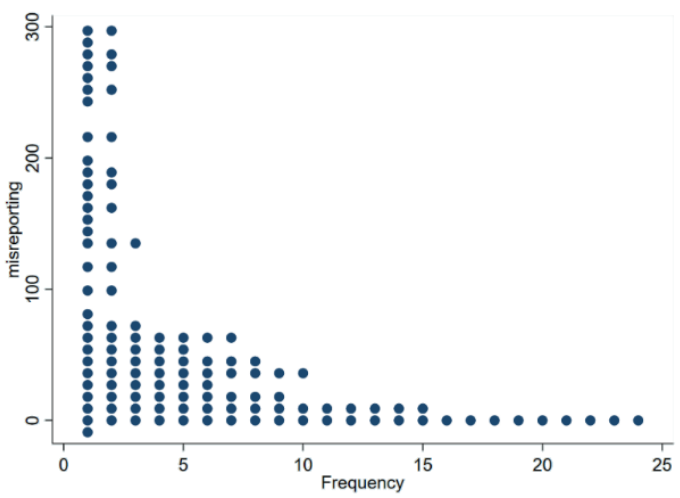

Panel B: Only participants in the aggregated setting

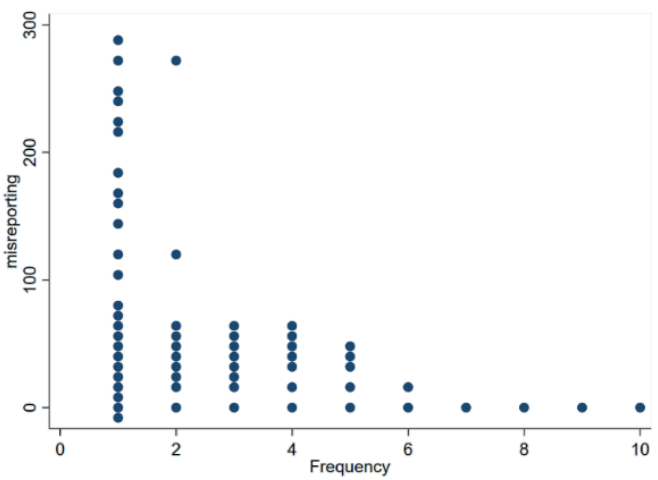

Panel C: Only participants in the disaggregated setting

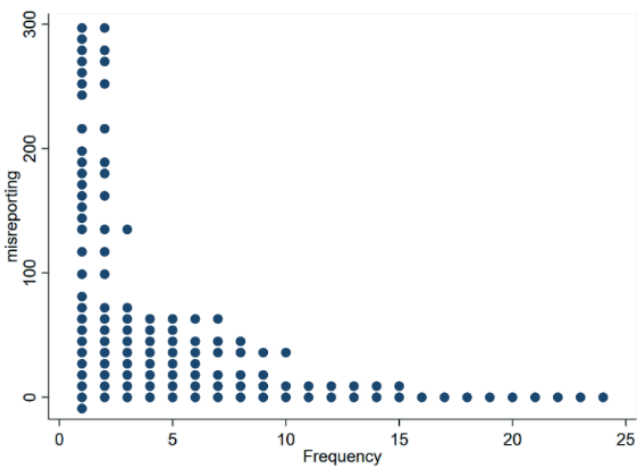

Misreporting is the difference between the true performance and the performance reported. The maximum level of misreporting possible was 300 , which serves as the upper limit. The frequency scale indicates the number of participants who misreported the corresponding level $(n=119)$. 


\section{Table 7}

\section{Descriptive Statistics: Median (mean in parentheses)}

\begin{tabular}{lcc}
\hline Panel A: Actual Performance & & \\
\hline \multicolumn{1}{c}{ Variable } & Disaggregate & Aggregate \\
\hline No target & $51(51.72)$ & $49(50.57)$ \\
Target & $45(60.07)$ & $52(50.78)$ \\
& & \\
\hline Panel B: Misreporting & & Aggregate \\
\hline \multicolumn{1}{c}{ Variable } & Disaggregate & $52.5(78.79)$ \\
\hline No target & $19(73.51)$ & $35(59.16)$ \\
Target & $33(65.03)$ & \\
& & Aggregate \\
\hline Panel C: Marginal Means & & $50.5(50.68)$ \\
\hline \multicolumn{1}{c}{ Variable } & Disaggregate & $43.75(68.98)$ \\
\hline Actual Performance & $48(55.90)$ & \\
Misreporting & $26(69.27)$ &
\end{tabular}

Descriptive statistics for the different treatments are shown in Table 7. The actual performance for the different treatments is shown in Panel $\mathrm{A}$. The highest median performance was 52 (mean $=50.78$ ) for people in the aggregated-target setting. This group was followed by people in the disaggregate-no target setting, with a median of 51 (mean $=51.72$ ), which was larger than the median of 49 (50.57) for people in the aggregate-no target setting and the median of 45 (60.07) for people in the disaggregate-target setting. The different levels of misreporting are shown in Panel B. The highest level of misreporting occurred in the aggregate setting, with a median of 52.5 (mean $=78.79$ ) in the no target treatment and a median of 35 (mean = 59.16) in the target treatment. The level of misreporting for the disaggregate setting is 33 (mean $=65.03$ ) for the target setting and 19 (mean $=73.51$ ) for the no target setting. The marginal medians are shown in Panel $\mathrm{C}$ and give interesting first insights into our proposed hypothesis. While the actual performance values are nearly equal for the disaggregate and aggregate settings, with marginal medians of 48 (mean = 55.90 ) and 50.5 (mean $=50.68$ ), respectively, the misreporting values differ to a larger extent. Here, the marginal median of 26 (mean $=69.27$ ) for the disaggregate setting is considerably smaller than the marginal median of 43.75 (mean $=68.98$ ) in the aggregate setting. These results indicate that people misreport to a higher level in case a performance target is not provided (see Figure 8). Lastly, the results give 
interesting insights into misreporting strategies of participants in a disaggregated setting. Participants had the opportunity to misreport everything on one number or to distribute the total overreported amount across the number of opportunities to misreport. While the minority of participants misreport all their amount in one round $(3.33 \%)$ or two rounds $(6.67 \%)$, the majority misreports on all three rounds $(73.33 \%)$. The remaining participants did not engage in misreporting. In addition, the results indicate that the majority of participants did not only misreport on all three rounds but also distributes the misreported amount equally. On average participants misreported 22.8 in round one, 23.5 in round two, and 22.9 in round three.

\section{Figure 8}

\section{Misreporting of participants with regards to target setting}

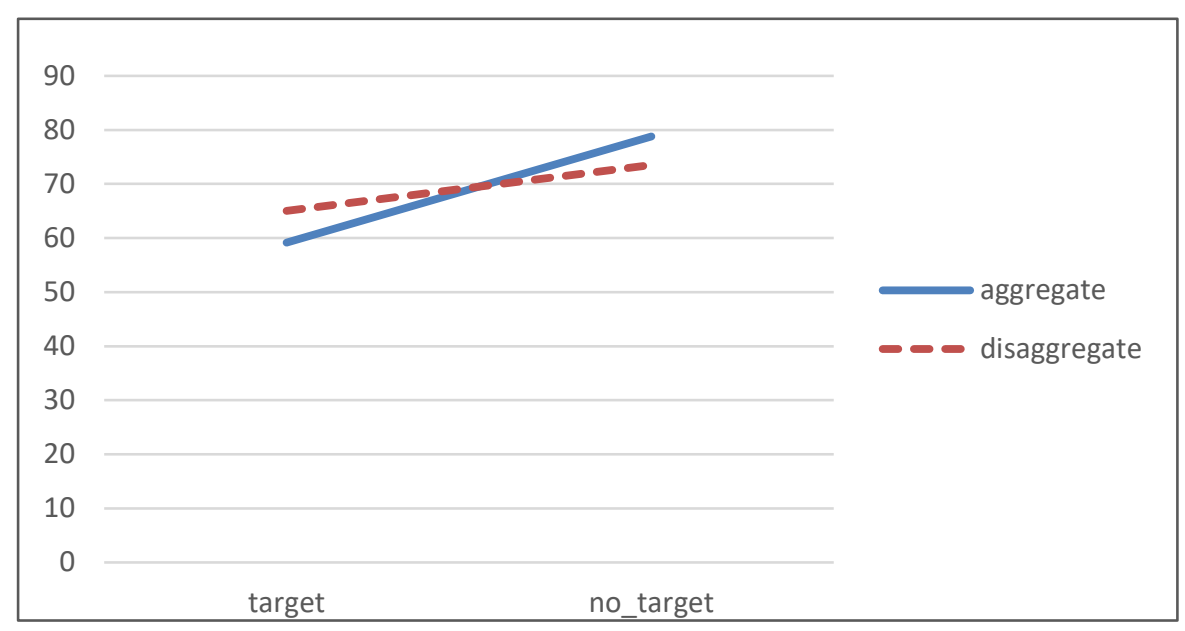

\subsubsection{Hypotheses Testing}

Hypothesis 1 predicts that the level of misreporting is significantly lower when disaggregated performance reporting are used, and hypothesis 2 predicts that the relative difference in misreporting between more highly aggregated performance measures compared with less highly aggregated performance measures will be lower when targets are part of the performance measurement than when targets are absent. To test these hypotheses, we run the following model (Model 1): 
Misreporting $=\alpha_{0}+\alpha_{1}$ Target $+\alpha_{2}$ Aggregate $+\alpha_{3}$ Target $\times$ Aggregate $+\varepsilon$

As seen in our descriptive analysis, our dependent variable is not normally distributed, which is confirmed with a Shapiro-Wilk test $(z=6.78, p<0.00)$. Some participants never misreported and others always misreported, which is in line with prior research (Halevy, Shalvi, and Verschuere 2014). This circumstance renders a mean regression difficult to interpret. To accommodate this difficulty, we use a wrapper of quantile regression to report robust standard errors that are valid under heteroscedasticity (Parente and Silva 2016).

The results of our Model 1 are shown in Table 8. The coefficient for Target is not significant ( $\alpha_{1}=19$, $p$-value $=0.23$ ), which indicates that setting a target or omitting a target does not directly affect misreporting. The effect of aggregation is positive and significant $\left(\alpha_{2}=36, p=0.012\right)$. This indicates that the misreporting median is higher by 36 under aggregated performance measures than under disaggregated measures. These results thus support $\mathrm{H} 1$. They indicate that individuals are more reluctant to misreport on multiple performance measures, relative to people who report on aggregated performance measures. The coefficient for the interaction between disaggregation and target is negative and significant $\left(\alpha_{3}=-38, p=0.076\right)$. Results thus show that the increase in misreporting under aggregate performance reporting is mitigated by the presence of a target. This finding provides support for $\mathrm{H} 2$.

\section{Table 8}

Median Regression of Misreporting ( $n=119)$

\begin{tabular}{|c|c|c|c|c|c|}
\hline \multicolumn{2}{|l|}{$\begin{array}{l}\text { Independent } \\
\text { Variable }\end{array}$} & Estimate & Std. Err. & z-value & $p$-value \\
\hline Intercept & $\alpha_{0}$ & $19^{* \star *}$ & 6.407 & 2.97 & 0.003 \\
\hline Target & $\alpha_{1}$ & 19 & 14.129 & -1.34 & 0.179 \\
\hline Aggregate & $\alpha_{2}$ & $36^{* *}$ & 14.128 & 2.55 & 0.011 \\
\hline Target $\times$ Aggregate & $\alpha_{3}$ & $-38^{*}$ & 21.222 & 1.79 & 0.073 \\
\hline \multicolumn{6}{|c|}{$\begin{array}{l}\text { Misreporting is measured as the difference between the true performance and the reported } \\
\text { performance. } \\
\text { Target is a dummy variable that equals one for the treatments with a performance target and zero } \\
\text { otherwise. } \\
\text { Aggregate is a dummy variable that equals one for the treatments in which participants had to report all } \\
\text { rounds together in one number and zero otherwise. }\end{array}$} \\
\hline
\end{tabular}




\subsubsection{Further Analysis}

Another potential factor affecting an individual's relative preference for honesty is their inherent relationship with the truth. In particular, the role of narcissism in this relationship has received increased attention. Studies have found that narcissism is common among top managers (Lipman 2014), and narcissistic individuals have been characterized as frequently revising real-world facts to meet their internal needs (Ford, King, and Hollender 1988). This characterization suggests that such individuals are less concerned about the truth than their own needs. In our further analysis, we explore the effect of narcissism on the relationship between performance measurement aggregation and target setting.

As part of our post-experimental questionnaire, we also measured a narcissism score. The variable is constructed using the Narcissistic Personality Inventory (NPI) scale (Raskin and Hall 1979). The questionnaire consists of 40 questions and is created as a forced choice instrument. We construct a dummy variable based on the overall NPI score (median $=17$ ) of the given sample. Every participant with a score of 17 or higher is classified as being high on the narcissism scale, which aligns with an experiment conducted by Dworkis and Patelli (2017). In total, 63 people had a high narcissism score; 35 were female (50.7 percent of all female participants), and 28 were male (56 percent of all male participants). A comparison of people with a high narcissism score and true performance showed significant results. Of the previously mentioned 29 participants who scored higher than the indicated target of 70, 19 participants had a high narcissism score. The mean performance for participants with a low narcissism score was 48 , whereas for participants with a high narcissism score, it was 58.05 . This outcome can be linked to results reported by Wallace and Baumeister (2002), who indicated that narcissists perform better under high pressure and when tasked with high-profile jobs.

To examine the effect of narcissism, we test the following model (Model 2):

Misreporting $=\alpha_{0}+\alpha_{1}$ Aggregate $+\alpha_{2}$ Target $+\alpha_{3} D_{\mathrm{Nar}}+\alpha_{4}$ Aggregate $\times$ Target + $\alpha_{5}$ Aggregate $\times D_{\mathrm{Nar}}+\alpha_{6}$ Target $\times D_{\mathrm{Nar}}+\alpha_{7}$ Aggregate $\times$ Target $\times D_{\mathrm{Nar}}+\varepsilon$

where $D_{N a r}$ is a dummy variable that equals one for respondents with a narcissism score above the median and zero otherwise. All other variables are specified as in Model 1. 
Results are shown in Table 9. The coefficient on aggregate performance reporting remains positive and significant $\left(\alpha_{1}=55, p=0.01\right)$. Further, the interaction between Aggregate and Target is significant ( $\alpha_{4}=-79, p=0.01$ ), confirming results of Model 1. The coefficient for $D_{\mathrm{Nar}}$ is insignificant $(\alpha 3=13 ; p=0.31)$, but the coefficient for the three-way interaction is significant and positive $(\alpha 7=73, p=0.07)$.

To investigate this finding further, we split the sample based on the variable DNar. Figure 9 provides graphical illustrations for the effect. These graphs show that narcissists seem to be reluctant to lie in instances in which a target is provided. In general, the target could serve as reference point and a narcissist might always want to greatly exceed this point in order to generate a high self-concept. If a target indeed serves as a reference point, their true performance could have demotivated narcissists, leading them to protect themselves against the vulnerability of getting caught. In addition, when in a disaggregated setting, lying on multiple performance measures could greatly increase the threat of being caught and thereby destroy the self-concept. Our data lack statistical power to find statistical support for this effect. Future research could address this question directly.

\section{Table 9}

Median Regression on Misreporting

\begin{tabular}{|c|c|c|c|c|c|}
\hline Independent Variable & & Estimate & Std. Err. & z-value & p-value \\
\hline Intercept & $\alpha_{0}$ & 8 & 10.258 & 0.78 & 0.435 \\
\hline Aggregate & $\alpha_{1}$ & $55^{\star \star *}$ & 20.398 & 2.70 & 0.007 \\
\hline Target & $\alpha_{2}$ & $50^{* *}$ & 22.221 & 2.25 & 0.024 \\
\hline$D_{\text {Nar }}$ & $\alpha_{3}$ & 13 & 12.759 & 1.02 & 0.308 \\
\hline Aggregate $\times$ Target & $\alpha_{4}$ & $-79^{\star \star \star}$ & 30.115 & -2.62 & 0.009 \\
\hline Aggregate $\times D_{N a r}$ & $\alpha_{5}$ & -32 & 29.909 & -1.07 & 0.285 \\
\hline DNar $\times$ Target & $\alpha_{6}$ & $-47^{*}$ & 26.402 & -1.78 & 0.075 \\
\hline Aggregate $\times$ Target $\times D_{N a r}$ & $\alpha_{7}$ & $73^{*}$ & 39.995 & 1.83 & 0.068 \\
\hline \multicolumn{6}{|c|}{$\begin{array}{l}{ }^{* \star *},{ }^{* *},{ }^{*} \text { is statistically significant at the } 1 \%, 5 \%, \text { and } 10 \% \text { level, respectively (two-tailed). } \\
\text { Misreporting is measured as the difference between the true performance and the reported } \\
\text { performance. } \\
\text { Target is a dummy variable that equals one for the treatments with a performance target and zero } \\
\text { otherwise. } \\
\text { Aggregate is a dummy variable that equals one for the treatments in which participants had to report } \\
\text { all rounds together in one number and zero otherwise. } \\
D_{\text {Nar is a dummy variable that equals one for respondents who score above the median of the }} \\
\text { narcissism score and zero otherwise }\end{array}$} \\
\hline
\end{tabular}




\section{Figure 9}

\section{Misreporting and Narcissism Score of participants}

\section{Panel A: Misreporting of participants scoring low on Narcissism}

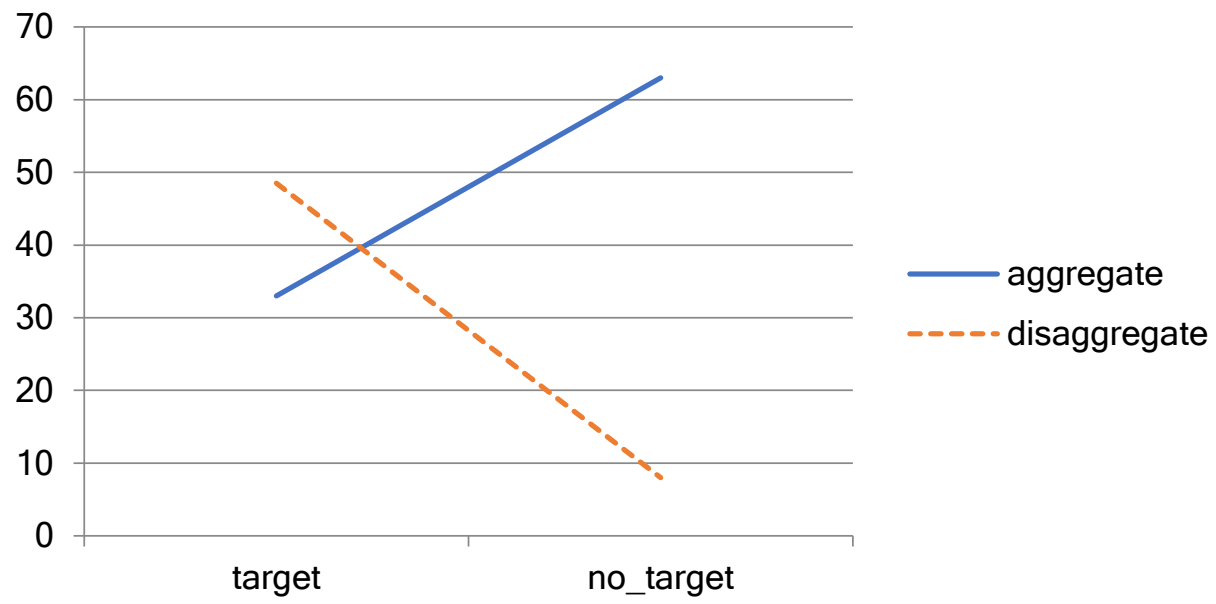

Panel B: Misreporting of participants scoring high on Narcissism

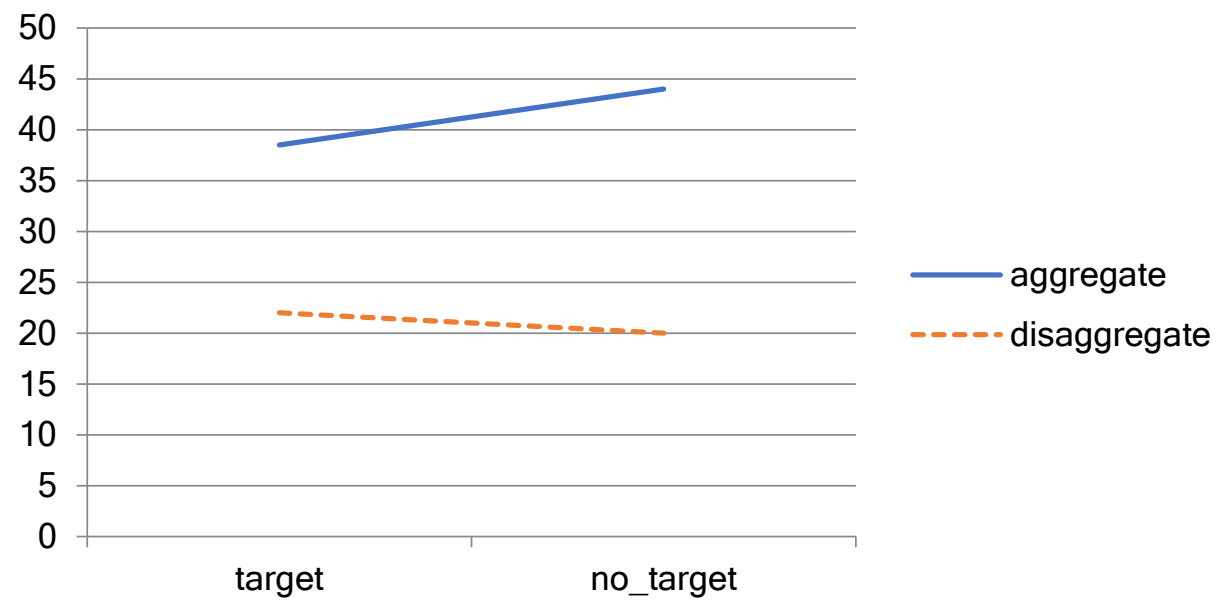




\subsection{Conclusion}

One of the considerations faced by designers of performance measurement systems is the level of aggregation used to measure performance. With the introduction of more disaggregated performance measures, the number of potential times individuals can engage in misreporting increases. As such, the individual is able to achieve the same absolute amount of misreporting, and thus the associated benefit from the magnitude of misreporting, via a number of smaller amounts of misreporting.

Consistent with prior work (e.g., Evans et al. 2001), we find that individuals prefer honesty and do not dare to misreport to the maximum extent possible. Nevertheless, our results indicate that individuals engage in dishonest behavior and that aggregated performance measurement mechanisms increase the proportion of unethical behavior as predicted by our theory. Hence, while more detailed and thus an increased number of self-reporting instances increased the opportunity to misreport, they not only did not increase the level of absolute misreporting but rather decreased the absolute amount being misreported.

We further find that the presence of an a priori performance target reduces the difference in misreporting between the levels of aggregation and thus results in the two levels of aggregation having a more similar level of misreporting. However, our findings show this result arises both via an increase (and thus reduced effectiveness) in the more disaggregated context as well as a decrease in the more aggregated context.

We also find evidence of an interaction involving narcissism. Thus, personality traits, such as narcissism, affect the relationship reported. Our results in regard to personality traits are exploratory, however, and our theory is not specific enough to warrant more precise a priori expectations in regard to the nature of the three-way interaction. Further, we do not have sufficient statistical power to unpack the overall three-way interaction.

This study contributes to research literature in several ways. First, the results show that people do not lie to the maximum extent possible, but misreporting is a harmful behavior among people and thus presents an important field for researchers to understand. It is critical to analyze accounting findings on all hierarchical levels 
and to incorporate psychology-based research to a greater extent into accounting literature. Second, regarding the level of aggregation the findings add important insights to the literature stream on reporting behavior. Our results underline the results Nikias et al. (2010) find for the budgeting process. As in the budgeting process, individuals show similar behavior in the performance reporting process. They misreport more under aggregated reporting mechanisms compared to disaggregated reporting mechanisms. Likewise, our results underline the effect Mendoza (2020) finds for aggregated (budgeting) targets. As their study aims at reducing underperformance, our study shows that this mechanism also has a beneficial effect in a context where overreporting leads to individual benefits.

Our results have important implications for practitioners with regards to the design of performance measurement systems. Since people engage in misreporting despite their preference for honesty, it is important for organizations to carefully design performance reporting mechanisms and to have efficient control functions in place. This study provides guidelines for practitioners to reduce the level of misreporting in both settings, aggregated and disaggregated performance measurement. In case practitioners can choose between an aggregated or disaggregated setting, the results indicate that a disaggregated mechanism is beneficial to reduce the level of misreporting. If the aggregated setting is more feasible to the situation at hand, the introduction of performance targets reduces the level of misreporting by individuals.

Our study has a number of limitations. First, it is based on an experiment that simulates an abstracted and simplified task. We only model a single performance measure in this context. Future research could examine more complex environments where individuals can trade-off multiple tasks and/or misreport on multiple performance measures. Second, this study has only tested one target for both settings (aggregated and disaggregated reporting), which was close to the mean and median of the pilot study. Our results could be reproduced with more challenging or very easy-to-attain targets as well as an aggregated target and disaggregated targets. Third, our study only took one-time interactions into account and did not consider any long-term effects, such as misreporting potentially resulting in social costs or job insecurities. 


\section{CONCLUSION}

\subsection{Summary}

In this dissertation, I examine the role of determinants in the implementation process of a digital business strategy as well as the effects of this implementation process. Due to the rapidly changing business environment, largely caused by digitalization, the successful implementation of a digital business strategy becomes vital for many organizations. While multiple studies have focused on the strategy formulation process, we know relatively little about the strategy implementation process. This is particularly true with regards to digital business strategy, since this field has just recently begun to emerge from a combination of the two fields of management information systems and strategic management. In order to shed more light on the developing field, the studies in this dissertation focus on specific preconditions or actions facilitating the implementation of a digital business strategy as well as its effect on aspects like performance. The final conceptualization of this dissertation including the findings of each study are illustrated in Figure 10.

In the first study (chapter 2), I focus on the dynamic capabilities construct as the appropriate precondition for the implementation of a digital business strategy. To explore this field, I investigate the question whether higher dynamic capabilities lead to higher implementation levels of digital business strategy. Further, I analyze the question if stronger dynamic capabilities lead to an increase in business unit performance. Lastly, I explore the question of whether the latter relation is mediated by the implementation level of a digital business strategy. In order to find answers to these questions, I cooperated with a large German manufacturing firm, which had implemented a digital business strategy two years prior to the data gathering process. Using expert interviews and an online survey addressing all senior vice presidents and vice presidents, I find that dynamic capabilities lead to a higher implementation level of a digital business strategy. I further find that in addition, dynamic capabilities improve a business unit's performance, which further highlights the beneficial role of dynamic capabilities. Lastly, while I find a positive effect of dynamic capabilities on business unit performance, I did not find a mediating effect of digital business strategy on this relation. These findings hold regardless of the implementation level of digital business strategy within a business unit or its daily 
Figure 10

Final Model of Dissertation

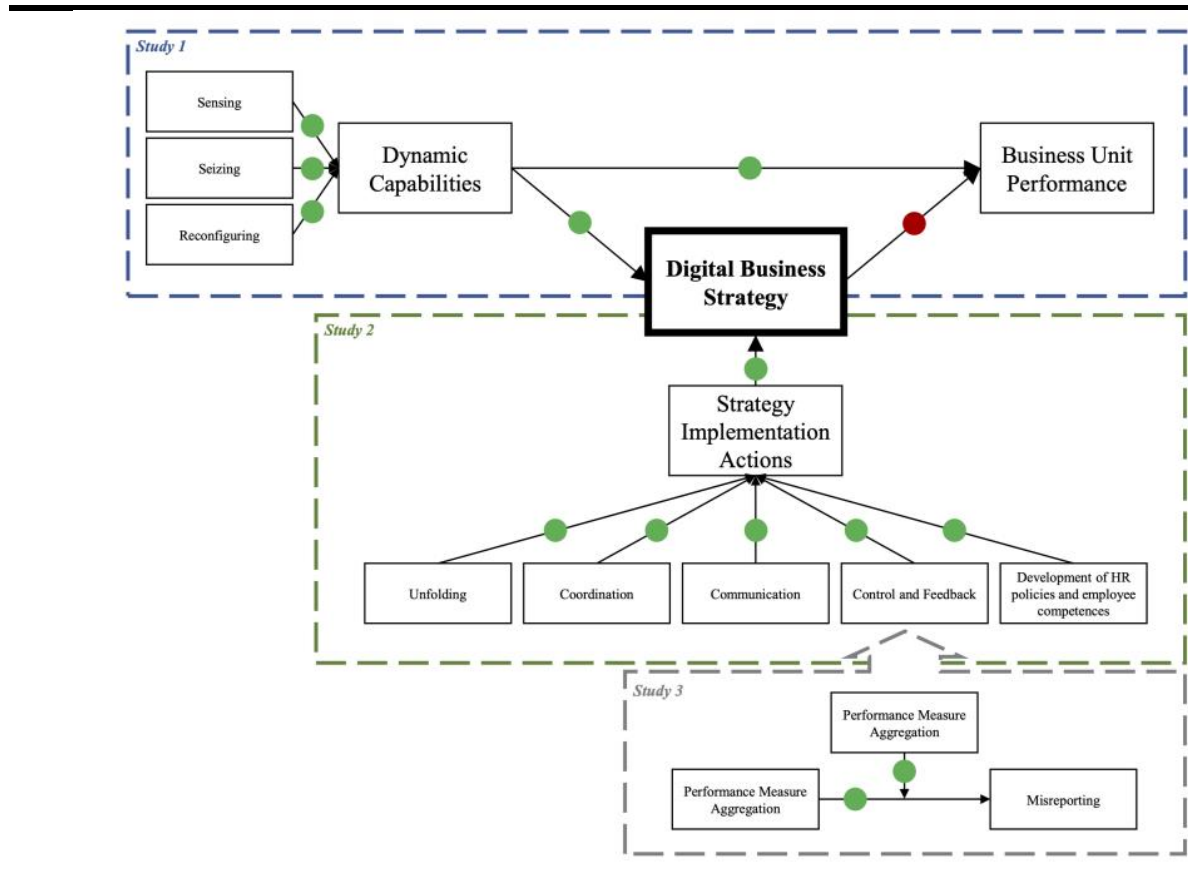

= significant effect

$=$ insignificant effect

tasks. Overall, this study adds to the understanding of the required preconditions for implementing digital business strategy.

In the second study (chapter 3), I focus on actions that enhance the implementation of a digital business strategy. Even though the implementation of a strategy is an essential stage to achieve the anticipated success (e.g., Ho et al. 2014; Hrebiniak 2006), many executives largely focus on the formulation stage. Similar problems can be observed in the academic literature, where most studies focus on the formulation process (Pryor et al. 2007). It is however important for organizations to understand the underlying mechanism during the implementation process, in order to adequately address the threats and opportunities resulting from digitalization. To explore this field, I examine the question of whether strategy implementation actions facilitate the implementation of a digital business strategy. 
Aiming to answer this question, I used an action component proposed by Oliveira et al. (2019) as the basis for my study and investigated the question, whether their developed actions are indeed crucial components in the strategy implementation process. To examine these questions, I again used all senior vice presidents and vice presidents of a large German manufacturing organization as my sample. I utilized an online survey to get insights on the variables of interest. The findings indicate that the proposed action dimensions by Oliveira et al. (2019) represent important components of strategy implementation actions. I further find that these strategy implementation actions are an important lever towards increasing the implementation level of a digital business strategy. Lastly, the findings indicate that these results are generalizable and that they hold irrespective of the implementation level of digital business strategy already achieved, or the everyday tasks of a business unit. The results of the second study provide novel evidence on the implementation process of a digital business strategy. The identified strategy implementation actions can serve as guidelines for future implementation initiatives.

In the third study (chapter 4), I focus on a narrow aspect of the strategy implementation actions introduced in the second study. More specifically, I concentrate on the performance reporting process, which applies in the strategy implementation action 'control and feedback'. As the second study showed that control and feedback actions subsequently result in an increased implementation level of digital business strategy, it is important to identify mechanisms that ensure the correctness of the reported performance. I therefore raise the question of how the required aggregation level of information during the reporting process, as well as performance targets, influence the level of misreporting. The aggregation level of information is an important aspect to consider as it presents the person that reports its performance, with more or fewer instances to misreport actual performance. With regards to targets, their introduction serves as an effective management tool (Locke and Latham 1990) and increases reporting honesty (Newman 2014). Consistent with my expectations, I find that the level of misreporting increases in cases of aggregated performance reporting mechanisms. This finding is however reduced in instances in which performance targets are introduced under more aggregated performance reporting schemes, as they lead to a decrease in the level of misreporting. The results indicate the important interplay of different mechanism in the performance 
reporting process. It is therefore important to always consider potential reciprocal effects. These findings are especially valuable during the implementation process of a digital business strategy as control and feedback activities play an important role here.

Overall, the three studies highlight that the implementation of a digital business strategy is a highly sensitive topic and depends on the interplay of various factors. First, it is important to establish a common understanding regarding the aspects included in a digital business strategy. As this field has not been sufficiently analyzed in the past, this dissertation adds several aspects to the pre-existing model. Besides the aspects identified in Leischnig et al. (2017), future digital business strategy initiatives should incorporate the fields of data, IT, working methods, culture and customer centricity to the construct in order to have a complete view on the construct. This is an important step in the theory building exercise of digital business strategy. Second, this dissertation provides important insights regarding the effect of digital business strategy. As I failed to find a positive effect of digital business strategy on performance, it is important to have the right expectations for all stakeholders involved regarding the outcome of implementing a digital business strategy. Recognizing that digital business strategy does not lead to increased team effectiveness does however not state that implementing digital business strategy might result in an increase in different aspects of performance like an increase in capital market rating, employee satisfaction, customer satisfaction, and quality. Third, the findings indicate that concepts like dynamic capabilities or strategy implementation actions, which normally address a different scope, apply in the context of digital business strategy likewise. This points to the fact, that digital business strategy in itself is not a detached concept but is highly interdependent on a diverse set of determinants like activities or competences within an organization. Fourth, the findings of this dissertation give clear guidelines on how to organize the implementation process of a digital business strategy. On the one hand, it is important to consider the given competences as these have a strong impact on the success of an implementation initiative. On the other hand, organizations need to strictly organize their implementation initiative among the five strategy implementation actions (i.e. unfolding, coordination, communication, control and feedback, and development of human resources policies and employee 
competences) in order to ensure a successful implementation of digital business strategy.

\subsection{Contributions and Implications}

This dissertation contributes important findings to academic and business practices. The research questions and settings examined in the three studies are timely and of concern to a wide audience. While all contributions have earlier been discussed in detail for each chapter, this section will revisit the most important aspects. First, the academic contributions and implications will be highlighted, followed by a discussion of the contributions and implications for practice.

\subsubsection{Contributions and Implications for Academics}

In general, this dissertation contributes to several academic fields. While the first and second study largely contribute to the fields of management information systems, strategic management and the newly developing field of digital business strategy, the third study mostly contributes to the intercept between the fields of management accounting and behavioral science. The findings of the last study, albeit its main audience will be found in the management accounting and behavioral science field, provide important insights for the implementation of a digital business strategy based on the findings of this dissertation.

The dissertation contributes to the field of digital business strategy in various ways. First, the dissertation proves that the digital business strategy concept can be related to theoretical models from different disciplines like strategic management or management information systems. Among others, I find that a strategic management framework (i.e. strategy implementation framework) is applicable to the field of digital business strategy. This adds quantitative evidence to the field and presents an important move towards increasing the understanding of digital business strategy. Second, the work provides important insights on the understanding of the digital business strategy concept itself. By means of expert interviews, several important characteristics have been added to the initial measurement instrument of Leischnig et al. (2017), which refines the construct. Third, the dissertation analyzes the effects of a digital business strategy. More specifically, it indicates that the level of digital business strategy implemented does not influence the relation between dynamic 
capabilities and business unit performance. ${ }^{23}$ Even though some scholars state that the effect of dynamic capabilities is context-dependent (e.g., Wilden et al. 2013), my findings do not contribute meaningful insights within the context of a digital business strategy. Fourth, the dissertation shows that it is important to consider the present preconditions when studying digital business strategy. The findings indicate that scholars should include certain preconditions in future studies on digital business strategy, since the implementation of a digital business strategy is heavily dependent on the circumstances within firms. The dissertation thereby focused on three specific determinants (i.e. dynamic capabilities, strategy implementation action, and control and feedback mechanisms during the implementation process) to understand the implementation process in depth. These determinants are discussed in detail in the following.

The dissertation contributes important findings to the debate on the effects of the first determinant, dynamic capabilities. I thereby highlight the importance of dynamic capabilities and show that they are more than a vague and fuzzy construct, which is measurable. The findings indicate that the implementation of a digital business strategy is significantly influenced by dynamic capabilities. This is an important finding with regards to evaluating the success of strategy implementation ex ante or ex post. In addition, dynamic capabilities can become an important indicator for evaluating the performance of business units within firms. This can prove especially helpful in instances in which it is hard to predict performance based on hard facts or if a comparison between business units is impractical. The second determinant investigated in this dissertation deals with the right actions to be taken when implementing a digital business strategy. Here, I analyzed the use of strategy implementation actions. While most studies focus on the formulation process, there is little knowledge about the implementation process. The findings show that a focus on strategy implementation actions represents a promising avenue for a better comprehension of any intervening mechanisms during the strategy process. The findings indicate that the proposed action component of de Oliveira et al. (2019) provides an important framework to guide strategy implementation research in the future. The last determinant studied in this dissertation is related to specific control and feedback mechanisms during the implementation process. More specifically, the

\footnotetext{
${ }^{23}$ In this case business unit performance is measured by means of an effectiveness scale.
} 
role of different aggregation levels and performance targets during the performance reporting process. The findings specify that both aspects play an important role in the performance reporting process, depending on the reporting scheme in place. Regarding the aggregation level of information required during the reporting process, the findings indicate that a higher aggregation level results in more misreporting. The introduction of performance targets in more aggregated performance reporting schemes however mitigates the increase in misreporting. The findings therefore provide important implications on the design of performance measurement systems as well as promising study settings on this phenomenon in the future. These results help in optimally adjusting the implementation process of a digital business strategy with regards to control and feedback mechanisms.

\subsubsection{Contributions and Implications for Practice}

Next to the contributions and implications for academics, this dissertation provides very insightful findings to practitioners on all kinds of management levels. The aim of the findings is to improve the highly needed preparation within organizations to approach digitalization appropriately. Overall, this dissertation adds to the understanding of digital business strategy, the appropriate expectations towards a digital business strategy, and the optimal preconditions of a digital business strategy. I reiterate the most important contributions and implications for management with regards to the different aspects below.

The dissertation represents an important cornerstone towards a common understanding of the digital business strategy concept itself. It is central to realize that digital business strategy serves a wide scope and includes aspects like digital technology usage, data, IT, working methods, culture, customer centricity and digital interaction. A narrow focus on single aspects like usage of digital technology can lead to neglecting aspects like working methods or culture. This limits the anticipated benefit of a digital business strategy. Organization therefore have to staff their strategy teams accordingly. Next to the understanding of the digital business strategy concept, this dissertation adds important insights towards the appropriate expectation practitioners should have regarding the anticipated impact of a digital business strategy. Organizations should not expect a performance boost shortly after implementing a digital business strategy. This is an important contribution as it might prevent an early experience of frustration. Lastly, the dissertation identifies 
important determinants to ensure a successful implementation of a digital business strategy. I thereby focus on specific capabilities and actions to be taken by organizations, which are presented in the following.

The findings indicate that managers have to closely monitor the capabilities of their own workforce. It is important for managers to actively develop and foster dynamic capabilities of employees. While it automatically improves performance, dynamic capabilities are an important trigger to increase the implementation level of a digital business strategy. This provides organizations with the right preconditions for the ongoing digital disruption. Consequently, organizations have to choose the right departments for their implementation efforts, closely manage their hiring process, pay close attention to the building of dynamic capabilities, and manage the expectations organizations should have of their digital business strategy. Regarding the hiring process, organizations should consider using dynamic capability indices to check whether a candidate is suitable for the job. One potential solution is to use these tests during an online assessment as it is customary practice for analytical tests. In order to select the right departments for the implementation, prior literature shows that the type of department focused on is crucial to ensure the success of implementation initiatives (Battilana and Casciaro 2013). Regarding the implementation of digital business strategy, the findings suggest to first focus on departments with strong dynamic capabilities to guarantee some early success during the implementation process. Relating to the build-up of dynamic capabilities, management should carefully evaluate the given dynamic capabilities within different business units and consider appropriate investments (i.e. implementing new management tools, inviting keynote speakers to inform the workforce on new trends, establishing customer feedback as decision criterion) to benefit from higher dynamic capabilities. Supplementary to the given capabilities within business units, this dissertation provides evidence on actions that significantly improve the implementation level of a digital business strategy. Based on findings from the online survey, strategy implementation actions need to form an integral part of every strategy process. Management must closely plan for the stage after the strategy has been formulated. As a result, I provide action guidelines for management to implement a digital business strategy successfully. Organizations have to focus on five action dimensions (i.e. unfolding, coordination, communication, control and feedback, and development of human resources policies and employee 
competences) in order to increase the success rates of future digital business strategy implementations. Since these strategy implementation actions require the efforts of individuals across all hierarchical levels, I highlight the fact that only a collaborative approach will in the end lead to successful implementation. Just like it needs the coordination and communication skills of management, it also requires the commitment of employees across all levels to follow management down this road. In sum, these results provide unique insights on the implementation of a digital business strategy and represent an important step towards decreasing the failure rate of implementation initiatives in the future. In order to increase the success rate of implementation initiatives in the future, one potential improvement suggestion is the introduction of steering committees, which regularly compare the agreed implementation plan to the status quo. As a last determinant that ensures the successful implementation of a digital business strategy, this dissertation presents more detailed findings for the control and feedback action dimension. More precisely, I provide important knowledge on the design of performance reporting processes. While this knowledge can be applied to a wide range of settings, it is largely beneficial for management accountants and decision-makers. The findings indicate that managers have to carefully weigh the benefits against the drawbacks of adopting more or less aggregated performance reporting schemes whenever control and feedback is necessary. In general, disaggregated performance reporting leads to less misreporting and subsequently to well-founded information as a basis for future decisions. In case managers prefer more aggregated performance reporting schemes, the findings highlight the beneficial effect of introducing performance reporting targets, as these will mitigate the increased misreporting level caused by aggregation.

\subsection{Limitations and Future Research}

As with any study, this dissertation is subject to a number of limitations. While these are individually discussed for each study within the previous chapters, in the following I reiterate some important limitations and highlight how they present opportunities for future avenues of research.

There are some common limitations regarding the first and second study (chapter 2 and 3). First, owing to the data collection by means of an online survey, all measures rely on the subjective perception of management. This limitation is 
largely driven by the fact that the sample organization does not publicly disclose the needed objective measures. All data therefore contains the typical limitations such as sampling issues and self-selection bias. Future studies should find a way to gather both subjective and objective data to overcome the given limitation. Second, I only measured the variables within one organization. While this carries the benefit of more detailed insights into the underlying processes and activities within the one organization, it cannot provide insights into observations such as between-industry differences or differences in the type of digital business strategies formulated. Future studies can overcome this limitation by testing various business units across different organizations and industries. For both limitations, these future research opportunities would further enhance the generalizability of the results found in this dissertation. Third, all variables are measured at one single point in time. While this is not a problem with regards to the second study, as it is intended to merely measure specific actions towards implementing a digital business strategy, it does pose a problem in the first study. Here, the aim is to measure the effect of digital business strategy on the subsequent improvement of performance. This setting might ignore potential time lag effects. Future research should conduct a longitudinal study and measure the proposed effects over time.

In light of the divergent research design applied in study three, the limitations are largely different from the ones identified for the other two studies. The context used in this experiment simulates an abstract and simplified setting, which provides some limitations. First, I only used one type of performance measure, which makes it impossible to take any differences between performance measures into account. Second, I only applied one type of performance target, ignoring differences between binding and non-binding or aggregated and disaggregated targets. Future research could therefore try to replicate the applied setting within a more complex environment. 


\section{APPENDIX}

\section{Appendix 1: Survey Material Chapter 2 and 3}

\section{Introduction}

Thank you very much for taking part in this survey, your time and effort are highly appreciated! The purpose of the study is to understand the effect of a digitalization strategy. More specifically, we want to gain insights into the interplay of strategy and different characteristics within departments. To gain a deeper insight into this topic we will address all senior vice presidents and vice presidents of the

. Please note that the questions address your current business unit only.

The study at hand is a collaboration project between Maastricht University and the and will take approximately 10-15 minutes to complete. Be assured that all answers you provide will be kept in the strictest confidence and that it is not possible to trace back answers to individuals. Please answer honestly and to the best of your knowledge, there are no right or wrong answers.

In order to ensure a common understanding among all participants, the following picture represents the 's current digitalization strategy:

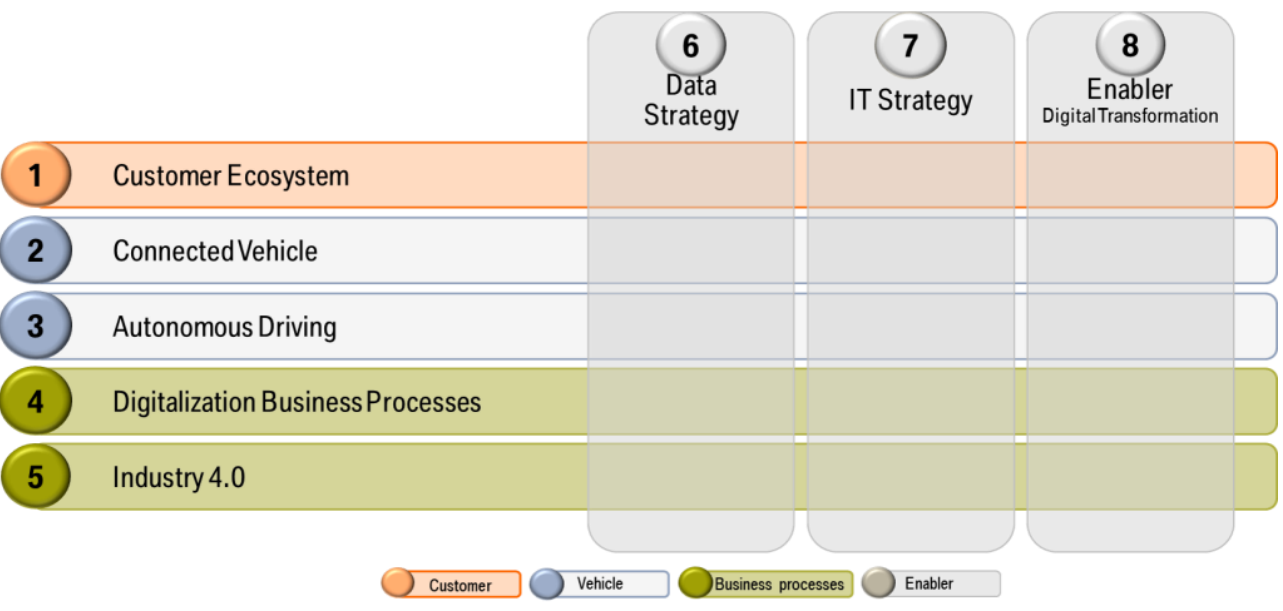




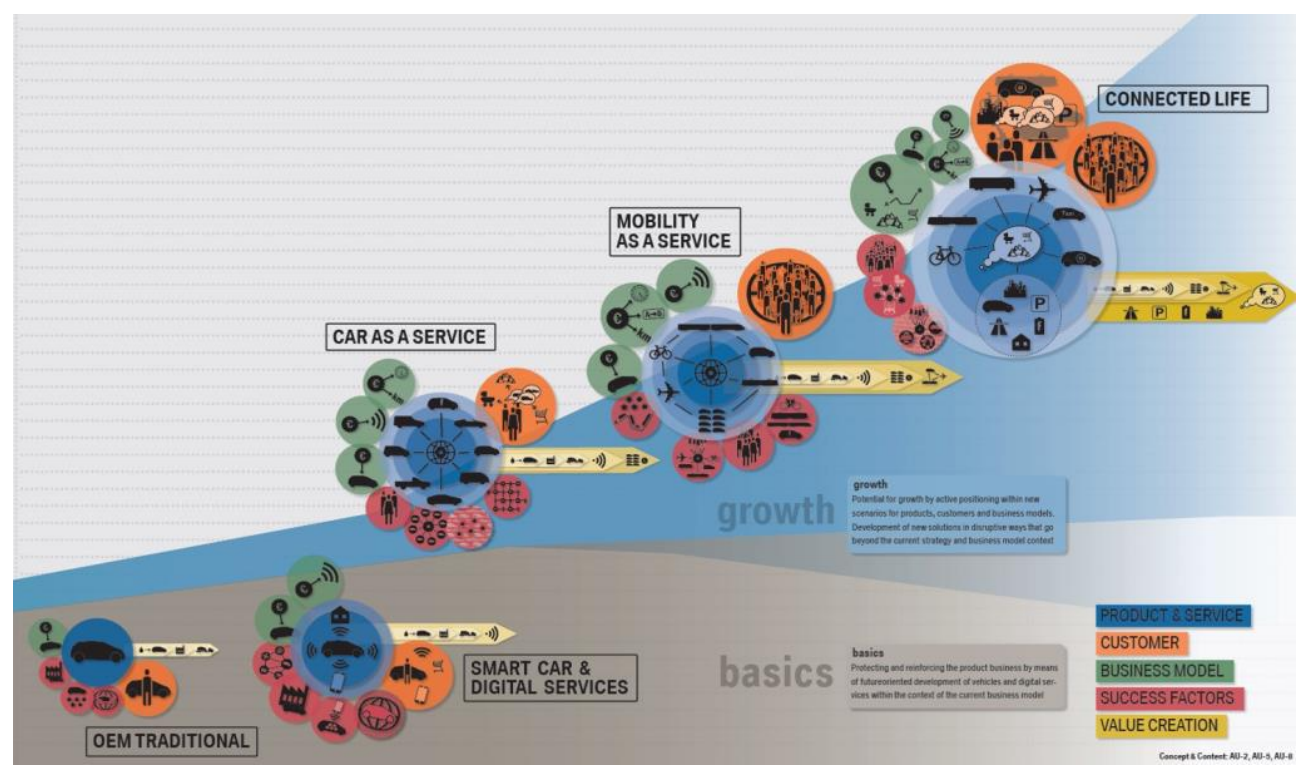

In addition to the pictures above, please find further information under following link:

Please click "Next" to begin. 


\section{Digital Business Strategy}

This part will deal with the topic of digitalization and digitalization strategy within your business unit. Please read the questions carefully.

I consider digitalization as a key factor for the achievement of my business unit's target.

Strongly Disagree Somewhat Neither Somewhat Agree Strongly disagree disagree agree nor agree agree disagree

The core values of my business unit include digitalization as a key for improvement.

Strongly Disagree Somewhat Neither Somewhat Agree Strongly disagree disagree agree nor agree agree disagree

We as a business unit offer several digital solutions.

Strongly Disagree Somewhat Neither Somewhat Agree Strongly disagree disagree agree nor agree agree disagree

Many of my business unit's processes, programs, or activities relate to the integration of new digital technologies.

\begin{tabular}{|c|c|c|c|c|c|}
\hline $\begin{array}{l}\text { Strongly } \\
\text { disagree }\end{array}$ & Disagree & $\begin{array}{l}\text { Somewhat } \\
\text { disagree }\end{array}$ & $\begin{array}{l}\text { Neither } \\
\text { agree nor } \\
\text { disagree }\end{array}$ & $\begin{array}{l}\text { Somewhat } \\
\text { agree }\end{array}$ & Agree \\
\hline
\end{tabular}

We, as a business unit, use many digital resources for our business activities.

\begin{tabular}{|c|c|c|c|c|c|}
\hline $\begin{array}{l}\text { Strongly } \\
\text { disagree }\end{array}$ & Disagree & $\begin{array}{c}\text { Somewhat } \\
\text { disagree }\end{array}$ & $\begin{array}{l}\text { Neither } \\
\text { agree nor } \\
\text { disagree }\end{array}$ & $\begin{array}{l}\text { Somewhat } \\
\text { agree }\end{array}$ & Agree \\
\hline
\end{tabular}

In my business unit we consider data as a valuable source in all decisions. 


\begin{tabular}{|c|c|c|c|c|c|}
\hline $\begin{array}{l}\text { Strongly } \\
\text { disagree }\end{array}$ & Disagree & $\begin{array}{c}\text { Somewhat } \\
\text { disagree }\end{array}$ & $\begin{array}{l}\text { Neither } \\
\text { agree nor } \\
\text { disagree }\end{array}$ & $\begin{array}{l}\text { Somewhat } \\
\text { agree }\end{array}$ & $\begin{array}{l}\text { Strongly } \\
\text { agree }\end{array}$ \\
\hline
\end{tabular}

Decisions related to corporate IT topics are becoming more important in my business unit's daily work.

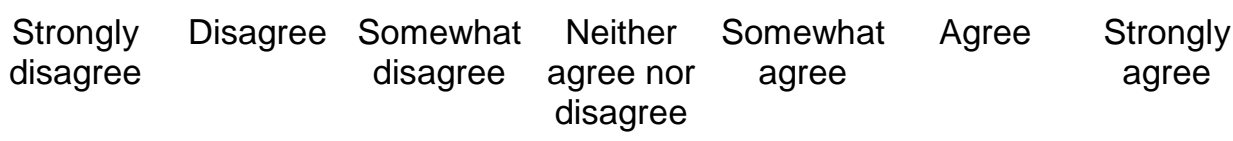

The working methods in my business unit have changed due to digitalization.

Strongly Disagree Somewhat Neither Somewhat Agree Strongly disagree disagree agree nor agree agree disagree

The culture in my business unit has changed due to digitalization.

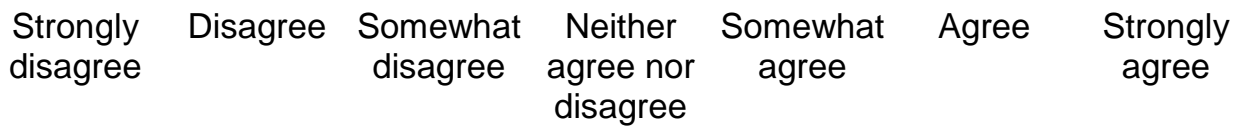

Over the past two years my business unit became more customer focused due to digitalization.

$\begin{array}{ccccc}\text { Strongly Disagree } & \begin{array}{c}\text { Somewhat } \\ \text { disagree }\end{array} \text { agree nor } & \begin{array}{c}\text { Somewhat } \\ \text { disagree }\end{array} & \text { Agree } & \begin{array}{c}\text { Strongly } \\ \text { agree }\end{array}\end{array}$




\section{Dynamic Capabilities}

The following part will deal with specific capabilities within your business unit. Please read the questions carefully.

In my business unit people participate in professional association activities (e.g. external events/conferences/workshops).
Rarely 0
0
0
$0 \quad 0$
o Very often

In my business unit we use established processes to identify target market segments, changing customer needs and customer innovation (customers can be external as well as internal).
Rarely 0
0
0
0
0
0
o Very often

In my business unit we observe best practices in our sector.
Rarely 0
0
0
$0 \quad 0$
0
o Very often

In my business unit we gather economic information on our operations and operational environment.
Rarely 0
0
0
0
0
0
o Very often

In my business unit we invest in finding solutions for our customers (customers can be external as well as internal).
Rarely 0
0
0
0
0
0
o Very often

In my business unit we adopt the best practices in our sector.
Rarely 0
0
0
0
$0 \quad 0$
o Very often 
In my business unit we respond to issues pointed out by our employees.
Rarely 0
o
0
0
$0 \quad 0$
o Very often

In my business unit we change our practices when customer feedback gives us a reason to change (customers can be external as well as internal).
Rarely 0
0
0
0
00
o Very often

How often have you carried out the following activities between 2016 and 2018 ?

Implementation of new kinds of management tools.
Rarely 0
0
0
0
0
0
o Very often

Substantial renewal of business processes.
Rarely 0
0
0
0
$0 \quad 0$
o Very often

New or substantially changed ways of achieving your targets and objectives.
Rarely 0
0
0
0
00
o Very often 


\section{Strategy Implementation Actions}

The following questions will address specific actions regarding strategy implementation. Please read the questions carefully.

In my business unit we establish specific actions to implement the digitalization strategy.

$\begin{array}{ccccc}\begin{array}{c}\text { Strongly } \\ \text { disagree }\end{array} & \text { Disagree } \begin{array}{c}\text { Somewhat } \\ \text { disagree }\end{array} \begin{array}{c}\text { Neither } \\ \text { agree nor } \\ \text { disagree }\end{array} & \begin{array}{c}\text { Somewhat } \\ \text { agree }\end{array} & \text { Agree } & \begin{array}{c}\text { Strongly } \\ \text { agree }\end{array} \\ & & \end{array}$

In my business unit we establish actions in order to commit employees towards the digitalization strategy.

$\begin{array}{ccccc}\begin{array}{c}\text { Strongly } \\ \text { disagree }\end{array} & \text { Disagree } \begin{array}{c}\text { Somewhat } \\ \text { disagree }\end{array} \text { agree nor } \begin{array}{c}\text { Somewhat agree } \\ \text { disagree }\end{array} & \text { Agree } & \begin{array}{c}\text { Strongly } \\ \text { agree }\end{array} \\ & & & \end{array}$

In my business unit we define resources and time limits and designate who will be responsible for each action with regards to the digitalization strategy.

$\begin{array}{ccccc}\begin{array}{c}\text { Strongly } \\ \text { disagree }\end{array} & \text { Disagree } \begin{array}{c}\text { Somewhat } \\ \text { disagree }\end{array} & \begin{array}{c}\text { Neither } \\ \text { agree nor } \\ \text { disagree }\end{array} & \begin{array}{c}\text { Somewhat agree } \\ \text { agree }\end{array} & \begin{array}{c}\text { Strongly } \\ \text { agree }\end{array}\end{array}$

In my business unit we adopted a set of procedures to monitor results.

\begin{tabular}{|c|c|c|c|c|c|}
\hline $\begin{array}{l}\text { Strongly } \\
\text { disagree }\end{array}$ & Disagree & $\begin{array}{l}\text { Somewhat } \\
\text { disagree }\end{array}$ & $\begin{array}{l}\text { Neither } \\
\text { agree nor } \\
\text { disagree }\end{array}$ & $\begin{array}{l}\text { Somewhat } \\
\text { agree }\end{array}$ & $\begin{array}{l}\text { Strongly } \\
\text { agree }\end{array}$ \\
\hline
\end{tabular}

In my business unit we identify obstacles to the execution of the digitalization strategy.

\begin{tabular}{|c|c|c|c|c|c|}
\hline $\begin{array}{l}\text { Strongly } \\
\text { disagree }\end{array}$ & Disagree & $\begin{array}{c}\text { Somewhat } \\
\text { disagree }\end{array}$ & $\begin{array}{l}\text { Neither } \\
\text { agree nor } \\
\text { disagree }\end{array}$ & $\begin{array}{l}\text { Somewhat } \\
\text { agree }\end{array}$ & $\begin{array}{l}\text { Strongly } \\
\text { agree }\end{array}$ \\
\hline
\end{tabular}

In my business unit HR personnel and I were engaged in the definition of actions, responsible persons, time and resources. 
Strongly Disagree Somewhat Neither Somewhat Agree Strongly disagree disagree agree nor agree agree

In my business unit we define indicators and goals in order to monitor the execution of the digitalization strategy.

$\begin{array}{ccccc}\begin{array}{c}\text { Strongly } \\ \text { disagree }\end{array} & \text { Disagree } \begin{array}{c}\text { Somewhat } \\ \text { disagree }\end{array} & \begin{array}{c}\text { Neither Somewhat } \\ \text { agree nor } \\ \text { disagree }\end{array} & \text { Agree } & \begin{array}{c}\text { Strongly } \\ \text { agree }\end{array}\end{array}$

In my business unit we designate responsible persons to coordinate the activities related to execution of the digitalization strategy.

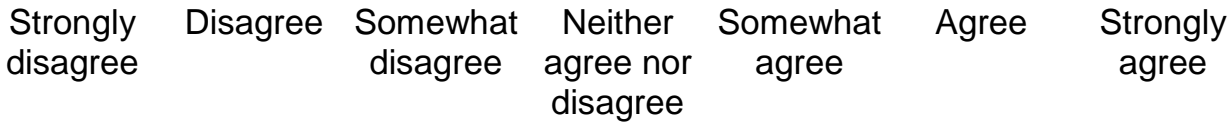

In my business unit we establish actions to align organizational culture with the digitalization strategy.

$\begin{array}{ccccc}\begin{array}{c}\text { Strongly } \\ \text { disagree }\end{array} & \text { Disagree } \begin{array}{c}\text { Somewhat } \\ \text { disagree }\end{array} \begin{array}{c}\text { Neither } \\ \text { agree nor } \\ \text { disagree }\end{array} & \begin{array}{c}\text { Somewhat } \\ \text { agree }\end{array} & \text { Agree } & \begin{array}{c}\text { Strongly } \\ \text { agree }\end{array}\end{array}$

In my business unit we promote the progress of action across the interfaces of processes and organizational areas with regards to the digitalization strategy.

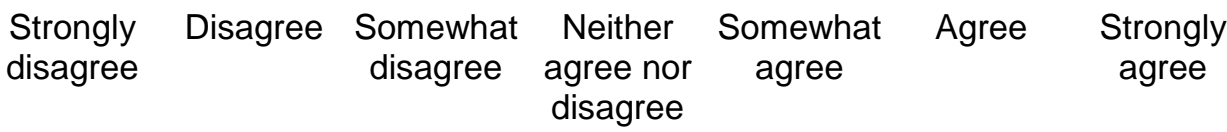

In my business unit we mobilize facilitating employees (change agents) and neutralize complicating employees with regards to the digitalization strategy.

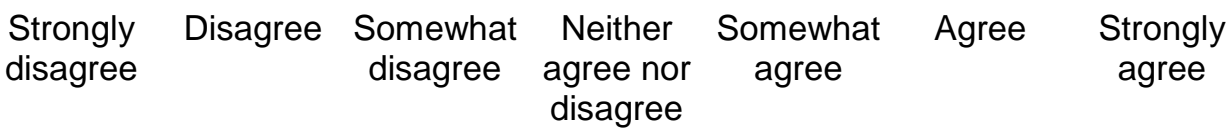

In my business unit we make use of multiple communication means (billboard, meeting, reports, emails) in order to disseminate information about digitalization strategy execution.

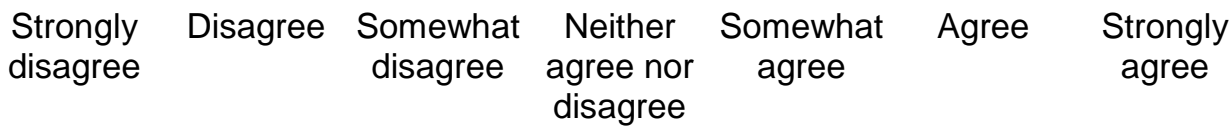


In my business unit we promote information flow bottom-up (from employees to managers) and laterally (between areas/peers).

$\begin{array}{ccccc}\begin{array}{c}\text { Strongly } \\ \text { disagree }\end{array} & \text { Disagree } \begin{array}{c}\text { Somewhat } \\ \text { disagree }\end{array} & \begin{array}{c}\text { Neither } \\ \text { agree nor } \\ \text { disagree }\end{array} & \begin{array}{c}\text { Somewhat agree } \\ \text { agree }\end{array} & \begin{array}{c}\text { Strongly } \\ \text { agree }\end{array} \\ & & \end{array}$

In my business unit we identify changes in the internal environment.

$\begin{array}{ccccc}\begin{array}{c}\text { Strongly } \\ \text { disagree }\end{array} & \text { Disagree } \begin{array}{c}\text { Somewhat } \\ \text { disagree }\end{array} & \begin{array}{c}\text { Neither } \\ \text { agree nor agree } \\ \text { disagree }\end{array} & \begin{array}{c}\text { Somewhat } \\ \text { agree }\end{array} & \begin{array}{c}\text { Strongly } \\ \text { agree }\end{array} \\ & & \end{array}$

In my business unit we identify changes in the external environment.

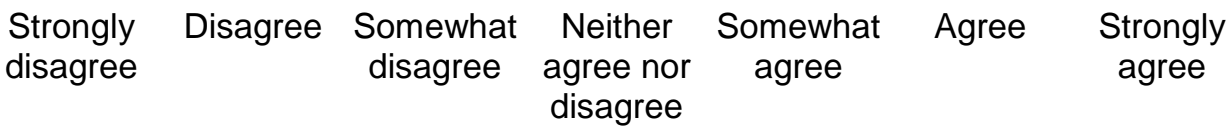

In my business unit we analyze the collected data (results attained, changes in internal or external environment).

$\begin{array}{ccccc}\begin{array}{c}\text { Strongly } \\ \text { disagree }\end{array} & \text { Disagree } \begin{array}{c}\text { Somewhat } \\ \text { disagree }\end{array} \text { agree nor } \begin{array}{c}\text { Somewhat } \\ \text { disagree }\end{array} & \text { Agree } & \begin{array}{c}\text { Strongly } \\ \text { agree }\end{array} \\ & & \end{array}$

In my business unit we align HR policies (recruitment, development, evaluation, compensation) with the digitalization strategy.

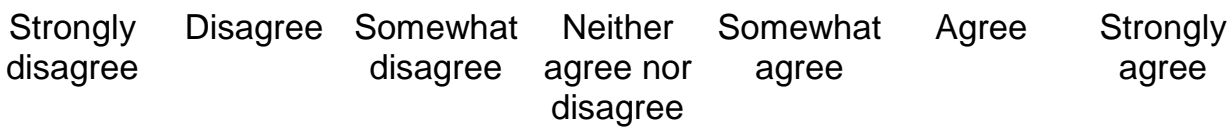

In my business unit we integrate the HR area with managers of other areas regarding digitalization strategy execution.

$\begin{array}{ccccc}\begin{array}{c}\text { Strongly } \\ \text { disagree }\end{array} & \text { Disagree } \begin{array}{c}\text { Somewhat } \\ \text { disagree }\end{array} & \begin{array}{c}\text { Neither } \\ \text { agree nor } \\ \text { disagree }\end{array} & \begin{array}{c}\text { Somewhat agree } \\ \text { Agree }\end{array} & \begin{array}{c}\text { Strongly } \\ \text { agree }\end{array} \\ & & \end{array}$

In my business unit we define employee competences necessary for digitalization strategy execution. 
Strongly Disagree Somewhat Neither Somewhat Agree Strongly disagree disagree agree nor agree agree

In my business unit we adopt actions (recruitment, reallocation, training) in order to reach the necessary competences with regards to the digitalization strategy.

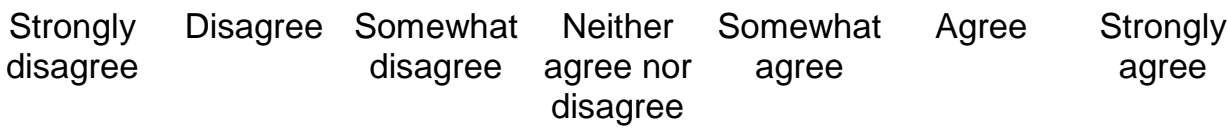

My targets encourage me to engage in the execution of the digitalization strategy.

$\begin{array}{ccccc}\begin{array}{c}\text { Strongly } \\ \text { disagree }\end{array} & \text { Disagree } \begin{array}{c}\text { Somewhat } \\ \text { disagree }\end{array} & \begin{array}{c}\text { Neither Somewhat } \\ \text { agree nor agree } \\ \text { disagree }\end{array} & \begin{array}{c}\text { Strongly } \\ \text { agree }\end{array}\end{array}$

I would consider myself to be "open" to the changes digitalization will bring to my work role.

$\begin{array}{ccccc}\text { Strongly Disagree } & \begin{array}{c}\text { Somewhat } \\ \text { disagree }\end{array} \text { agree nor } \\ \text { disagree } & \text { disagree } & \text { agree } & \text { Agree } & \begin{array}{c}\text { Strongly } \\ \text { agree }\end{array} \\ & & \end{array}$

In my business unit we share information (about the digitalization strategy and related actions, responsible persons, deadlines, goals, results and adjustments) in a broad and comprehensive manner.

$\begin{array}{ccccc}\begin{array}{c}\text { Strongly } \\ \text { disagree }\end{array} & \text { Disagree } \begin{array}{c}\text { Somewhat } \\ \text { disagree }\end{array} \begin{array}{c}\text { Neither } \\ \text { agree nor } \\ \text { disagree }\end{array} & \begin{array}{c}\text { Somewhat } \\ \text { agree }\end{array} & \text { Agree } & \begin{array}{c}\text { Strongly } \\ \text { agree }\end{array}\end{array}$

Right now, I am somewhat resistant to the proposed changes by digitalization.

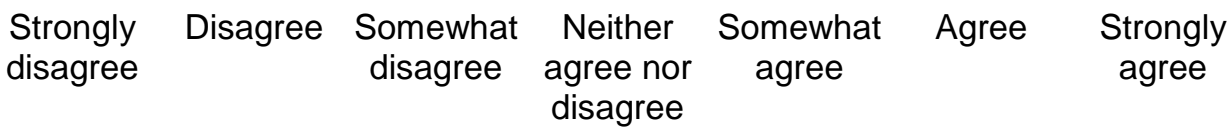

I am looking forward to the changes in my work role brought about by the implementation of digitalization.

$\begin{array}{ccccc}\text { Strongly Disagree } & \begin{array}{c}\text { Somewhat } \\ \text { disagree }\end{array} \text { agree nor } & \begin{array}{c}\text { Somewhat agree } \\ \text { disagree }\end{array} & \text { Agree } & \begin{array}{c}\text { Strongly } \\ \text { agree }\end{array} \\ & & & \end{array}$


In light of the proposed changes by digitalization, I am quite reluctant to consider changing the way I now do my work.

$\begin{array}{ccccc}\begin{array}{c}\text { Strongly } \\ \text { disagree }\end{array} & \text { Disagree } \begin{array}{c}\text { Somewhat } \\ \text { disagree }\end{array} & \begin{array}{c}\text { Neither } \\ \text { agree nor agree } \\ \text { disagree }\end{array} & \begin{array}{c}\text { Somewhat } \\ \text { agree }\end{array} & \begin{array}{c}\text { Strongly } \\ \text { agree }\end{array} \\ & & \end{array}$

I think that the implementation of digitalization will have a positive effect on how I accomplish my work.

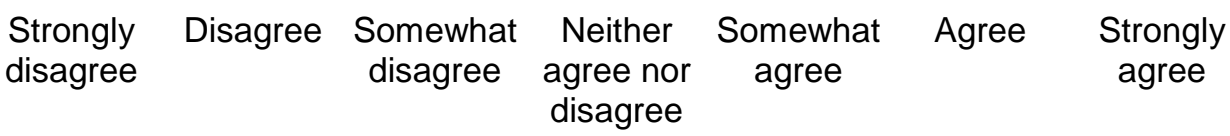

From my perspective, the proposed changes by digitalization will be for the better.

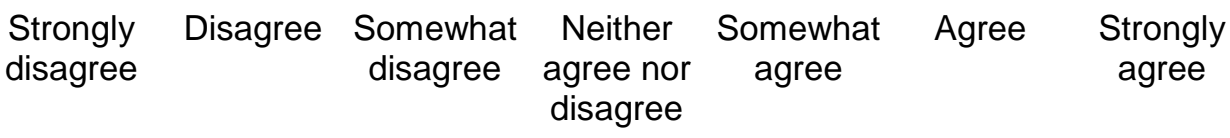

The proposed changes by digitalization will be for the worse in terms of the way that I have to get my work done.

$\begin{array}{ccccc}\text { Strongly Disagree } & \begin{array}{c}\text { Somewhat } \\ \text { disagree }\end{array} \text { agree nor } & \begin{array}{c}\text { Somewhat agree } \\ \text { disagree }\end{array} & \text { Agree } & \begin{array}{c}\text { Strongly } \\ \text { agree }\end{array} \\ & & & \end{array}$

I think that the proposed changes by digitalization will have a negative effect on how I perform my role in the organization.

\begin{tabular}{|c|c|c|c|c|c|}
\hline $\begin{array}{l}\text { Strongly } \\
\text { disagree }\end{array}$ & Disagree & $\begin{array}{c}\text { Somewhat } \\
\text { disagree }\end{array}$ & $\begin{array}{l}\text { Neither } \\
\text { agree nor } \\
\text { disagree }\end{array}$ & $\begin{array}{l}\text { Somewhat } \\
\text { agree }\end{array}$ & $\begin{array}{c}\text { Strongly } \\
\text { agree }\end{array}$ \\
\hline
\end{tabular}




\section{Business Unit Performance}

This part deals with the effectiveness of business units. In this case 1 indicates a very low effectiveness while 9 indicates very high effectiveness. Please note that a score of 9 on every aspect is highly unlikely. Please read the questions carefully.

My Business Unit actively engages in reviewing their work so that they can improve it.
1
2
3
4
5
$6 \quad 7$
8
9

My Business Unit comes up with ideas on how to reduce costs.
1
2
3
4
5
$6 \quad 7$
89

My Business Unit works effectively.
1
2
34
5
$6 \quad 7$
8
9

My Business Unit has to redo their work because of sloppy workmanship
1
2
3
4
5
$\begin{array}{ll}6 & 7\end{array}$
8
9

My Business Unit has successfully implemented ideas to reduce costs.
1
2
3
4
5
6
7
8
9

My Business Unit puts considerable effort into their jobs.
1
2
3
4
5
6
7
8
9

My Business Unit is concerned about the quality of their work.
1
2
3
4
5
6
7
8
9

My Business Unit is wasteful in how they use their work materials.
1
2
3
4
5
6
7
8
9 
My Business Unit meets or exceeds their productivity requirements.
1
2
34
5
6
7
8
9

My Business Unit is committed to producing quality work.
1
2
34
5
6
7
8
9

My Business Unit takes good care of their tools and machinery.
1
2
34
5
6
7
8
9

My Business Unit does their part to ensure that their products will be delivered on time.
1
2
$3 \quad 4$
5
$6 \quad 7$
8
9

My Business Unit comes up with ideas on how to produce higher-quality work.
1
2
3
4
5
6
7
8
9

My Business Unit takes preventive action so that machinery and tools will not be damaged.
1
2
3
4
5
6
7
8
9

My Business Unit searches for ways to be more productive.
1
2
34
5
$6 \quad 7$
8
9

My Business Unit has successfully implemented ideas to come up with higher quality.
1
2
3
4
5
6
7
8
9

My Business Unit does not abuse their sick leave policy.
1
2
34
5
$6 \quad 7$
89

My Business Unit has successfully implemented plans to be more productive.
1
2
3
4
5
6
7
8
9 


\section{Demographics}

The last part of this questionnaire deals with general demographics. Please read the questions carefully.

How long have you worked for the

Years

Months

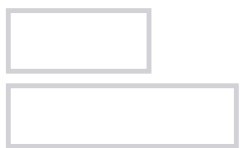

How long have you been working in your current position?

Years

Months

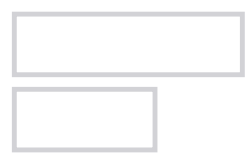

What resort do you currently work for?
A
B
E
F
M
P T
U 


\section{Appendix 2: Experiment Material Chapter 4}

\section{Treatment Aggregate - No Target}

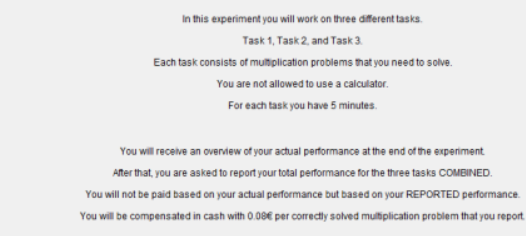




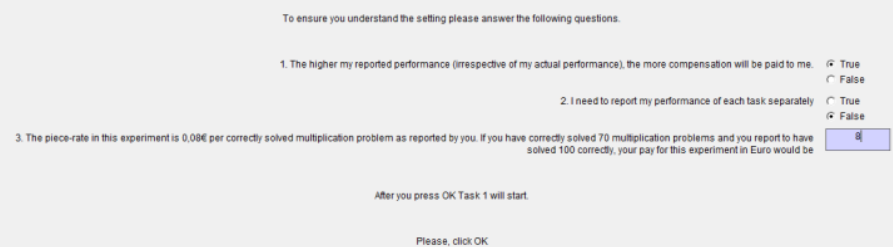

Please, chick oK

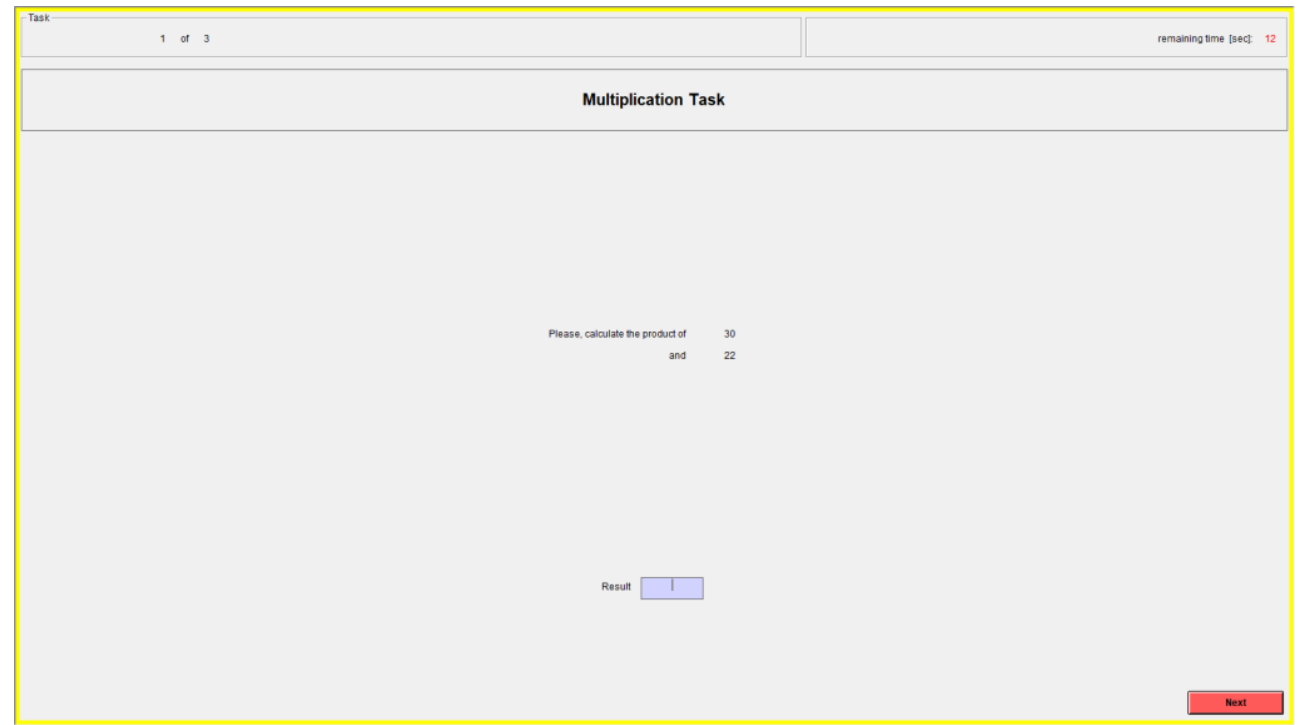



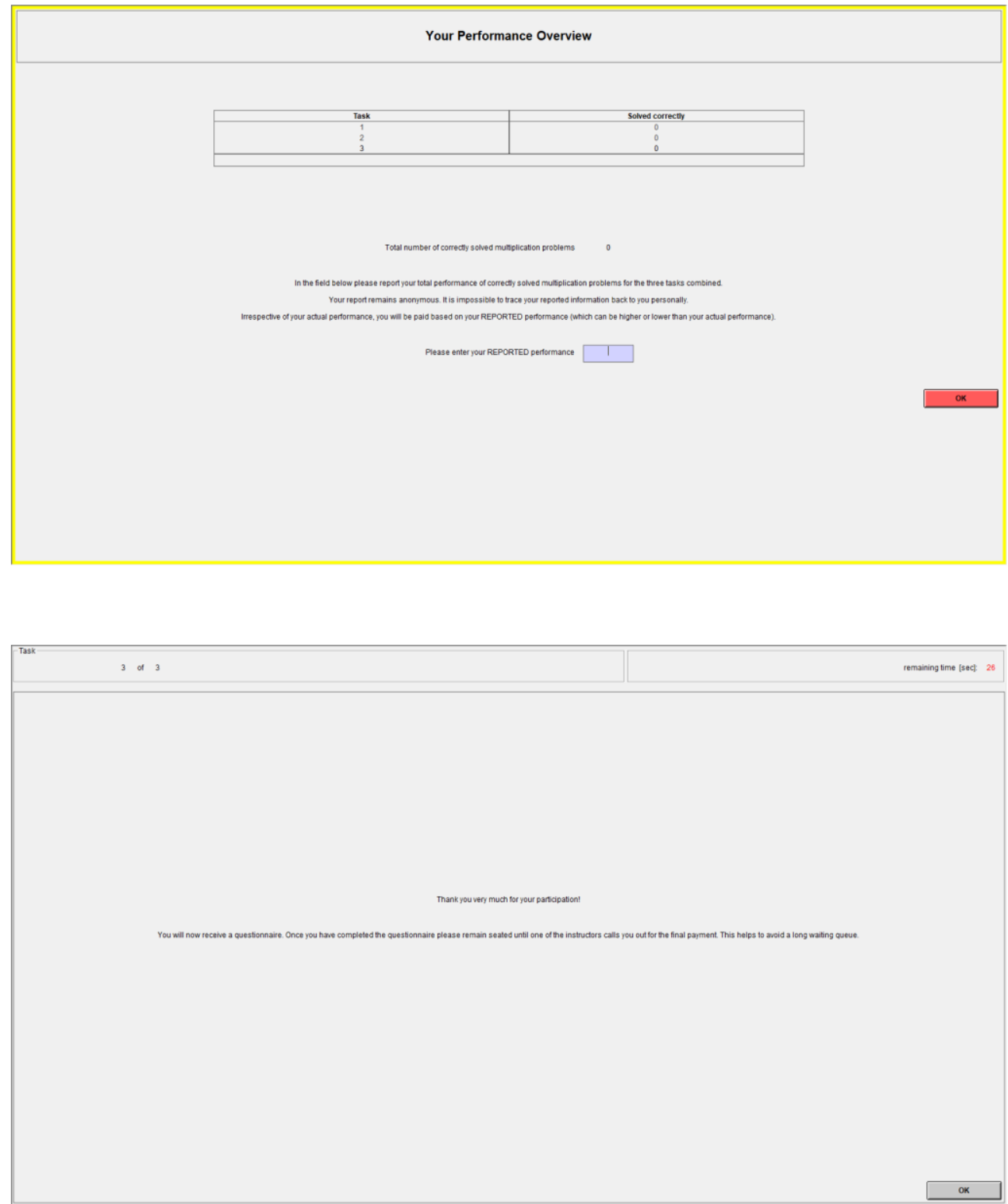


\section{Treatment Aggregate - Target}

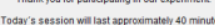

You will be compensated in cash at the end of the erperiment

Please smitch offrour mobile phone Now.

Please fll in your personal code $\quad 1$

Please, cicic ok

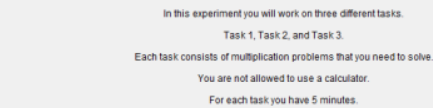

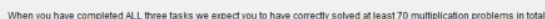

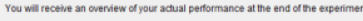

Wher that rou are askod to report your total pertormance for the three tasks COMEINED.

You will not be palid based on your actual pertormance but based on your REPORTED pettormance

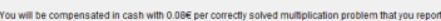

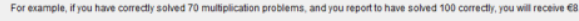

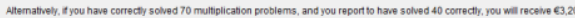

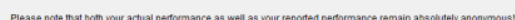

Please, chick ok 


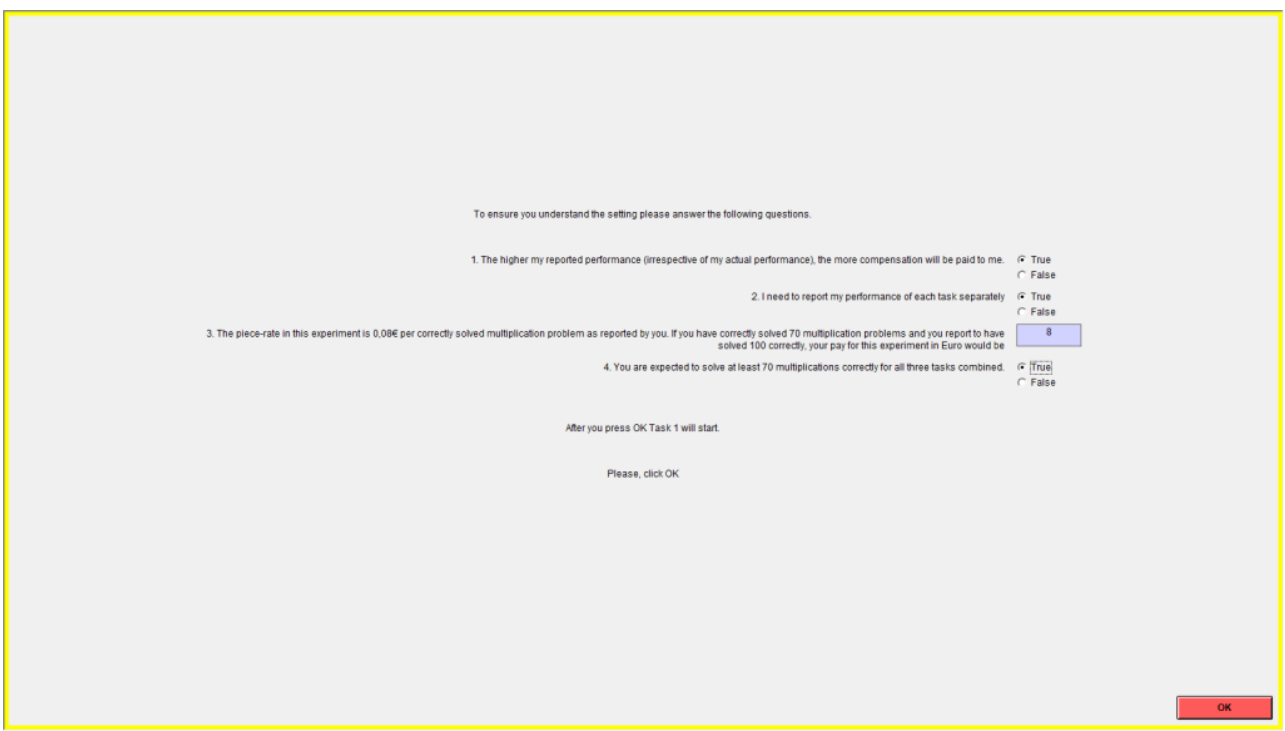

\begin{tabular}{|c|c|c|c|}
\hline 1 of 3 & & & remanning the secct 12 \\
\hline \multicolumn{4}{|c|}{ Multiplication Task } \\
\hline & $\begin{array}{l}\text { Please. Calualate ne prowud of } \\
\text { and }\end{array}$ & $\begin{array}{l}30 \\
{ }_{22}^{30}\end{array}$ & \\
\hline & Result 1 & & \\
\hline & & & Next \\
\hline
\end{tabular}



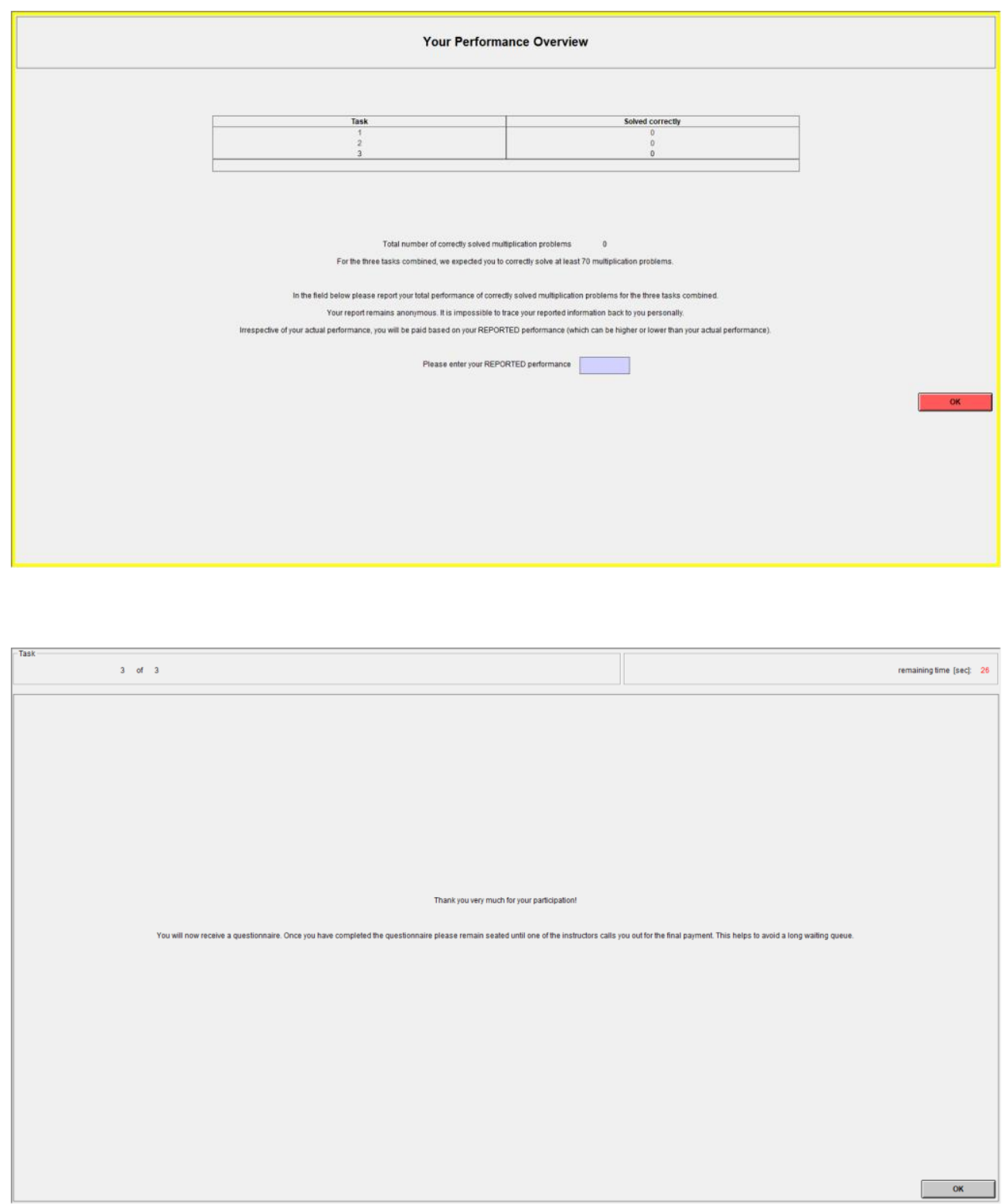


\section{Treatment Disaggregate - No Target}
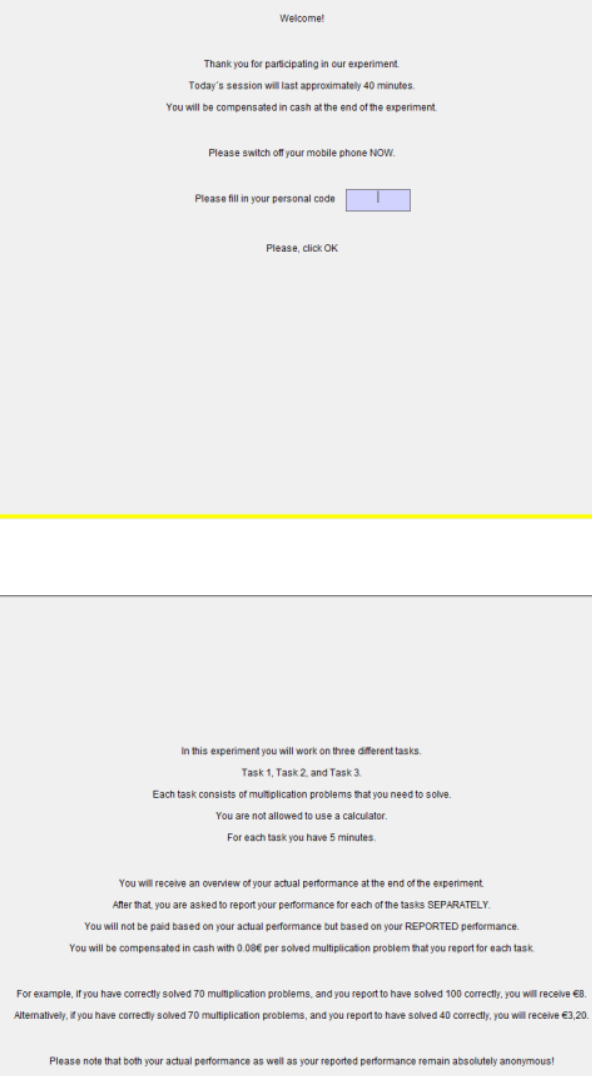

Please, chick oK 


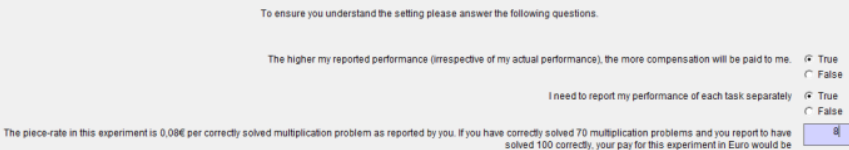

Ater you press OK Task 1 will star.

Please, clicico or

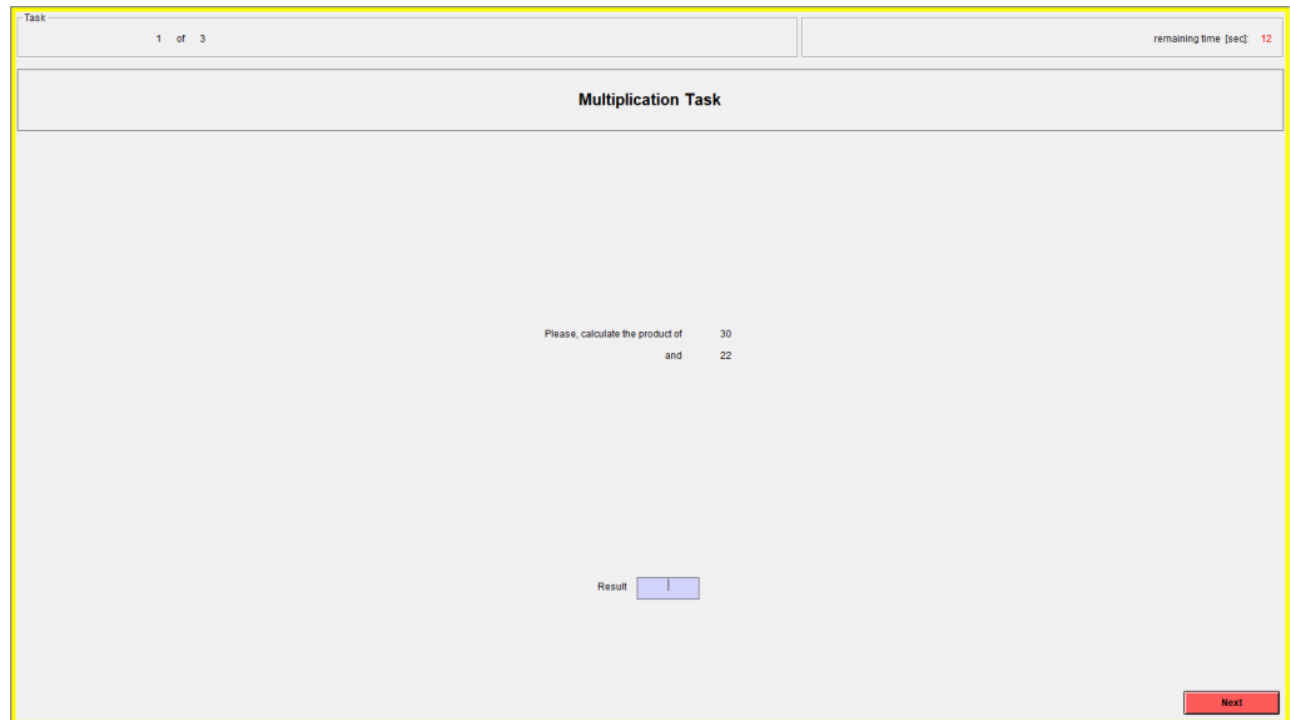



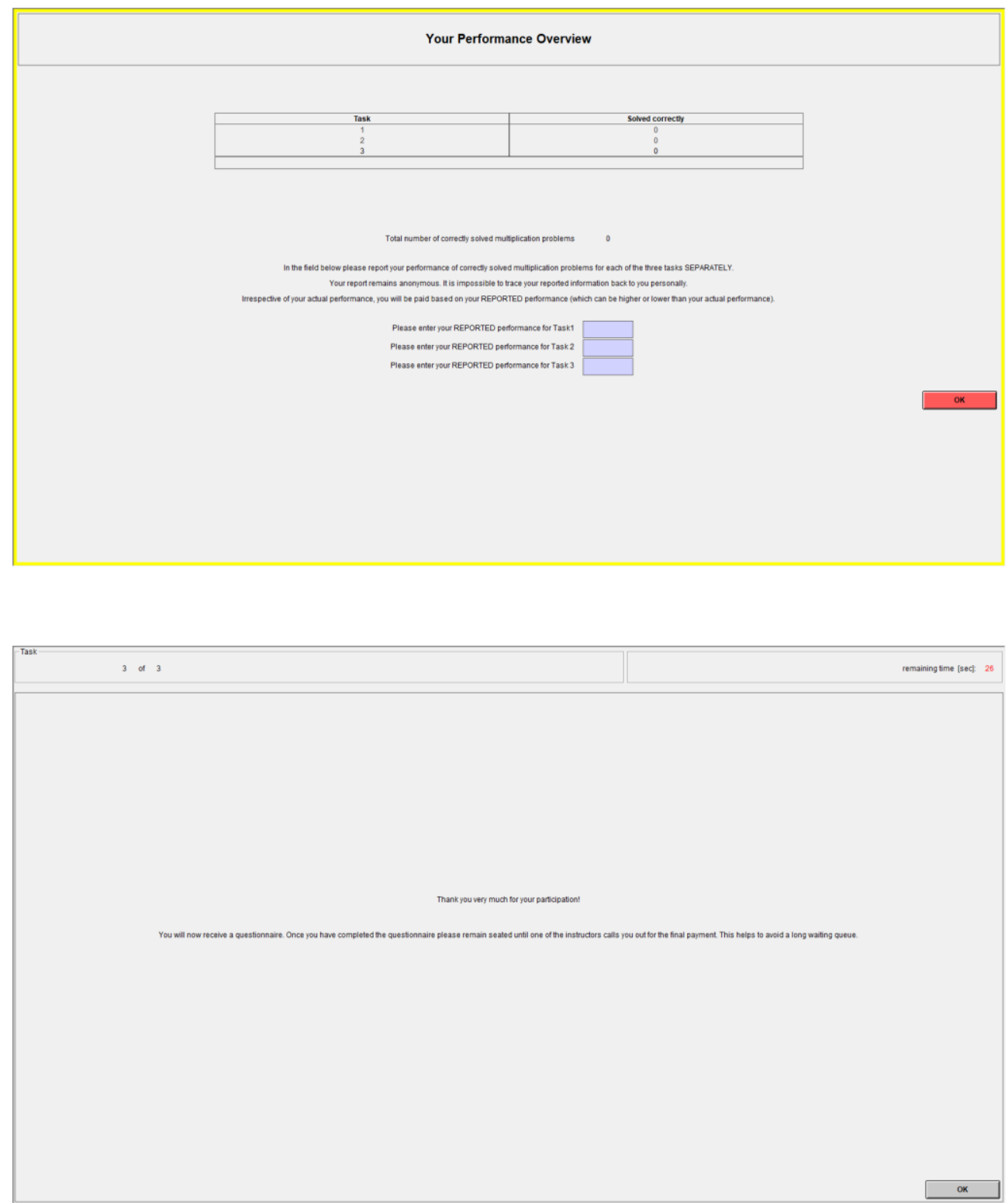


\section{Treatment Disaggregate - Target}

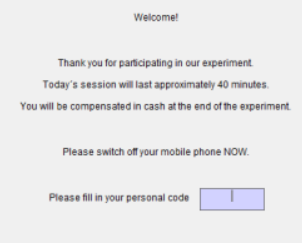

Please, cick OK

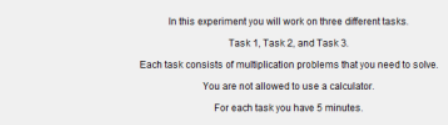

When you have completed all trree tasks we exped you to hare corredy solved a teast 70 multhplicabon problems in total

You wit recelve an oremiew ot your actual performance at the end of the esperiment

Afer that you are asked to repot your performanco tor oach of the tasis SEPARUTELY

You will not be pasd based on your actual pertermance but Dases on your REPORTED pertcemance

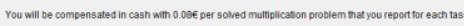

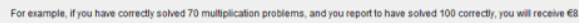

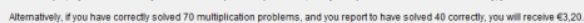

Please notet that boln your actual pefformance as well as your reponted performance temain absolutely anonymous!

Please, click ok 


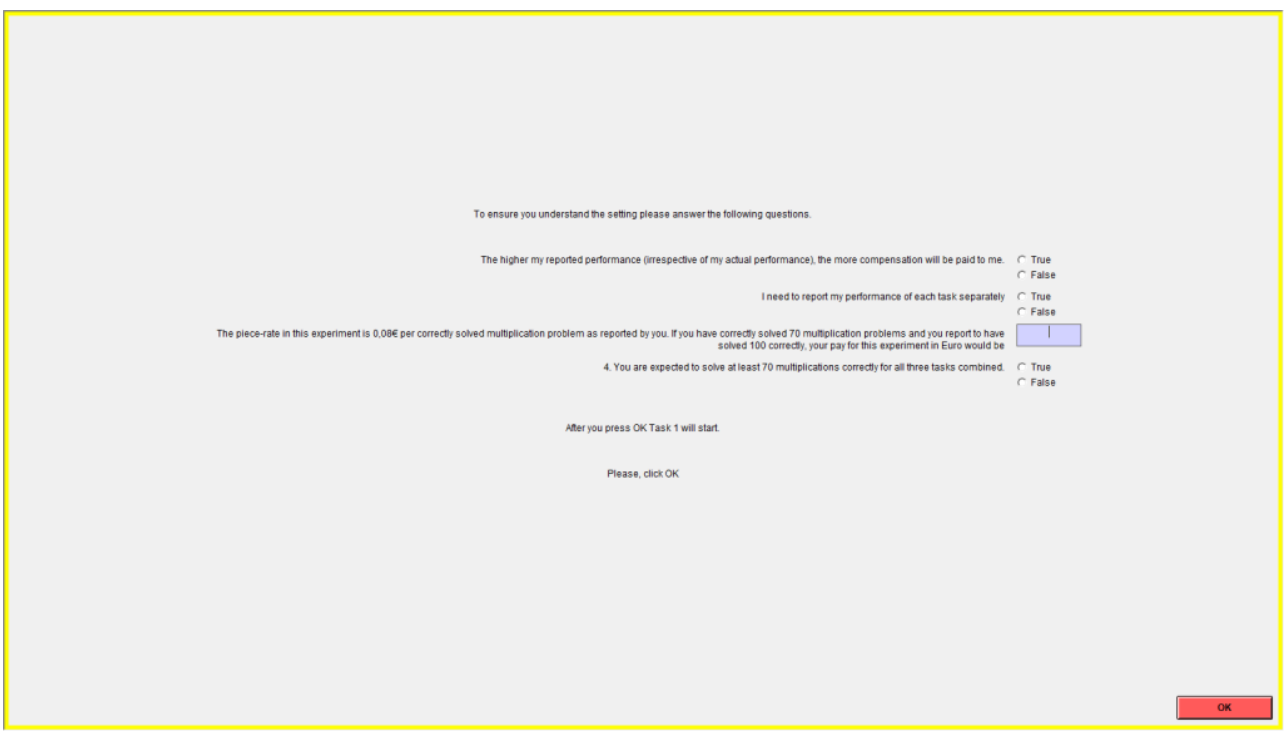

\begin{tabular}{|c|c|c|c|}
\hline 1 of 3 & & & remanning the secct 12 \\
\hline \multicolumn{4}{|c|}{ Multiplication Task } \\
\hline & $\begin{array}{l}\text { Please. Calualate ne prowud of } \\
\text { and }\end{array}$ & $\begin{array}{l}30 \\
{ }_{22}^{30}\end{array}$ & \\
\hline & Result 1 & & \\
\hline & & & Next \\
\hline
\end{tabular}



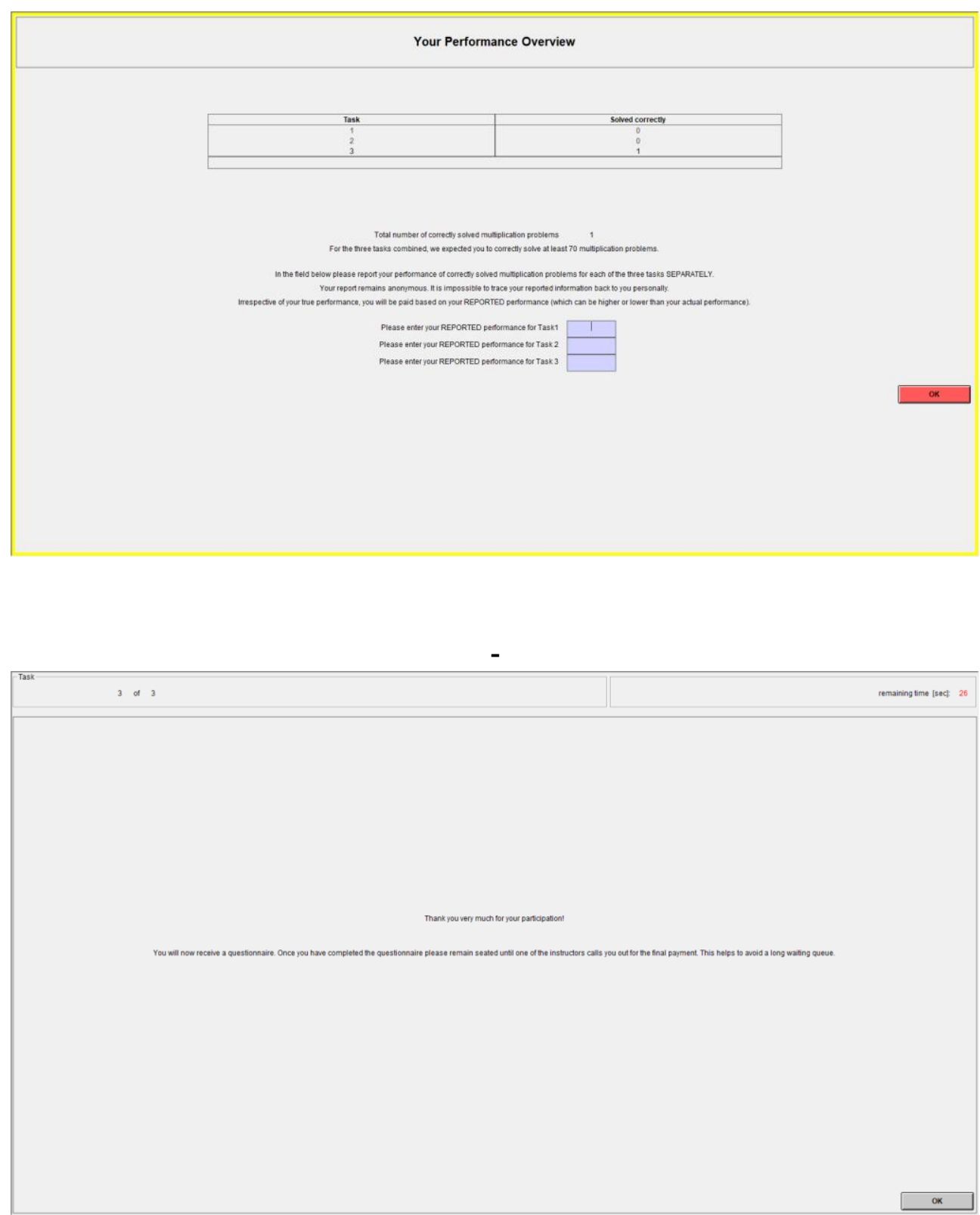


\section{REFERENCES}

Aaltonen, P., and H. Ikävalko. 2002. Implementing strategies successfully. Integrated manufacturing systems 13 (6): 415-418.

Alexander, L. D. 1985. Successfully implementing strategic decisions. Long range planning 18 (3): 91-97.

Alper, S., D. Tjosvold, and K. S. Law. 2000. Conflict management, efficacy, and performance in organizational teams. Personnel Psychology 53 (3): 625642.

Ambrosini, V., and C. Bowman. 2009. What are dynamic capabilities and are they a useful construct in strategic management? International Journal of Management Reviews 11 (1): 29-49.

Arbuckle, J. L., and W. Wothke. 1999. Amos 4.0 user's guide. Chicago, IL: SmallWaters Corporation.

Atkinson, H. 2006. Strategy implementation: a role for the balanced scorecard? Management Decision 44 (10): 1441-1460.

Augier, M., and D. J. Teece. 2009. Dynamic capabilities and the role of managers in business strategy and economic performance. Organization Science 20 (2): 410-421.

Baiman, S. 1990. Agency research in managerial accounting: A second look. Accounting, Organizations and Society 15 (4): 341-371.

Baiman, S., and B. Lewis. 1989. An experiment testing the behavioral equivalence of strategically equivalent employment contracts. Journal of Accounting Research 27 (1): 1-20.

Banker, R. D., and S. M. Datar. 1989. Sensitivity, precision, and linear aggregation of signals for performance evaluation. Journal of Accounting Research 27 (1): 21-39.

Barney, J. 1991. Firm resources and sustained competitive advantage. Journal of management 17 (1): 99-120.

Barreto, I. 2010. Dynamic capabilities: A review of past research and an agenda for the future. Journal of management 36 (1): 256-280.

Battilana, J., and T. Casciaro. 2013. Overcoming resistance to organizational change: Strong ties and affective cooptation. Management Science 59 (4): 819-836.

Beer, M., and R. A. Eisenstat. 2000. The silent killers of strategy implementation and learning. IEEE Engineering Management Review 28 (4): 35-45.

Benitez, J., J. Llorens, and J. Braojos. 2018. How information technology influences opportunity exploration and exploitation firm's capabilities. Information \& Management 55 (4): 508-523. 
Bharadwaj, A. S., S. G. Bharadwaj, and B. R. Konsynski. 1999. Information technology effects on firm performance as measured by Tobin's q. Management science 45 (7): 1008-1024.

Bharadwaj, A., O. El Sawy, P. Pavlou, and N. Venkatraman. 2013. Digital business strategy: toward a next generation of insights. MIS Quarterly 37 (2): 471482.

Bommer, W. H., J. L. Johnson, G. A. Rich, P. M. Podsakoff, and S. B. MacKenzie. 1995. On the interchangeability of objective and subjective measures of employee performance: A meta-analysis. Personnel psychology 48 (3): 587605.

Bollen, N. P. B., and V. K. Pool. 2009. Do hedge fund managers misreport returns? Evidence from the pooled distribution. The Journal of Finance 64 (5): 22572282.

Bonner, S. E., S. M. Clor-Proell, and L. Koonce. 2014. Mental accounting and disaggregation based on the sign and relative magnitude of income statement items. The Accounting Review 89 (6): 2087-2114.

Browne, M. W., and R. Cudeck. 1993. Alternative ways of assessing model fit. Sociological methods \& research 21 (2): 230-258.

Brüggen, A., and F. Moers. 2007. The role of financial incentives and social incentives in multi-task settings. Journal of Management Accounting Research 19(1): 25-50.

Bughin, J., and T. Catlin. 2019. 3 Digital Strategies for Companies That Have Fallen Behind. Harvard Business Review. February 12, 2019. https://hbr.org/2019/02/3-digital-strategies-for-companies-that-have-fallenbehind

Bughin, J., L. LaBerge, and A. Mellbye. 2017. The case for digital reinvention. McKinsey Quarterly 2: 1-15.

Burns, N., and S. Kedia. 2006. The impact of performance-based compensation on misreporting. Journal of Financial Economics 79 (1): 35-67.

Byrne, B. M. 2010. Structural equation modeling with AMOS: Basic concepts, applications, and programming. 2nd. Edition, New York: Routledge.

Cândido, C. J., and S. P. Santos. 2015. Strategy implementation: What is the failure rate? Journal of Management \& Organization 21 (2): 237-262.

Carmines, E. G., and J. P. Mclver. 1981. Analyzing Models with Unobserved Variables: Analysis of Covariance Structures. In G. W. Bohrnstedt, \& E. F. Borgatta (Eds.), Social Measurement: Current Issues. Beverly Hills: Sage Publications, Inc: 65-115.

Chen, F., P. J. Curran, K. A. Bollen, J. Kirby, and P. Paxton. 2008. An empirical evaluation of the use of fixed cutoff points in RMSEA test statistic in 
structural equation models. Sociological methods \& research 36 (4): 462494.

Chenhall, R. H., and D. Morris. 1986. The impact of structure, environment, and interdependence on the perceived usefulness of management accounting systems. The Accounting Review 61 (1): 16-35.

Chow, C. W., J. C. Cooper, and W. S. Waller. 1988. Participative budgeting: Effects of a truth-inducing pay scheme and information asymmetry on slack and performance. The Accounting Review 63 (1): 111-122.

Coyne, I., and D. Bartram. 2000. Personnel managers' perceptions of dishonesty in the workplace. Human Resource Management Journal 10 (3): 38-45.

Crittenden, V. L., and W. F. Crittenden. 2008. Building a capable organization: The eight levers of strategy implementation. Business Horizons 51 (4), 301-309.

Danneels, E. 2008. Organizational antecedents of second-order competences. Strategic management journal 29 (5): 519-543.

Davenport, T. H., and G. Westerman. 2018. Why so many high-profile digital transformations fail. Harvard Business Review. April 10, 2018. https://hbr.org/2018/03/why-so-many-high-profile-digital-transformations-fail

de Oliveira, C. A., J. Carneiro, and F. Esteves. 2019. Conceptualizing and measuring the "strategy execution" construct. Journal of Business Research 105: 333-344.

Drnevich, P. L., and A. P. Kriauciunas. 2011. Clarifying the conditions and limits of the contributions of ordinary and dynamic capabilities to relative firm performance. Strategic Management Journal, 32 (3): 254-279.

Dworkis, K., and L. Patelli. 2017. Do personality traits influence individual performance under balanced incentive systems: An experimental investigation using Amazon Mechanical Turk. Working paper.

Easterby-Smith, M., M. A. Lyles, and M. A. Peteraf. 2009. Dynamic capabilities: Current debates and future directions. British Journal of Management 20: 18.

Eisenhardt, K. M., and J. A. Martin. 2000. Dynamic capabilities: what are they? Strategic Management Journal 21 (10-11): 1105-1121.

Evans III, J., R. L. Hannan, R. Krishnan, and D. Moser. 2001. Honesty in managerial reporting. The Accounting Review 76 (4): 537-559.

Felin, T., and N. J. Foss. 2005. Strategic organization: a field in search of microfoundations. Strategic Organization 3 (4): 441-455.

Felin, T., N. J. Foss, and R. E. Ployhart. 2015. The microfoundations movement in strategy and organization theory. The Academy of Management Annals 9 (1): 575-632. 
Fischbacher, U. 2007. z-Tree: Zurich toolbox for ready-made economic experiments. Experimental Economics 10 (2): 171-178.

Fisher, J. G., L. A. Maines, S. A. Peffer, and G. B. Sprinkle. 2002. Using budgets for performance evaluation: Effects of resource allocation and horizontal information asymmetry on budget proposals, budget slack, and performance. The Accounting Review 77 (4): 847-865.

Floyd, S. W., and B. Wooldridge. 1992. Middle management involvement in strategy and its association with strategic type: A research note. Strategic management journal 13: 153-167.

Ford, C., B. King, and M. Hollender. 1988. Lies and liars: Psychiatric aspects of prevarication. The American Journal of Psychiatry 145 (5): 554-562.

Furnham, A., and H. C. Boo. 2011. A literature review of the anchoring effect. The Journal of Socio-Economics 40 (1): 35-42.

Gefen, D., D. Straub, and M. C. Boudreau. 2000. Structural equation modeling and regression: Guidelines for research practice. Communications of the association for information systems 4 (1): 1-77.

Govindarajan, V., and A. K. Gupta. 1985. Linking control systems to business unit strategy: impact on performance. Accounting, Organizations and Society 10 (1): 51-66.

Grafton, J., A. M. Lillis, and S. K. Widener. 2010). The role of performance measurement and evaluation in building organizational capabilities and performance. Accounting, Organizations and Society 35 (7): 689-706.

Grant, R.M. 2016. Contemporary Strategy Analysis: Text and Cases Edition. 9th ed., John Wiley \& Sons.

Hair, J. F., C. M. Ringle, and M. Sarstedt. 2011. PLS-SEM: Indeed a silver bullet. Journal of Marketing theory and Practice 19 (2): 139-152.

Hair, J. F. Jr., R. E. Anderson, R. L. Tatham, and W. C. Black. 2006. Multivariate data analysis. 6th ed., Upper Saddle River, NJ: Pearson Education.

Halevy, R., S. Shalvi, and B. Verschuere. 2014. Being honest about dishonesty: Correlating self-reports and actual lying. Human Communication Research 40 (1): 54-72.

Harreld, J. B., C. A. O'Reilly, and M. L. Tushman. 2007. Dynamic capabilities at IBM: Driving strategy into action. California Management Review 49 (4): $21-$ 43.

Heath, C., R. P. Larrick, and G. Wu. 1999. Goals as reference points. Cognitive Psychology 38 (1): 79-109.

Hecht, G., J. L. Hobson, and L. Wang. 2019. The effect of performance reporting frequency on employee performance. The Accounting Review. 
Helfat, C. E., and S. G. Winter. 2011. Untangling dynamic and operational capabilities: Strategy for the (n)ever-changing world. Strategic Management Journal. 32 (11): 1243-1250.

Higgins, J. M. 2005. The eight 'S's of successful strategy execution. Journal of Change Management 5 (1): 3-13.

Ho, J. L., A. Wu, and S. Y. Wu. 2014. Performance measures, consensus on strategy implementation, and performance: Evidence from the operationallevel of organizations. Accounting, Organizations and Society 39 (1): 38-58.

Hölmstrom, B. 1979. Moral hazard and observability. The Bell Journal of Economics 10 (1): 74-91.

Hrebiniak, L. G. 2006. Obstacles to effective strategy implementation. Organizational dynamics 35 (1): 12-31.

Hu, L. T., and P. M. Bentler. 1999. Cutoff criteria for fit indexes in covariance structure analysis: Conventional criteria versus new alternatives. Structural Equation Modeling: A Multidisciplinary Journal 6 (1): 1-55.

Hunton, J. E., B. Lippincott, and J. L. Reck. 2003. Enterprise resource planning systems: comparing firm performance of adopters and nonadopters. International Journal of Accounting Information Systems 4 (3): 165-184.

Jantunen, A. 2005. Knowledge-processing capabilities and innovative performance: an empirical study. European Journal of Innovation Management 8 (3): 336-349.

Jantunen, A., K. Puumalainen, S. Saarenketo, and K. Kyläheiko. 2005. Entrepreneurial orientation, dynamic capabilities and international performance. Journal of International Entrepreneurship 3: 223-243.

Johnson, G., L. Melin, and R. Whittington. 2003. Micro strategy and strategizing: towards an activity-based view. Journal of Management Studies 40 (1): 322.

Johnson, G., K. Scholes, R. Whittington. 2008. Exploring Corporate Strategy: Text and Cases, 8th ed., Prentice-Hall Financial Times, Pearson Education Limited.

Kachelmeier, S. J., M. G. Williamson, and X. Zhang. 2017. Cash vs. non-cash rewards: Motivational effect of reward type for group performance. Working paper.

Kahneman, D., and A. Tversky. 1979. Prospect Theory: An Analysis of Decision under Risk. Econometrica 47 (2): 263-292.

Kane, G. C., D. Palmer, A. N. Phillips, D. Kiron, and N. Buckley. 2016. Aligning the organization for its digital future. MIT Sloan Management Review and Deloitte University Press, July 2016. 
Kaplan, R. S., and D. P. Norton. 2005. The office of strategy management. Harvard Business Review 83 (10): 72-80.

Kenny, D. A., B. Kaniskan, and D. B. McCoach. 2015. The performance of RMSEA in models with small degrees of freedom. Sociological Methods \& Research 44 (3): 486-507.

Legner, C., T. Eymann, T. Hess, C. Matt, T. Böhmann, P. Drews, ... and F. Ahlemann. 2017. Digitalization: opportunity and challenge for the business and information systems engineering community. Business \& Information Systems Engineering 59 (4): 301-308.

Leischnig, A., S. Wölfl, and B. Ivens. 2016. When does digital business strategy matter to market performance? Proceedings of the International Conference on Information Systems (ICIS 2016), Dublin, Ireland.

Leischnig, A., S. Wölfl, B. Ivens, and D. Hein. 2017. From digital business strategy to market performance: insights into key concepts and processes.

Proceedings of the International Conference on Information Systems (ICIS 2017), Seoul, South Korea.

Lillis, A. M. 2002. Managing multiple dimensions of manufacturing performanceAn exploratory study. Accounting, Organizations and Society 27 (6): 497529.

Lipman, V. 2014. The unfortunate appeal of narcissists in management. Psychology Today (March 2). Available at: https://www.psychologytoday.com/blog/mind-the-manager/201403/theunfortunate-appeal-narcissists-in-management

Locke, E. A., and G. P. Latham. 1990. A Theory of Goal Setting and Task Performance. Englewood Cliffs, NJ: Prentice-Hall, Inc.

Luft, J. L. 1997. Fairness, ethics and the effect of management accounting on transaction costs. Journal of Management Accounting Research 9: 199-216.

Mankins, M. C., and R. Steele. 2005. Turning great strategy into great performance. Harvard Business Review 83 (7/8): 64-72.

Marsh, H. W., and D. Hocevar. 1985. Application of confirmatory factor analysis to the study of self-concept: First-and higher order factor models and their invariance across groups. Psychological Bulletin 97 (3): 562-582.

Matt, C., T. Hess, and A. Benlian. 2015. Digital transformation strategies. Business \& Information Systems Engineering 57 (5): 339-343.

Mazar, N., O. Amir, and D. Ariely. 2008. The dishonesty of honest people: A theory of self-concept maintenance. Journal of Marketing Research 45 (6): 633644.

McGrath, R. G., and R. McManus. 2020. Discovery-Driven Digital Transformation. Harvard Business Review. May 01, 2020. https://hbr.org/2020/05/discoverydriven-digital-transformation 
Mendoza, K. I. 2020. Reducing Underreporting by Aggregating Budgeted Time. The Accounting Review, 0000-0000.

Merchant, K. 1985. Budgeting and the propensity to create budgetary slack. Accounting, Organizations and Society 10 (2): 201-210.

Miller, S. 1997. Implementing strategic decisions: Four key success factors. Organization Studies 18 (4): 577-602.

Miller, S., D. Wilson, and D. Hickson. 2004. Beyond Planning: Strategies for Successfully Implementing Strategic Decisions. Long Range Planning 37 (3): 201-218.

Mintzberg, H. 1987. The strategy concept I: Five Ps for strategy. California Management Review 30 (1): 11-24.

Mithas, S., and H. C. Lucas. 2010. What is your digital business strategy? IT Professional 12 (6): 4-6.

Mithas, S., A. Tafti, I. Bardhan, and J. M. Goh. 2012. Information technology and firm profitability: mechanisms and empirical evidence. MIS Quarterly 36 (1): 205-224.

Mithas, S., A. Tafti, and W. Mitchell. 2013. How a firm's competitive environment and digital strategic posture influence digital business strategy. MIS Quarterly 37 (2): 511-536.

Neely, A., M. Gregory, and K. Platts. 1995. Performance measurement system design: A literature review and research agenda. International Journal of Operations \& Production Management 15 (4): 80-116.

Neilson, G. L., K. L. Martin, and E. Powers. 2008. The secrets to successful strategy execution. Harvard Business Review 86 (6): 60-70.

Newman, A. H. 2014. An investigation of how the informal communication of firm preferences influences managerial honesty. Accounting, Organizations and Society 39 (3): 195-207.

Nicolaou, A. I. 2004. Firm performance effects in relation to the implementation and use of enterprise resource planning systems. Journal of Information Systems 18 (2): 79-105.

Nikias, A. D., S. T. Schwartz, E. E. Spires, J. R. Wollscheid, and R.A. Young. 2010. The effects of aggregation and timing on budgeting: An experiment. Behavioral Research in Accounting 22 (1): 67-83.

Noble, C. H. 1999. The eclectic roots of strategy implementation research. Journal of Business Research 45 (2): 119-134.

Nutt, P. C. 1986. Tactics of implementation. Academy of Management Journal 29 (2): 230-261. 
O'Reilly, C. A., D. F. Caldwell, J. A. Chatman, M. Lapiz, and W. Self. 2010. How leadership matters: The effects of leaders' alignment on strategy implementation. The Leadership Quarterly 21 (1): 104-113.

Okumus, F. 2001. Towards a strategy implementation framework. International Journal of Contemporary Hospitality Management 13 (7): 327-338.

Okumus, F. 2003. A framework to implement strategies in organizations. Management Decision 41 (9): 871-882.

Parente, P. M., and J. M. S. Silva. 2016. Quantile regression with clustered data. Journal of Econometric Methods 5 (1): 1-15.

Pavlou, P. A., and O. A. El Sawy. 2010. The "third hand": IT-enabled competitive advantage in turbulence through improvisational capabilities. Information Systems Research 21 (3): 443-471.

Peteraf, M., G. Di Stefano, and G. Verona. 2013. The elephant in the room of dynamic capabilities: Bringing two diverging conversations together. Strategic Management Journal 34 (12): 1389-1410.

Pezeshkan, A., S. Fainshmidt, A. Nair, M. L. Frazier, and E. Markowski. 2016. An empirical assessment of the dynamic capabilities-performance relationship. Journal of Business Research 69 (8): 2950-2956.

Pisano, G. P. 2017. Toward a prescriptive theory of dynamic capabilities: connecting strategic choice, learning, and competition. Industrial and Corporate Change 26 (5): 747-762.

Porter, M. E. 1996. What is strategy? Harvard Business Review 74 (6): 61-78.

Porter, M. E., and J. E. Heppelmann. 2015. How smart, connected products are transforming companies. Harvard Business Review 93 (10): 96-114.

Poston, R., and S. Grabski. 2001. Financial impacts of enterprise resource planning implementations. International Journal of Accounting Information Systems 2 (4): 271-294.

Pryor, M. G., D. Anderson, L. A. Toombs, and J. H. Humphreys. 2007. Strategic implementation as a core competency: The 5P's model. Journal of Management Research 7 (1): 3-17.

Rapert, M. I., A. Velliquette, and J. A. Garretson. 2002. The strategic implementation process: evoking strategic consensus through communication. Journal of Business Research 55 (4): 301-310.

Raskin, R., and C. Hall. 1979. A narcissist personality inventory. Psychological Reports 45 (2): 590.

Reed, R., and M. R. Buckley. 1988. Strategy in action-Techniques for implementing strategy. Long Range Planning 21 (3): 67-74. 
Rigdon, E. E. 1996. CFI versus RMSEA: A comparison of two fit indexes for structural equation modeling. Structural Equation Modeling: A Multidisciplinary Journal 3 (4): 369-379.

Robinson, J. P., P. R. Shaver, and L. S. Wrightsman. 1991. Criteria for scale selection and evaluation. In J. P. Robinson, P. R. Shaver, and L. S. Wrightsman (Eds.), Measures of personality and social psychological attitudes. San Diego, CA: Academic Press: 1-16.

Ross, J. W., I. M. Sebastian, C. M. Beath. 2017. How to develop a great digital strategy. MIT Sloan Management Review 58 (2): 7-9.

Roth, K., D. M. Schweiger, and A. J. Morrison. 1991. Global strategy implementation at the business unit level: Operational capabilities and administrative mechanisms. Journal of International Business Studies 22: 369-402.

Rumelt, R. P. 1991. How much does industry matter? Strategic Management Journal 12 (3): 167-185.

Santhanam, R., and E. Hartono. 2003. Issues in linking information technology capability to firm performance. MIS Quarterly 27 (1): 125-153.

Schumacker, R. E., and R. G. Lomax. 1996. A beginner's guide to structural equation modeling. Mahwah, NJ: Lawrence Erlbaum Associates.

Schweitzer, M. E., and C. K. Hsee. 2002. Stretching the truth: Elastic justification and motivated communication of uncertain information. Journal of Risk and Uncertainty 25 (2): 185-201.

Schweitzer, M. E., L. Ordóñez, and B. Douma. 2004. Goal setting as a motivator of unethical behavior. Academy of Management Journal 47 (3): 422-432.

Sebastian, I. M., J. W. Ross, C. Beath, M. Mocker, K. G. Moloney, and N. O. Fonstad. 2017. How Big Old Companies Navigate Digital Transformation. MIS Quarterly Executive 16 (3): 197-213.

Shrout, P. E., and N. Bolger. 2002. Mediation in experimental and nonexperimental studies: new procedures and recommendations. Psychological Methods 7 (4): 422-445.

Steers, R. M. 1975. Problems in the measurement of organizational effectiveness. Administrative Science Quarterly 20 (4): 546-558.

Sutcliff, M., R. Narsalay, A. Sen. 2019. The Two Big Reasons That Digital Transformations Fail. Harvard Business Review. October 18, 2019. https://hbr.org/2019/10/the-two-big-reasons-that-digital-transformations-fail

Teece, D. J. 2007. Explicating dynamic capabilities: the nature and microfoundations of (sustainable) enterprise performance. Strategic Management Journal 28 (13): 1319-1350. 
Teece, D. J. 2014. A dynamic capabilities-based entrepreneurial theory of the multinational enterprise. Journal of International Business Studies 45: 8-37.

Teece, D. J. 2018. Business models and dynamic capabilities. Long Range Planning 51 (1): 40-49.

Teece, D. J., G. Pisano, and A. Shuen. 1997. Dynamic capabilities and strategic management. Strategic Management Journal 18 (7): 509-533.

Thaler, R. 1985. Mental accounting and consumer choice. Marketing Science 4 (3): 199-214.

Tversky, A., and D. Kahneman. 1974. Judgement under uncertainty: Heuristics and biases. Science 185 (4157): 1124-1131.

Vivas López, S. 2005. Competitive advantage and strategy formulation: The key role of dynamic capabilities. Management Decision 43 (5): 661-669.

Wallace, H., and R. Baumeister. 2002. The performance of narcissists rises and falls with perceived opportunity for glory. Journal of Personality and Social Psychology 82 (5): 819-834.

Waterman Jr, R. H., T. J. Peters, and J. R. Phillips. 1980. Structure is not organization. Business Horizons 23 (3): 14-26.

Wernerfelt, B. 1984. A resource-based view of the firm. Strategic Management Journal 5 (2): 171-180.

Wessel, M. 2015. What Driverless Cars Mean for Today's Automakers. Harvard Business Review. August 27, 2015. https://hbr.org/2015/08/what-driverlesscars-mean-for-todays-automakers

Wilden, R., S. P. Gudergan, B. B. Nielsen, and I. Lings. 2013. Dynamic capabilities and performance: strategy, structure and environment. Long Range Planning 46 (1-2): 72-96.

Winter, S. G. 2003. Understanding dynamic capabilities. Strategic Management Journal 24 (10): 991-995.

Wright, K. B. 2005. Researching Internet-based populations: Advantages and disadvantages of online survey research, online questionnaire authoring software packages, and web survey services. Journal of Computer-Mediated Communication 10 (3): 00-00.

Wunderlich, N., and R. Beck. 2018. You'll be surprised-digital business strategy as driver of organizational innovativeness. Proceedings of the 51st Hawaii International Conference on System Sciences (HICSS), Waikoloa Village, Hawaii: 4035-4044.

Xu, J. and X. Liu. 2018. Technology Is Changing What a Premium Automotive Brand Looks Like. Harvard Business Review. May 22, 2018. https://hbr.org/2018/05/technology-is-changing-what-a-premium-automotivebrand-looks-like 
Yeow, A., C. Soh, and R. Hansen. 2018. Aligning with new digital strategy: A dynamic capabilities approach. The Journal of Strategic Information Systems 27 (1): 43-58.

Yoo, Y., O. Henfridsson, and K. Lyytinen. 2010. Research commentary-the new organizing logic of digital innovation: an agenda for information systems research. Information Systems Research 21 (4): 724-735.

Young, S. M. 1985. Participative budgeting: The effects of risk aversion and asymmetric information on budgetary slack. Journal of Accounting Research 23 (2): 829-842. 


\section{IMPACT OF RESEARCH}

Digitalization concerns people in all disciplines as it is associated with dramatic shifts in professional and private life and it heavily affects society and the economy. It changes aspects like the way we collaborate, the way we learn, the way we predict the future, and the way we produce outcomes. Although this list is by far not exhaustive, it gives a first impression on the changes we face in the near future. Due to the changes associated with digitalization, people perceive the related opportunities and threats very differently. While some people are open to the associated changes and feel that their organizations, their countries or even themselves as individuals are well prepared for the digital age. Others fear losing their jobs, do not believe in their business or political leaders to successfully manage the change, or have the feeling that digital technology is developing at a pace they cannot catch up with. In light of these developments and the different perceptions it is important to expand the knowledge in this field by evidence-based insights. An understanding of the underlying determinants and effects of these digital developments is therefore crucial for organizations as well as academics in order to understand digitalization as an opportunity rather than a threat.

This dissertation investigates specific preconditions and actions facilitating the implementation of a digital business strategy as well as its effect on aspects like performance. The findings suggest specific preconditions as beneficial to implement a digital business strategy. Firstly, dynamic capabilities serve as important preconditions in any business unit as they significantly facilitate the implementation of a digital business strategy. In case members of a business unit possess high dynamic capabilities, a digital business strategy will be implemented more easily. Besides their positive influence during the implementation process, the results indicate a positive effect of dynamic capabilities on performance. This further highlights the beneficial role of dynamic capabilities. Second, the results indicate the important role of the strategy implementation stage associated with a digital business strategy. In case the implementation stage is coordinated successfully using an appropriate actions framework the level of implementation achieved can be increased significantly. More precisely, the findings highlight five specific actions: unfolding, coordination, communication, control and feedback, and development of human resources policies and employee competences. Especially with regards to 
the action dimension 'control and feedback' the findings presented in this dissertation highlight the role of different performance reporting mechanisms to foster honest behavior by employees. This increases the value of information needed for control and feedback activities. With regards to the effects of digital business strategy, this dissertation failed to find a direct effect of digital business strategy on business unit performance two years after its implementation.

Considering the findings of this dissertation, several important contributions can be highlighted. For science this dissertation contributes to several academic fields like management information systems, strategic management and management accounting. Given the empirical setting, this dissertation provides unique insights on the perception of the highest management levels from a global market leader with more than 100,000 employees. With regards to the findings, this dissertation shows that frameworks like strategy implementation actions can be applied to digital business strategy. In addition, the expert interviews conducted strengthen the understanding of digital business strategy as a theoretical construct itself. Aspects like data, working methods, or culture are added to the initial measurement instrument. Overall, the results provide a better knowledge on the elements of digital business strategy. This is an important prerequisite for future studies in this field. Next, the results add important quantitative evidence to the debate on the effect of dynamic capabilities. More precisely they show that dynamic capabilities are an important trigger in order to improve performance and increase the implementation level of a digital business strategy. Thereby, the results contradict the opinion that dynamic capabilities are not more than a fuzzy construct. Overall, this dissertation is one of the first works to bring quantitative evidence from the business sector to the field of digital business strategy. For practice, this dissertation contributes to the appropriate preparation and execution within organizations to approach the changes associated with digitalization. It enhances the common understanding of digital business strategy by widening its scope in order to ensure that practitioners do not neglect important aspects due to a narrow focus on single aspects like data or IT. Regarding beneficial determinants to implement a digital business strategy the dissertation highlights that managers have to closely manage the capabilities of their employees and ensure a detailed planning process for the implementation activities associated with a digital business strategy. As the dissertation fails to find a significant effect of digital business strategy implementation on performance, one 
important contribution is associated with people's expectations towards a digital business strategy. As it highlights the fact that we cannot expect rapid improvements after implementation. This is an important step regarding the correct expectation management in place and addresses a wide audience like decision-makers, investors, and accountants.

Overall, the findings of this dissertation shed light on the determinants and effects of implementing a digital business strategy. More specifically, this dissertation provides insights into the appropriate implementation actions and mechanisms (how to implement a digital business strategy), the useful prerequisites to implement a digital business strategy (where to start implementing a digital business strategy), and the expected results of implementing a digital business strategy (why to implement a digital business strategy). The different research questions raised in the chapters of this dissertation are of relevance to academics in a diverse set of fields, practitioners on all levels, investors, and the public at large that is confronted with the challenges associated with digitalization. All research questions are timely and are under current or continued discussion. 


\section{CURRICULUM VITAE}

Marc de Baat Doelman was born on December 13, 1991 in Düsseldorf, Germany. After finishing school in Germany, Marc lived in England and the Peoples Republic of China for several internships. For his Bachelor of Science degree, which he received in 2015, Marc studied International Business with major in Accounting and minor in Strategy at Maastricht University and the Nanyang Technology University in Singapore. From 2015 until 2017 he obtained his Master of Science degree in International Business (cum laude) in two tracks, namely 'Controlling' and 'Organization: Management, Change and Consultancy'. During his master studies Marc worked as an intern for the BMW Group in Munich. In 2017 he started his PhD project in cooperation with the BMW Group and the department of Accounting and Information Management at Maastricht University. As of January 2021, Marc started working for Porsche Consulting as Consultant in Munich, Germany.

Parts of this dissertation have already been presented at the American Accounting Association (AAA) Annual Meeting 2018 in Washington D.C., the 2018 ABO Research Conference in Phoenix, and the HICSS-54 conference 2021 in Hawaii. 